Cite this: DOI: 10.1039/x0xx00000x

Received 00th January 2012

Accepted 00th January 2012

DOI: $10.1039 / \times 0 \times x 00000 x$

www.rsc.org/

\section{A brief review on novel pyrene based fluorometric and colorimetric chemosensors for the detection of $\mathrm{Cu}^{2+}$}

\author{
Zannatul Kowser, ${ }^{a, b}$ Ummey Rayhan, ${ }^{a, c}$ Thamina Akther, ${ }^{a}$ \\ Carl Redshaw $^{d}$ and Takehiko Yamato ${ }^{* a}$
}

The development of colorimetric and fluorometric chemosensors that are able to detect $\mathrm{Cu}^{2+}$ ions by a change of colour and fluorescence intensity have been described. Herein, chemosensors that have pyrene functional groups as the signaling moiety will be discussed in detail as pyrene derivatives show significant photophysical properties superior to those of other commonly used

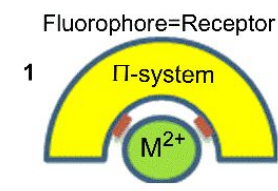

2

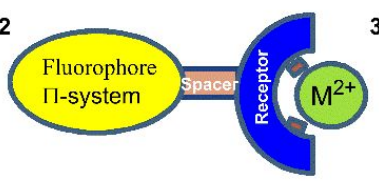

2

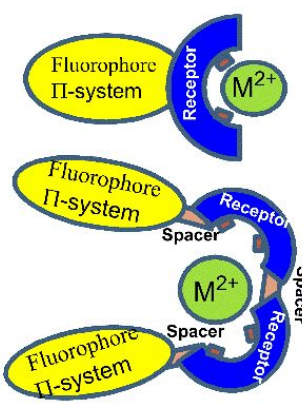
scaffolds. This review article provides a detailed overview of pyrene containing chemosensors based on fluorescence mechanisms, such as excimer/exciplex formation, photoinduced electron transfer (PET), photoinduced charge transfer (PCT), aggregation induced emission (AIE), ligand to metal charge transfer process (LMCT), chelation enhanced quenching mechanism (CHEQ), $\mathrm{Cu}^{2+}$-selective reactions for the selective and sensitive detection of $\mathrm{Cu}^{2+}$. Potential future applications are discussed given that $\mathrm{Cu}^{2+}$ ion recognition has great significance in the biological, environmental and medical sectors.

categorized into four classes: (i) as fluorescent ligands which have identical receptor (the recognition site) and fluorophore (the signal source) (ii) as fluoroionophores where the fluorophore and receptor are involved in direct electronic conjugation, (iii) fluoroionophores combined via fluorophore-spacer-receptor systems, (iv) exciplex or excimer forming probes (EPs) where, the fluorophore and receptor units can construct an intramolecular exciplex or excimer. Herein, strong intramolecular geometry 
Fig. 1. Schematic presentation of fluorosensors with metal ions. (i) Fluorescent ligand (ii) Intrinsic fluorescent probe (iii) Fluorophore-spacer-receptor system (iv) Exciplex or excimer forming probe.

changes are observed after binding with the analyte by increasing or decreasing the ratio of excimer-to-monomer emission. ${ }^{14,15}$ To be an ideal fluorescent chemosensor, the receptor must have the strongest affinity with the relevant target (binding-selectivity) and the fluorescence signal should avoid any environmental interference (signal-selectivity). ${ }^{16}$

Among the heavy and transition metal ions, copper is one of the important trace elements for both plants and animals, including humans. ${ }^{17}$ When levels of $\mathrm{Cu}^{2+}$ exceeds cellular needs, it can be considered as toxic to biological systems. ${ }^{18}$ The US Environmental Protection Agency (EPA) has set the limit of $1.3 \mathrm{ppm}(\sim 20 \mu \mathrm{M})$ for copper in drinking water. ${ }^{14}$ For this reason, improved fluorescent chemosensors for the selective and sensitive detection of $\mathrm{Cu}^{2+}$ are of great importance. ${ }^{19-22}$ It is noteworthy that $\mathrm{Cu}^{2+}$ ion detection creates some challenges when designing fluorescence turn-on (fluorescence intensity increases) sensors due to its paramagnetic nature with an unfilled $\mathrm{d}$ shell orbital. Moreover, according to the Irving-Williams rule, $\mathrm{Cu}^{2+}$ has the strongest binding ability versus any other divalent metal ion of the first transition series. The paramagnetic cations $\mathrm{Cu}^{2+}, \mathrm{Ni}^{2+}$ and $\mathrm{Co}^{2+}$ are usually more strongly bound than the diamagnetic ions $\mathrm{Zn}^{2+}$ or $\mathrm{Cd}^{2+}$, which is determined on the basis of the ionic radius and the second ionization potential. ${ }^{14,23}$ Therefore, strong fluorescence "turn-off" (fluorescence intensity decreases) sensors were predominantly observed due to fluorescence quenching, upon addition of $\mathrm{Cu}^{2+} \cdot{ }^{24,25}$ Recently, many turn-on sensors have been studied for $\mathrm{Cu}^{2+}$ detection by using the concept of ion-induced changes in the geometry or the flexibility of the ligand as well as from the availability of certain functional groups involved in fluorescence quenching for the ligand in the unbound state. ${ }^{14}$ In this review, we discuss the sensing mechanisms of $\mathrm{Cu}^{2+}$ with pyrene based fluorescent sensors. This will help shape the design of new pyrene chemosensors for copper ion determination based on different mechanisms such as excimer/exciplex formation, photoinduced electron transfer (PET), photoinduced charge transfer (PCT), aggregation induced emission (AIE), ligand to metal charge transfer process (LMCT), chelation enhanced quenching mechanism (CHEQ) and $\mathrm{Cu}^{2+}$-selective reactions.

\section{The sources, applications, effects of $\mathrm{Cu}^{2+}$ 2.1. Sources of copper}

Copper is the third most abundant essential transition metal ion after iron and zinc in the human body. ${ }^{26}$ It is found in both natural sources and all body tissues. In the body, the liver, brain, heart, kidneys, and skeletal muscle contain the maximum amount of copper. High doses of copper are found in a lot of multiple vitamins. Moreover, naturally rich sources of copper are exhibited in oysters, sesame seeds, tahini, cocoa powder, chocolate, nuts, calamari, lobster, sunflower seeds, sun dried tomatoes, roasted pumpkin, squash seeds and dried herbs etc. Additionally, because of copper plumbing, it is present in water. In most of the vegetarian diets, copper is present in the food items. ${ }^{27}$

\subsection{Applications of copper}

Copper is an important trace element for human metabolism and plays a vital role in the physiological processes of organisms. It contributes to the making of red blood cells and in maintaining nerve cells and the immune system. It also helps to create energy in the body and plays a significant role in order? collagen formation and the absorption of iron. Copper intake also reduces the probability for the occurrence of cardiovascular disease and osteoporosis. Therefore, for normal development and for the proper working of the brain and as a cofactor of many enzymes, the presence of copper is essential. Moreover, copper has a vital contribution in energy efficiency and possesses the maximum electrical conductivity, except for silver. For this reason, it is used in power generation, transmission and electrical equipment. It also is in greatest demand in architecture (copper alloy materials), automotives, tubing, pipes, industrial and machined products, coins for currency, folk medicine and antimicrobial applications. ${ }^{27}$

\subsection{Deficiency and toxicity of copper}

Copper present at lower or higher levels can increase the risk to health. Free $\mathrm{Cu}^{2+}$ ion is both acutely and chronically toxic for aquatic life and microorganisms, even at micromolar concentrations. Copper deficiency is associated with growth failure and can affect deterioration of the nervous system. However, an excessive accumulation of copper may lead to neurodegenerative disorders, abnormalities in red blood cells and heart problems. Gene mutations are responsible for the two major genetic disorders of copper metabolism in humans such as Menkes' disease and Wilson's disease, and it is found that these diseases are the result of excessive intracellular copper transport. Increased serum copper levels have been linked with a higher risk of cardiovascular disease. Different diseases, including Alzheimer's disease, Indian childhood cirrhosis (ICC) and prion disease are also associated with the toxicity caused by $\mathrm{Cu}^{2+}$. Besides, copper is one of the most common metal pollutants because of its huge applications in our daily lives. For adults (19 years and above), the upper limit is $10 \mathrm{mg}$ a day and if anyone consumes above this level, it is considered toxic. Moreover, $\mathrm{Cu}^{2+}$ ions are often essential components in biochemical reactions such as catalysis, transport or biosynthesis at trace levels $(<1 \mu \mathrm{M})$. However, in the presence of large amounts of $\mathrm{Cu}^{2+}$, unhealthy interactions occur in biochemical redox processes and can, for instance result in the inhibition of enzyme activity or nephrotoxicity. ${ }^{27,28}$ Therefore, it is necessary to design a technique that is effective for a rapid response toward $\mathrm{Cu}^{2+}$ even at micromolar concentrations. The design and synthesis of fluorescent chemosensors for copper ion determination could help resolve these issues.

\section{Pyrene and pyrene derivatives as fluorophore}

Pyrene and pyrene derivatives have interesting photophysical properties notably a long lifetime, high quantum yield $\left(\tau_{\mathrm{M}}=450 \mathrm{~ns}\right.$ and $\Phi_{\mathrm{M}}=0.60$ in cyclohexane) and expanded $\pi$ electron delocalization of the pyrene monomers. Pyrene derivatives generally display five well-shaped and fine absorption bands between 210 and $330 \mathrm{~nm}$ and the emission spectrum usually consist of a broad band 
a) $\stackrel{\mathrm{hv}}{\longrightarrow} \mathrm{M}^{*}$

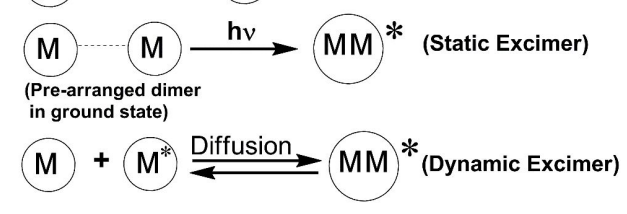

fluorophore can easily occur in the presence of a variety of quenchers (heavy metals, anionic species and NPs), which may be due to through-bond and through-space energy transfer between pyrene and the quenchers. ${ }^{29}$ A pyrene based fluorescent "off-on" chemosensor has been developed for detection of cyanide via ligand to $\mathrm{Cu}^{2+}$ complex as $\mathrm{Cu}^{2+}$ generally performs as a fluorescence quencher via a PET mechanism..$^{30}$ Pyrene also can perform as either an electron donor or acceptor during the energy transfer depending on the substituents attached to it, and as a result blue or red shifted emission bands are easily observed from the pyrene monomer emission band. One of the most interesting features of pyrene derivatives is that a pyrene monomer $\left(\lambda_{\mathrm{abs}}=\right.$ $350 \mathrm{~nm}, \lambda_{\mathrm{em}}=398 \mathrm{~nm}$ ) can combine with another pyrene monomer to form an excimer (or excited state dimer, $\lambda_{\mathrm{em}}=485$ $\mathrm{nm})$ because of its affinity for strong $\pi-\pi$ interactions. ${ }^{31}$ The changes in the emission properties of the pyrene excimer from a monomer has been used for designing sensors. ${ }^{32-34}$ A pyrene-based triazole ligand was reported which exhibited self-assembly in the presence of $\mathrm{ZnCl}_{2}$. The free ligand showed monomer emission bands at 382 and $402 \mathrm{~nm}$ with a broad shoulder at $420 \mathrm{~nm}$. After addition of $\mathrm{ZnCl}_{2}$, it can bind with $\mathrm{ZnCl}_{2}$ in a 2:1 ratio due to strong excimer emission at $410 \mathrm{~nm} \cdot{ }^{35}$

\section{Mechanism of $\mathrm{Cu}^{2+}$ sensing}

Fluorescent chemosensors for $\mathrm{Cu}^{2+}$ detection have been designed based on different binding mechanisms which fulfill the criteria of affinity, selectivity and sensitivity. In general, the chemosensor is designed such that it contains oxygen or nitrogen donor atoms for co-ordination of the $\mathrm{Cu}^{2+}{ }^{26} \mathrm{In}$ most of the cases, fluorescent sensors bind $\mathrm{Cu}^{2+}$ by the fluorescence quenching process due to its paramagnetic nature which opens up the excited state de-excitation pathways by enhancing the rate of non-radioactive processes such as electronic energy transfer (EET) and/or photoinduced electron transfer (PET) involving the metal centers. Also, the free electron in the orbital is likely to quench the fluorescence via spin-orbit coupling. ${ }^{37}$ There is also an enhancement of the fluorescence intensity in turn-on sensors, which are more desirable than turn-off sensors, with a red or blue shift of the emission after $\mathrm{Cu}^{2+}$ ion binding with ligand. Recently, some strategies have been developed for fluorescence off-on sensors for $\mathrm{Cu}^{2+}$ detection. The classical sensing mechanisms such as photoinduced electron transfer (PET), ${ }^{38,39}$ photoinduced charge transfer (PCT), ${ }^{40,41}$ excimer/exciplex formation $^{42}$ are mainly mentioned when investigating binding phenomenon. There are also some mechanisms which control the response of a fluorophore to substrate binding including aggregation induced emission (AIE), ligand to metal charge transfer process (LMCT), chelation enhanced quenching mechanism (CHEQ) and $\mathrm{Cu}^{2+}$-assisted reactions.

\subsection{Excimer emission mechanism}

When an excited fluorophore during its lifetime in an excited state interacts with a ground state fluorophore, an excimer is formed. ${ }^{43}$ Excimer emission typically shows a red shifted broad fluorescence b)

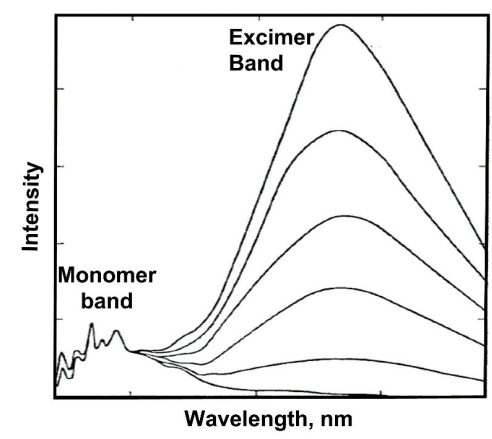

and a static excimer. The dynamic or static excimer formation depends on the distance between the two pyrene units (Fig. 2). ${ }^{45}$ The conventional dynamic excimers are produced due to the interaction of the diffused ground state fluorophore with the electronic excited state fluorophore during its lifetime within van der Waals contact distances. On the other hand, in case of the static excimer, initially a pyrene dimer is formed in the ground state. After photo-excitation, the monomer units interact with each other at very close distances (3.5-3.9 $\AA$ in the case of polycyclic hydrocarbons) to form the excimer. Importantly, metal ion co-ordination with the ligand controls the separation and relative orientation of multiple fluorophore units attached to the ligands. For this reason, cation recognition is investigated by the monomer to excimer fluorescence intensity ratio. ${ }^{46-49}$

Fig. 2. (a) Mechanism of static and dynamic excimer formation. (b) The monomer and excimer emission band of pyrene at various concentration in cyclohexane.

\subsection{Photoinduced electron transfer (PET)}

In photoinduced electron transfer (PET), an excited electron is transferred from the donor to the acceptor. These ideas can also be 
explained with the help of molecular orbital energy diagrams when the molecular device is non-luminescent and luminescent (Fig. 3). The emission of photons from LUMO to HOMO after excitation of electrons is called fluorescence and the molecule is termed as a fluorophore. However, photoinduced electron transfer occurs when one electron from the HOMO of the electron donor is transferred efficiently to the hole in the HOMO of the fluorophore and the initially excited electron of LUMO moves to the HOMO of the electron donor. This event happens if the HOMO of the electron donor is higher in energy than the singly occupied orbital of the fluorophore HOMO. The PET mechanism leads to nonradiative deactivation of the excited state, and as a result the emission intensity is decreased or "quenching" of fluorescence is observed. ${ }^{50-57}$ However, after interaction with metal ions, the donor electron containing orbital shifts its position from higher energy to lower energy and inhibits the electron-transfer process, resulting a radiative emission. In the case of metal ion binding, this effect is referred to as chelation-enhanced fluorescence $(\mathrm{CHEF}){ }^{58} \mathrm{It}$ is observed that in detection of $\mathrm{Cu}^{2+}$ by the photo-induced electron transfer method, the pyrene containing chemosensor mostly exhibits weak fluorescence due to fluorescence quenching from nitrogen lone pairs onto pyrene. The binding of $\mathrm{Cu}^{2+}$ with the ligand prevents the PET mechanism, resulting in significant enhancement in pyrene fluorescence.

\subsection{Photoinduced charge transfer (PCT)}

The chemosensors based on photoinduced charge transfer or internal charge transfers (ICT) are designed in which an electron withdrawing unit is conjugated with electron-donating substituents in the same molecule (Fig. 4). Therefore, the "push-pull" pi electron system of the chemosensor occurs in the excited state ${ }^{59}$ and the charge transfer can occur over long distances through conjugation and is related with major dipole moment changes. This phenomenon is used for cation sensing, as the close interaction of cations with the donor or the acceptor moiety affects the photophysical properties of the fluorophore ${ }^{60}$ Cation complexation of an electron donor group within a fluorophore decreases the electron-donating character of the donor group and produces a blue shift in the spectrum due to reduction of conjugation. On the other hand, a red-shifted absorption spectrum is observed for metal ion binding to the acceptor group that enhances its electron-withdrawing character. ${ }^{61}$ The fluorescence spectra should be shifted in the same direction as the absorption spectra. Receptors for the determination of $\mathrm{Cu}^{2+}$ sensing are designed from this PCT mechanism by using either the electron-donating, electron withdrawing ability or $\Pi$-conjugation degree of the fluorophores.

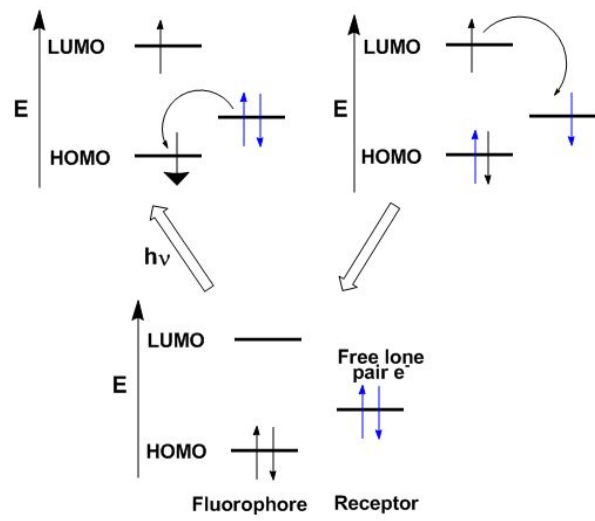

(a)

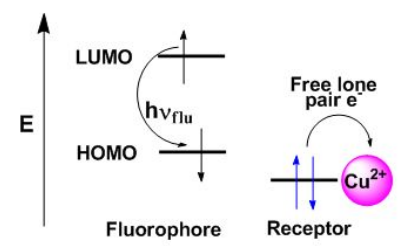

(b)

Fig. 3. Mechanisms for (a) PET (metal free receptor) and (b) CHEF (metal bound receptor) systems with the help of HOMO and LUMO of the molecular orbital energy diagrams of the fluorophore and an external molecular orbital.

\section{Chemosensors for sensing $\mathrm{Cu}^{2+}$}

\subsection{Chemosensors based on excimer emission}

Calixarenes are an important class of phenol-based macrocycles having some unique properties, specifically a nonpolar cavity, that are able to encapsulate various guest species, and possess well-defined conformations with tunable functionalization of their lower and upper rims. Like calixarenes, thiacalix[4]arenes containing bridging sulfur atoms with their 3-dimensional structure are an ideal platform for the development of chemosensors. ${ }^{62}$ Thiacalix[4]arenes appended with a pyrene moiety have been successfully designed utilizing the intensity ratio of the monomer to excimer emission $\left(\mathrm{I}_{\mathrm{M}} / \mathrm{I}_{\mathrm{E}}\right)$ of the pyrene moiety for the recognition of cations, anions or neutral molecules. ${ }^{63}$ In 2013, Kumar et al. developed a heteroditopic receptor based on a thiacalix[4]arene possessing 1,3-alternate conformation. The receptor has two urea linked pyrene moieties and a crown-ether moiety at the opposite sides of the thiacalix[4]arene cavity, and this exhibited ratiometric fluorescence for the selective recognition of $\mathrm{F}^{-}$and $\mathrm{CN}^{-}$ions in $\mathrm{THF}^{64}$ In 2014, Yamato and team established a heterodimeric system based on a thiacalix[4]arene possessing a 1,3-alternate conformation which was capable of binding $\mathrm{K}^{+}$ions and various anions via the crown-5-ring moiety and the two urea linked pyrene moieties in a $\mathrm{CH}_{2} \mathrm{Cl}_{2}-\mathrm{DMSO}$ solvent system. Moreover, a positive allosteric effect was observed for the formation of a heterogeneous dinuclear complex with $\mathrm{Br}^{-}$and $\mathrm{K}^{+}$ ions and a negative allosteric effect induces the decomplexation of the $\mathrm{K}^{+}$ion from the crown-5 ring for the recognition of $\mathrm{Cl}^{-}{ }^{65}$ However, very few ratiometric fluorescence sensors based on a thiacalix[4] arene have been designed for the recognition of $\mathrm{Cu}^{2+}$. For 
this purpose, in 2015 the Yamato group developed a ratiometric fluorescent chemosensor $\mathbf{1}$, in which an acetate group was introduced between the thiacalix[4]arene and triazolyl-pyrenyl groups in a 1,3-alternate conformation, which displays high selectivity toward $\mathrm{Cu}^{2+}$ ions. ${ }^{66}$ The free ligand $\mathbf{1}$ exhibits strong face-to-face $\pi$ - $\pi$ stacking because of excimer emission at $484 \mathrm{~nm}$ and weaker monomer emissions at 379 and $397 \mathrm{~nm}$. After gradual addition of $\mathrm{Cu}^{2+}$ ions (up to 20 equiv.), the monomer to excimer relative emission intensity ratio of $\mathbf{1}+\mathrm{Cu}^{2+}$ increased 228 -fold versus the monomer to excimer intensity ratio of the free ligand $\mathbf{1}$, which was 0.54 . The ligand 1 at low concentrations causes the excimer quenching and monomer enhancing due to the coordination bond of a $\mathrm{Cu}^{2+}$ ions between the nitrogen atoms of the triazole ring and the adjacent oxygen atoms of $\mathbf{1}$. This event forces the pyrenyl groups of 1 to move away from each other resulting in a conformational change. Notably, the monomer emission intensity of $\mathbf{1}$ was vividly reduced on addition of 5 to 45 equiv. of $\mathrm{Cu}^{2+}$ ions in $\mathrm{EtOH}$ solution, and this can be explained by a reverse PET from the pyrene unit to the nitrogen atoms of the triazole ring or to a heavy atom effect at

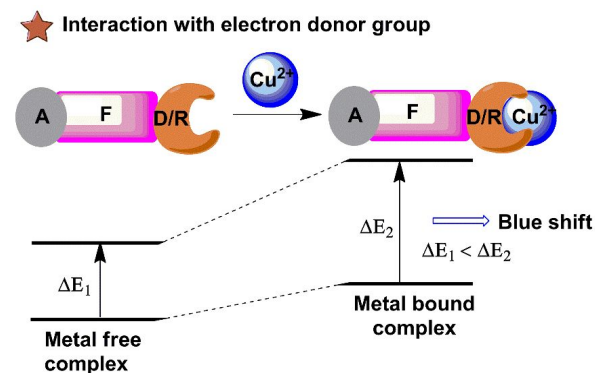

Interaction with acceptor group

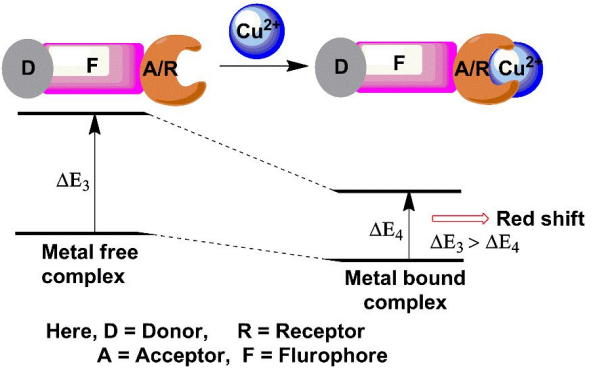

Fig. 4. Schematic representation of PCT or ICT for fluorescent probes with $\mathrm{Cu}^{2+}$ complex.

high ionic solution strength. A Job's plot for the ligand to $\mathrm{Cu}^{2+}$ complexation revealed a 1:1 stoichiometry with the detection limit $1.44 \times 10^{-7} \mathrm{M}$. The IR spectra of 1 revealed that the strong absorption band for the triazole group had disappeared and the band for the - $\mathrm{COO}$ - group changed to a weak absorption after binding with $\mathrm{Cu}^{2+}$. Moreover, ${ }^{1} \mathrm{H}$ NMR titration experiments for $\mathbf{1}$ were also consistent with reversibility characteristics as tested with $\mathrm{Cu}^{2+}$ and ethylenediamine. By using Density Functional Theory (DFT) computational studies, the geometry-optimized energies of 1 with $\mathrm{Cu}^{2+}$ complexes were calculated.

Homooxacalix[3]-arenes with a basic $\mathrm{C}_{3}$-symmetric cavity are related to calixarenes and crown ethers. Recently, homooxacalix[3]-arenes appended with pyrene functionality have also been used for the development of novel fluorescence chemosensors. $^{67}$ Our group reported a new type of fluorescent chemosensor based on a homooxacalix[3] arene which is connected with a pyrene moiety through a triazole group. The sensor exhibits great sensitivity and selectivity for the recognition of $\mathrm{Pb}^{2+}$ compared with most other competitive metal ions apart from $\mathrm{Cu}^{2+}$ where quenching was observed in an aqueous organic solvent system. ${ }^{68}$ Bearing this in mind, we developed a novel ratiometric chemosensor 2 using a pyrene linked triazole modified homooxacalix[3] arene for the recognition of $\mathrm{Hg}^{2+}$ and $\mathrm{Cu}^{2+}$. ${ }^{69}$ The free ligand $\mathbf{2}$ exhibited fluorescence monomer and excimer emissions at wavelengths of 396 and $485 \mathrm{~nm}$, respectively. The fluorescence spectral changes of the chemosensor 2 showed that the excimer and monomer emission of pyrene was dramatically quenched in the presence of $\mathrm{Cu}^{2+}$ and $\mathrm{Hg}^{2+}$ ions in pure acetonitrile solution. Interestingly, the monomer emission of 2 appeared to enhance during the addition of $\mathrm{Cu}^{2+}$ and $\mathrm{Hg}^{2+}$ to the organic/aqueous solutions. The time-dependent fluorescence spectral changes explained the detailed information of monomer enhancement of the $\mathbf{2}+\mathrm{Hg}^{2+}$ and $\mathbf{2}+\mathrm{Cu}^{2+}$ complexes at 396 $\mathrm{nm}$ in the presence of $5 \%$ water in acetonitrile solution. The binding phenomenon was further confirmed by matrix-assisted laser desorption ionization time-of-flight mass spectrometry (MALDI-TOF) and by ${ }^{1} \mathrm{H}$ NMR spectroscopic titration experiments. The participation of water molecules in the complexation procedure of 2 with $\mathrm{Hg}^{2+}$ and $\mathrm{Cu}^{2+}$ inhibits the heavy atom effect and thereby the enhancement of monomer emission is observed. Similar phenomenon was observed using $\mathrm{CH}_{3} \mathrm{OH}, \mathrm{CH}_{3} \mathrm{CH}_{2} \mathrm{OH}$ or 4,4'-bipyridine as solvent/melt for the $\mathbf{2}+\mathrm{Cu}^{2+}$ and $\mathbf{2}+\mathrm{Hg}^{2+}$ complexes.

Hexahomotrioxacalixarenes are defined as a class of synthetic macrocycles with phenolic units connected by $\mathrm{CH}_{2} \mathrm{OCH}_{2}$ bridges. By introducing different ionophores, homotrioxacalix[3]arenes have been used as potential receptors. ${ }^{70}$ The Yamato group incorporated a 2,2' -bipyridyl group attached via a carbonyl group at the upper rim and a diethylacetamide group at the lower rim of the hexahomotrioxacalix[3] arene that served as a tritopic receptor for $\mathrm{Ag}^{+}, \mathrm{Li}^{+}$and $\mathrm{Na}^{+}$ions in a cooperative fashion. ${ }^{71}$ Another representative example was reported by taking advantage of the excellent fluorescent properties of pyrene. Herein, we synthesized a pyrene-armed hexahomotrioxacalix[3] arene $\mathbf{3}$ as a ratiometric fluorescent sensor for the selective and sensitive detection of $\mathrm{Cu}^{2+}$ via a $\mathrm{Zn}^{2+}$ or $\mathrm{Cd}^{2+}$ triggered synergistic effect in a $\mathrm{CH}_{3} \mathrm{CN} / \mathrm{CH}_{2} \mathrm{Cl}_{2}$ solvent system. ${ }^{72}$ Furthermore, the ligand $\mathbf{3}$ with 

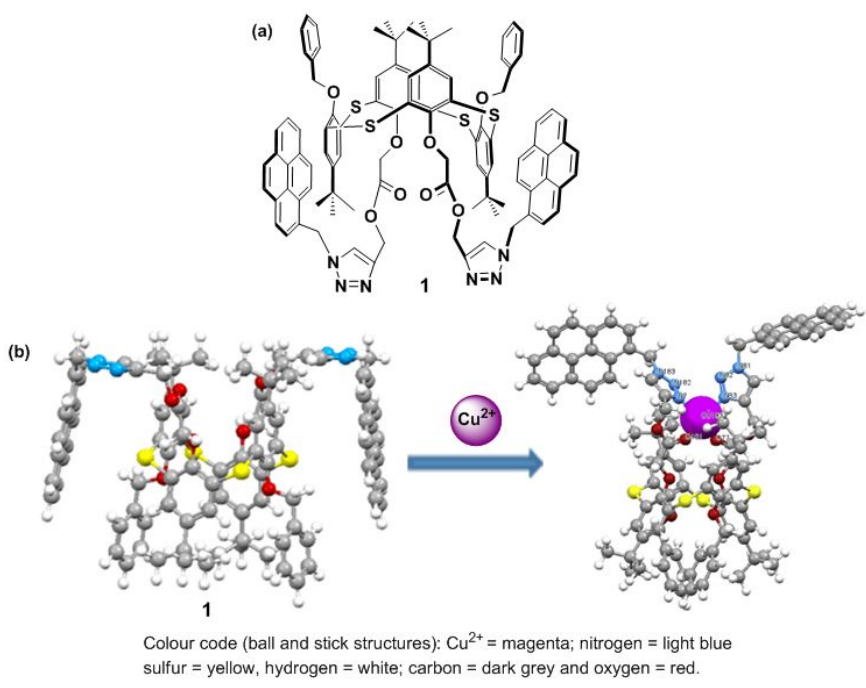

Fig. 5. (a) The molecular structure of ligand 1; (b) Geometry-optimized structures of 1 for $\mathrm{Cu}^{2+}$ in gas phase. Reprinted from ref. 66, with permission of Copyright 2015, Elsevier.

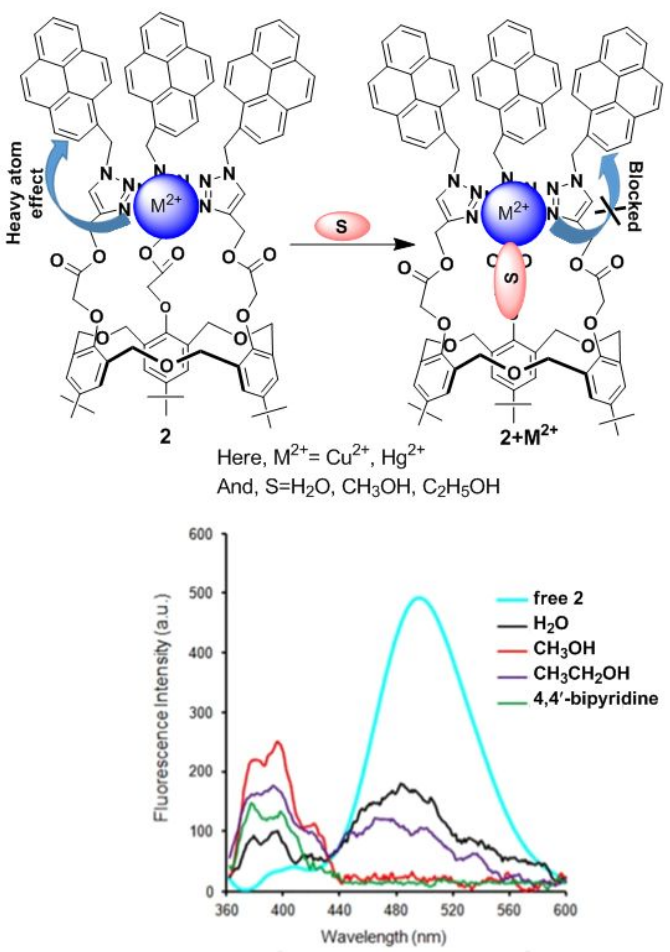

Fig. 6. (a) The heavy atom effect of $2+\mathrm{M}^{2+}$ complex blocked by solvent $\mathbf{S}$; (b) fluorescence response of $\mathbf{2}+\mathrm{M}^{2+}$ upon interaction with various solvents.

$\mathrm{Cu}^{2+}$ plays a vital role as an indirect sensor for $\mathrm{F}^{-}$recognition through demetallation. In this case, the fluorescence spectra of $\mathbf{3}$ in $\mathrm{CH}_{3} \mathrm{CN} / \mathrm{CH}_{2} \mathrm{Cl}_{2}$ exhibit a comparatively strong excimer emission at $518 \mathrm{~nm}$ and a weak monomer emission at $415 \mathrm{~nm}$, with an intensity ratio of monomer to excimer emission of 0.09 . The addition of $\mathrm{Cu}^{2+}$ ions to a solution of $\mathbf{3}$ leads to a significant increase in the monomer emission and a comparative decrease in the excimer emission to reveal a ratiometric change from 0.09 to 4.36 . These spectral changes of sensor 3 with $\mathrm{Cu}^{2+}$ can be ascribed to the cooperating effect of the geometrical structural changes and the reduced PET effect. The complex follows a 1:1 stoichiometry with a binding constant $(3.57 \pm 0.1) \times 10^{5} \mathrm{M}^{-1}$. Furthermore, the $3+\mathrm{Cu}^{2+}$ complex displays a highly sensitive response at $415 \mathrm{~nm}$ to both $\mathrm{Zn}^{2+}$ and $\mathrm{Cd}^{2+}$ through a synergistic effect. In this case, the quantum yield of the $3+\mathrm{Cu}^{2+}$ complex is considerably greater than before (from 0.05 to 0.19 ) upon addition of $\mathrm{Zn}^{2+}$ or $\mathrm{Cd}^{2+}$. From the fluorescence and NMR spectroscopic titration experiments, the following can be proposed: (i) the nitrogen atom of ligand 3 interacts with both $\mathrm{Cu}^{2+}$ and $\mathrm{Zn}^{2+}$. The $\mathrm{Cu}^{2+}$ coordination with nitrogen of $\mathbf{3}$ inhibits the electron transfer from the nitrogen to the photo-excited pyrene moieties, resulting in the enhancement of monomer emission. (ii) The presence of both $\mathrm{Zn}^{2+}$ and $\mathrm{Cu}^{2+}$ further decreases the electron density at the nitrogen atom which leads to the significant increase in the monomer emission intensity of the pyrene moieties and forms a trimer complex. However, spectral changes suggest that ligand $\mathbf{3}$ can sequentially recognize $\mathrm{Cu}^{2+}$ and $\mathrm{F}^{-}$through a two-step process, namely a complexation approach between $\mathbf{3}$ and $\mathrm{Cu}^{2+}$, and then a $\mathrm{Cu}^{2+}$ displacement approach by $\mathrm{F}^{-}$to form $\mathrm{CuF}_{2}$. Therefore, sensor 3 can act as a multifunctional molecular device by constructing a fluorescence-based combinational logic gate using the $\mathrm{Cu}^{2+}$, $\mathrm{Zn}^{2+} / \mathrm{Cd}^{2+}$ and $\mathrm{F}^{-}$fluorescence responses.

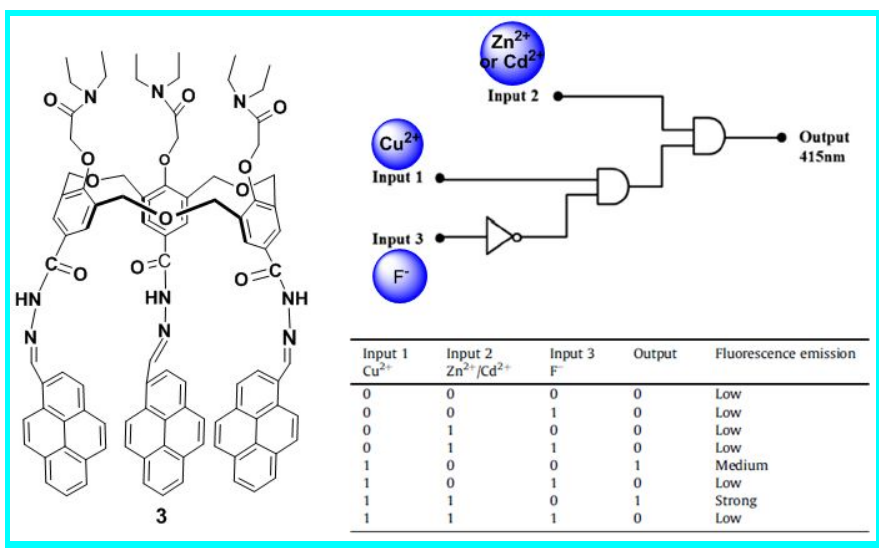

Fig. 7. The molecular structure of receptor 3 and the combinational logic gate for 3 with truth table using $\mathrm{Cu}^{2+}, \mathrm{Cd}^{2+} / \mathrm{Zn}^{2+}$ and $\mathrm{F}^{-}$as chemical inputs. Reproduced from ref. 72 with permission from the Elsevier, copyright 2015.

$\mathrm{Li}$ and co-workers have reported a pyrene based novel ratiometric fluorescent chemosensor for $\mathrm{Cu}^{2+}$ containing thiophene, namely compound 4 (see figure 8). ${ }^{73}$ The monomer to excimer conversion of chemosensor 4 occurred on gradual addition of $\mathrm{Cu}^{2+}$, owing to intermolecular $\pi-\pi$ stacked dimerization of the two pyrenes. The fluorescent emission of $4(10 \mu \mathrm{M})$ in tris- $\mathrm{HNO}_{3}$ buffer solution with high sensitivity and selectivity increases 127 -fold with 2 equiv. of $\mathrm{Cu}^{2+}(20 \mu \mathrm{M})$. In addition, the detection of $\mathrm{Cu}^{2+}$ present in environmental samples such as river and pond water has been determined by the use of $\mathbf{4}$. Moreover, cytotoxicity tests on $\mathbf{4}$ (from $0 \mu \mathrm{M}$ to $20 \mu \mathrm{M}$ ) using cells showed that more than $96 \%$ of the cells were viable which establish the real applicability of the chemosensor 4 in biological samples. The association constant $\left(\mathrm{K}_{\mathrm{a}}\right)$ for $\mathrm{Cu}^{2+}$ binding by chemosensor 4 was determined to be $2.18 \times 10^{4} \mathrm{M}^{-1}$. There was a good linear relationship covering $1.0 \times 10^{-7}$ to $2.0 \times$ 
$10^{-5} \mathrm{M}$ between the fluorescence ratio $\left(\mathrm{I}_{460} / \mathrm{I}_{375}\right)$ of 4 and the concentration of $\mathrm{Cu}^{2+}$ with a detection limit of $2 \times 10^{-8} \mathrm{M}$.

Two new chemosensors bearing either a single 5 or two $\mathbf{6}$ pyrene units linked by a flexible polyoxaethylene bridge have been developed that are sensitive to water and metal cations. ${ }^{74}$ Compound 5 in dioxane showed a single monomer absorption and emission band, whilst compound 6 gave an absorption band in the 400-500 $\mathrm{nm}$ region with an emission band with maxima at $\sim 500 \mathrm{~nm}$. In dioxane/water mixtures with $\mathrm{xH}_{2} \mathrm{O}=0.29$, the two probes exhibited a new band (with maxima varying from 405 to $490 \mathrm{~nm}$ ) due to exciplex formation. Time-resolved experiments have been used to explain a two-state system for ligand $\mathbf{5}$, which involves the monomer and a charged species, which can potentially be assigned to an exciplex-like species, whereas with 6, a three-state system is involved. After addition of the metal ions $\left(\mathrm{Cu}^{2+}, \mathrm{Zn}^{2+}\right.$ and $\left.\mathrm{Ag}^{+}\right)$to probe $\mathbf{5}$ in dioxane followed by absorption and emission studies, a gradual quenching effect of the monomer emission was observed and this was significantly selective for $\mathrm{Cu}^{2+}$. In case of ligand $\mathbf{6}$, after the interaction with metal cations, the emission band decreases at approximately $550 \mathrm{~nm}$ and the monomer emission band increases at $\sim 450 \mathrm{~nm}$. The binding ratio of ligand (5 and 6) to metal was proposed to be a 1:1 stoichiometry.

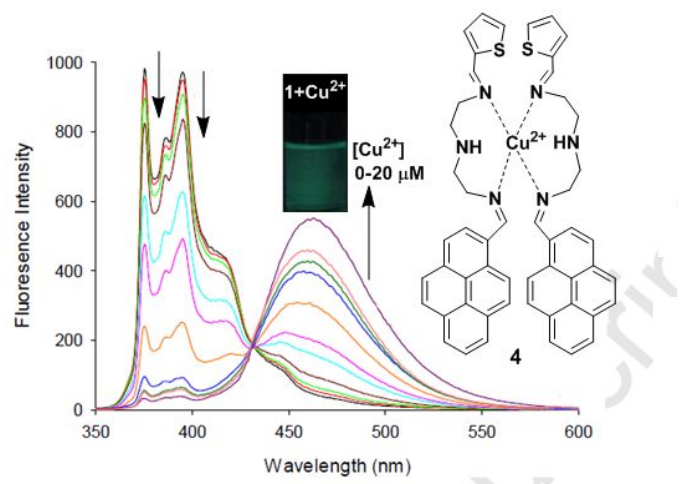

Fig. 8. Proposed binding mechanism of chemosensor 4 with fluorescence colour changes. Fluorescence Intensity changes of compound $\mathbf{4}(10 \mu \mathrm{M})$ with different concentrations of $\mathrm{Cu}^{2+}$ in Tris- $\mathrm{HNO}_{3}$ buffer solution at $\lambda_{\text {exc }}=342$ $\mathrm{nm}$. Reproduced from ref. 73 with permission from the Elsevier, copyright 2016.
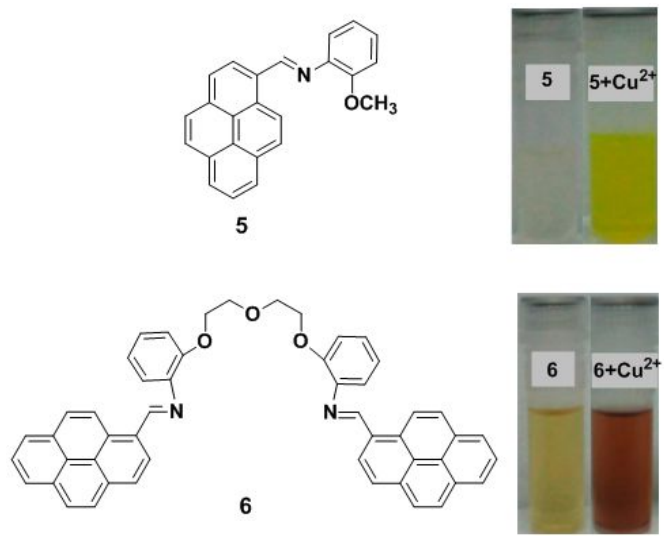

Fig. 9. Molecular structures of receptors 5 and 6. Observed colour change 5 and $\mathbf{6}$ with $\mathrm{Cu}^{2+}$. Reproduced from ref. 74 with permission from the American Chemical Society, copyright 2013.

A pentiptycene-bispyrenyl system 7 was developed from the reaction of pentiptycene hydroquinone with 1-bromomethylpyrene. ${ }^{75}$ Yang et al. reported compound 7 as a selective and sensitive fluorescent chemosensor for $\mathrm{Ca}^{2+} \mathrm{Cd}^{2+}$ and $\mathrm{Cu}^{2+}$. The fluorescence spectra of compound 7 exhibited typical monomer emission at 375 and $395 \mathrm{~nm}$ and an excimer emission at $475 \mathrm{~nm}$ in $\mathrm{CH}_{2} \mathrm{Cl}_{2}$. In particular, upon addition of $\mathrm{Cu}^{2+}$, a strong blue shifted (from 475 to $440 \mathrm{~nm}$ ) pyrene excimer emission was observed with increased intensity. This behaviour of sensor 7 was clarified by the excitation spectra which clearly showed a significant red shift at $\mathrm{Cu}^{2+}$-induced $440 \mathrm{~nm}$ than $375 \mathrm{~nm}$, due to the conversion of a partially overlapping static excimer from a sandwich-like dynamic excimer. Moreover, the $7+\mathrm{Cu}^{2+}$ complex at $440 \mathrm{~nm}$ has a short fluorescence lifetime (approximately 16-times) in comparison with $475 \mathrm{~nm}$ excimer emissions, which was explained by observation of the fluorescence decay times. Therefore, the radiative decay rate constant was larger for the static emission at $440 \mathrm{~nm}$ than the dynamic emission at 475 nm. In this case, $\mathrm{Cu}^{2+}$ binding with 7 brings the pyrene groups together in the ground state for the formation of static excimers and minimizes the relaxation event in the excited state leading to a blue-shifted excimer emission. The UV-Vis absorption spectra of ligand 7 also exhibited a clear broadening of the spectrum with four defined isobestic points at 325, 331, 339 and $348 \mathrm{~nm}$ and suggested a $1: 1$ complex with a binding constant of 4.4 .

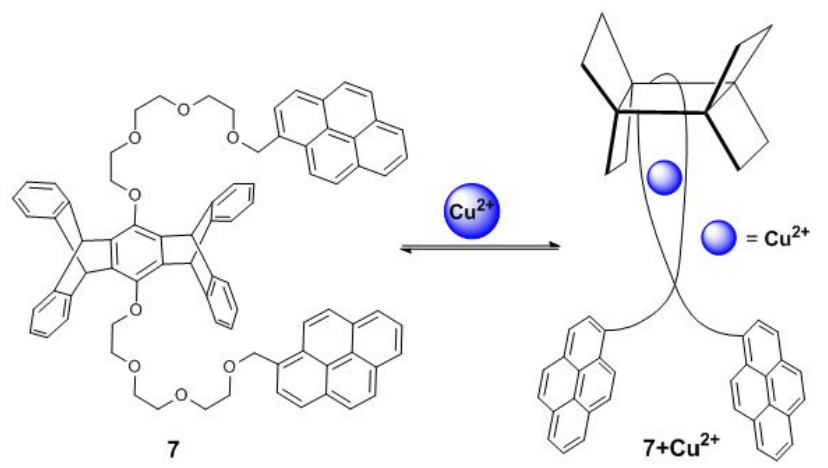

Fig. 10. Structure of chemosensor 7 and possible binding modes for $\mathrm{Cu}^{2+}$. Reproduced from ref. 75 with permission from the American Chemical Society, copyright 2001.

Kim et al. reported the mono-pyrenylalkylamine derivative $8{ }^{76}$ Upon addition of $\mathrm{Cu}^{2+}$, chemosensor $\mathbf{8}$ exhibited band broadening and a red-shift (from 342 to $455 \mathrm{~nm}$ ) in a mixed solvent system of $\mathrm{CH}_{3} \mathrm{CN} / \mathrm{H}_{2} \mathrm{O}$ (1:1). These observations were explained by favourable intermolecular $\pi-\pi$ stacking dimerization of the two pyrenes in the ground state. In the Job's plot measurements, the maximum point appeared at the mole fraction of 0.6 , which suggested a $2: 1$ ligand-to-metal complex. Fluorescence spectral changes of $\mathbf{8}$ revealed high selectivity toward $\mathrm{Cu}^{2+}$ over other competitive species $\left(\mathrm{Li}^{+}, \mathrm{Na}^{+}, \mathrm{K}^{+}, \mathrm{Rb}^{+}, \mathrm{Cs}^{+}, \mathrm{Mg}^{2+}, \mathrm{Ba}^{2+}, \mathrm{Ca}^{2+}, \mathrm{Sr}^{2+}, \mathrm{Ag}^{+}, \mathrm{Zn}^{2+}, \mathrm{Cd}^{2+}, \mathrm{Hg}^{2+}\right.$ and $\mathrm{Pb}^{2+}$ ). Moreover, the theoretical DFT calculations revealed that the pre-organized cavity is essential with two proximate nitrogen 
atoms of the sulfonamide groups to stabilize the complex of $\mathbf{8}$ with $\mathrm{Cu}^{2+}$ for static excimer emission.

The design and synthesis of new pyrene-derived fluorescent sensors containing quinolinylamide groups (9-11) was also reported by Kim and coworkers. The coordination behaviour was examined with variations in length of the methylene groups $(n=0,1,3)$ between the pyrene and quinolinylamide groups of 9-11 toward $\mathrm{Cu}^{2+}$ by fluorescence spectroscopy and theoretical DFT calculations. ${ }^{77}$ Addition of $\mathrm{Cu}^{2+}$ to ligand $9(n=0)$ produced a new broad emission band which supports strong static excimer emission at $460 \mathrm{~nm}$, whilst the binding constant was found to be $5.42 \times 10^{5} \mathrm{M}^{-1}$. Moreover, compound 9 interacts with $\mathrm{Cu}^{2+}$ following a 2:1 stoichiometry as deduced from the Job's plot analysis, mass spectra and fluorescence behaviour. A DFT study confirmed that the minimum intramolecular distance between the pyrene and quinoline amide is the main factor for $\mathrm{Cu}^{2+}$ ion detection. In the presence of 10 equiv. of $\mathrm{Cu}^{2+}$, the excimer emission intensity of 9 became approximately 8 times greater than that of probe $\mathbf{1 0}$ and $\mathbf{1 1}(n=1,3)$. Thus, it was concluded that the methylene spacers between the pyrene and carbonyl unit have a great impact on strong intermolecular Py-Py* formation in order to show an intense static excimer band.

A pyrene containing Schiff base fluorosensor $\mathbf{1 2}$ has been developed which showed high selectivity and sensitivity towards $\mathrm{Cu}^{2+}$ ions. ${ }^{78}$ This was due to the hindrance of the PET process upon complexation of the pyrene moiety with $\mathrm{Cu}^{2+}$ through interaction of the nitrogen lone pair electron of $\mathbf{1 2}$ with $\mathrm{Cu}^{2+}$ that induced the intermolecular excimer formation. The free ligand $\mathbf{1 2}$ exhibited two weak broad emissions centred at $385 \mathrm{~nm}$ and $452 \mathrm{~nm}$ in tris- $\mathrm{HCl}(10$ $\mathrm{mM}, \mathrm{pH}=7)$ buffer containing $\mathrm{CH}_{3} \mathrm{CN}-\mathrm{H}_{2} \mathrm{O}(\mathrm{v} / \mathrm{v}=1: 1)$ medium which were assigned due to monomer and excimer of the pyrene moieties respectively. Moreover, the presence of $\mathrm{Cu}^{2+}$ triggered a noticeable enhancement (10 fold) of the excimer peak at $452 \mathrm{~nm}$ along with two prominent monomer peaks at 378 and $396 \mathrm{~nm}$. The detection limit of the sensor 12 was found to be $4 \times 10^{-8} \mathrm{M}$. The emission property of $\mathbf{1 2}(5 \mu \mathrm{M})$ was dependent on the nature of the solvent, and was enhanced on increasing the concentration of water up to $80 \%$ and there after reduced at $90 \%$ water fraction. Moreover, since some active groups (e.g. $-\mathrm{NH}_{2}$ ) are present in the probe which are sensitive to $\mathrm{H}^{+}$ions, there is an effect of $\mathrm{pH}$ on the fluorescent response of the probe.

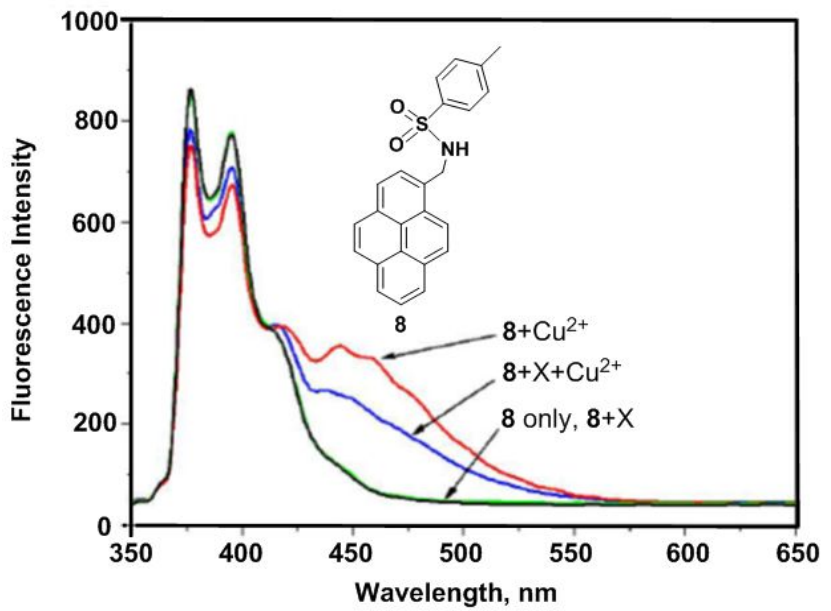

Fig. 11. The fluorescence spectra of $\mathbf{8}$ in the presence of $\mathrm{Cu}^{2+}$ and miscellaneous cations, $\mathbf{X}$ (10 equiv.). Reproduced from ref. 76 with permission from the American Chemical Society, copyright 2008.

Lin and co-workers have designed a simple pyrene containing derivative as a $\mathrm{Cu}^{2+}$ turn-on chemosensor $\mathbf{1 3}{ }^{79}$ The probe $\mathbf{1 3}$ in $\mathrm{CH}_{3} \mathrm{CN}$ revealed a greater photoluminescence intensity enhancement at $459 \mathrm{~nm}$ for $\mathrm{Cu}^{2+}(\Phi=0.284)$ versus other different metal ions $\left(\mathrm{Li}^{+}\right.$, $\mathrm{Ag}^{+}, \mathrm{K}^{+}, \mathrm{Na}^{+}, \mathrm{Cs}^{+}, \mathrm{Ni}^{2+}, \mathrm{Fe}^{3+}, \mathrm{Co}^{2+}, \mathrm{Zn}^{2+} \mathrm{Cd}^{2+}, \mathrm{Pb}^{2+}, \mathrm{Ca}^{2+}, \mathrm{Cr}^{3+}, \mathrm{Mg}^{2+}$, $\mathrm{Cu}^{2+}, \mathrm{Mn}^{2+}, \mathrm{Hg}^{2+}, \mathrm{Fe}^{2+}$ and $\left.\mathrm{Ag}^{+}\right)$. The sensing mechanism involves heteroatoms $(\mathrm{O}$ and $\mathrm{N})$ to form the excimer in which one $\mathrm{Cu}^{2+}$ binds with two $\mathrm{N}$ and two $\mathrm{O}$ (one $\mathrm{N}$ and one $\mathrm{O}$ from one molecule). The 2:1 stoichiometry of the $13+\mathrm{Cu}^{2+}$ complex was calculated from Job's plots based on UV-Vis absorption titrations. Moreover, the $13+\mathrm{Cu}^{2+}$ sensor was found to be active over a wide range of $\mathrm{pH}(1-14)$. After 10 minutes, the relative fluorescence intensity changes for $13+\mathrm{Cu}^{2+}$ reached a maximum value and so the system is effective with respect to time (0-10 minutes). The detection limit (LOD) of $\mathbf{1 3}$ with $\mathrm{Cu}^{2+}$ was calculated at $9.72 \times 10^{-7} \mathrm{M}$. Similarly, based on fluorescent binding isotherms, the association constant $\left(\mathrm{K}_{\mathrm{a}}\right)$ of the complex was estimated at $1.96 \times 10^{6} \mathrm{M}^{-1}$.
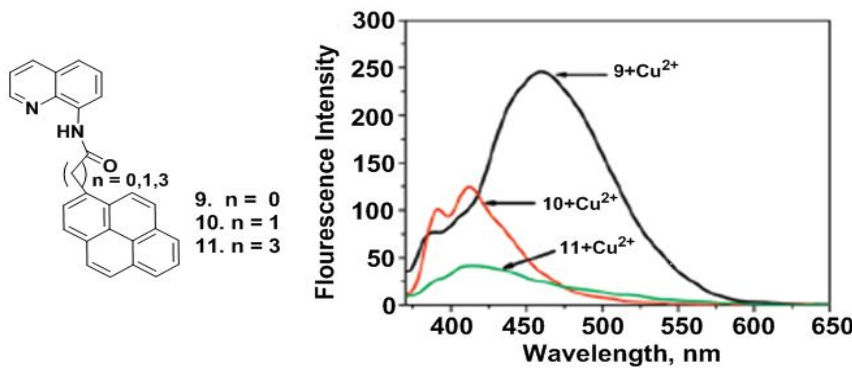

Fig. 12. The structures of the molecular receptors $\mathbf{9 , 1 0}$ and 11. Fluorescence spectra of 9-11 upon addition of $\mathrm{Cu}\left(\mathrm{ClO}_{4}\right)_{2}$ (10 equiv.). Reproduced from ref. 77 with permission from the American Chemical Society, copyright 2009.

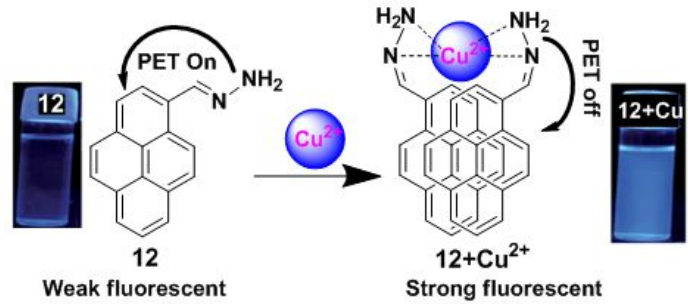

Fig. 13. Schematic representation of $\mathrm{Cu}^{2+}$ sensing by fluorosensor 12 and emission photograph of $\mathbf{1 2}$ and $\mathbf{1 2}+\mathrm{Cu}^{2+}$ under UV radiation. Reproduced from ref. 78, with permission from the Royal Society of Chemistry.

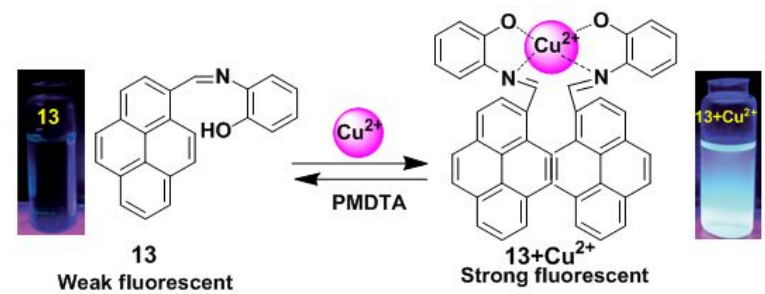


Fig. 14. Schematic presentation for detection of $\mathrm{Cu}^{2+}$ using receptors 13 . Photographs of $\mathbf{1 3}$ and $\mathbf{1 3}+\mathrm{Cu}^{2+}$ visualized under UV-light irradiations. Reproduced from ref. 79, with permission from the Royal Society of Chemistry.

A novel fluorescent chemosensor 14, made up of pyrene units connected by a binaphthyl-crown derivative was designed and prepared for the selective detection of $\mathrm{Cu}^{2+}$ in the presence of other metal cations $\left(\mathrm{Ca}^{2+}, \mathrm{Cd}^{2+}, \mathrm{Co}^{2+}, \mathrm{Cs}^{+}, \mathrm{Cu}^{2+}, \mathrm{Hg}^{2+}, \mathrm{K}^{+}, \mathrm{Mg}^{2+}, \mathrm{Mn}^{2+}, \mathrm{Na}^{+}\right.$, $\mathrm{Ni}^{2+}, \mathrm{Pb}^{2+}$, and $\left.\mathrm{Zn}^{2+}\right)$ in acetonitrile solution. ${ }^{80}$ Compound $14(1 \mu \mathrm{M})$ shows monomer and excimer emissions at 376 and $477 \mathrm{~nm}$ respectively for excitation at $342 \mathrm{~nm}$. Addition of $\mathrm{Cu}^{2+}$ produced a new blue shifted excimer emission band centered at $447 \mathrm{~nm}$ with increasing intensity maximum up to 3 -fold. The sensor 14 exhibits static excimer emission characteristics upon addition of $\mathrm{Cu}^{2+}$ that can be easily understood from excitation spectra. Here, the emission at $477 \mathrm{~nm}$ resulted from a dynamic excimer due to the identical excitation spectrum at both the monomer wavelength $(376 \mathrm{~nm})$ and the excimer wavelength $(477 \mathrm{~nm})$. The excitation spectrum of ligand 14 with $\mathrm{Cu}^{2+}$ monitored at $447 \mathrm{~nm}$ was significantly red-shifted compared with the spectrum taken at $376 \mathrm{~nm}$ which was attributed to the $447 \mathrm{~nm}$ from the static excimer. Moreover, from the fluorescence titration experiments, the association constant of $\mathbf{1 4}$ with $\mathrm{Cu}^{2+}$ was determined to be $65,600 \mathrm{M}^{-1}$.

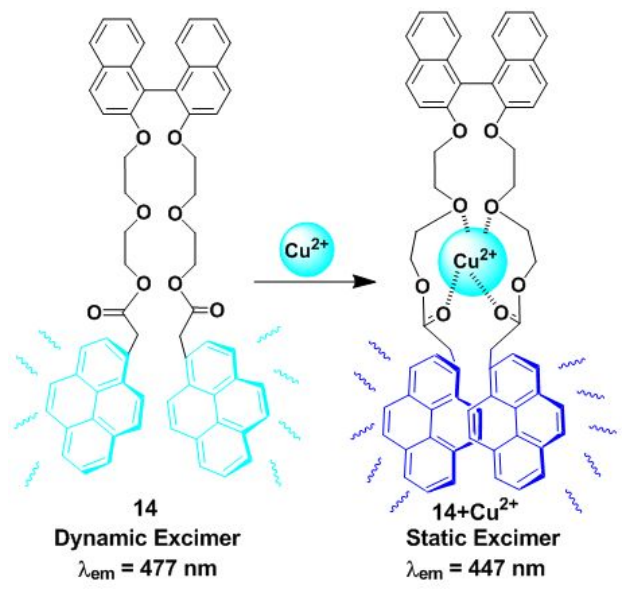

Fig. 15. Schematic representation of $\mathrm{Cu}^{2+}$ sensing by pyrene appended -binaphthyl-crown derivative compound, 14. Reproduced from ref. 80 with permission from the Elsevier, copyright 2006.

Kumar et al. have developed a new heteroditopic receptor $\mathbf{1 5}$, based on the 1,3-alternate conformation of thiacalix[4]-arene bearing amine groups appended with pyrene moieties and a crown- 4 ring. ${ }^{81}$ The receptor 15 can detect $\mathrm{Cu}^{2+}$ ions selectively among other metal ions with a detection limit of $40 \times 10^{-9} \mathrm{~mol} \mathrm{~L}^{-1}$ and follows a 1:2 stoichiometry of ligand to $\mathrm{Cu}^{2+}$ complexation. It shows negative allosteric behaviour between $\mathrm{Cu}^{2+} / \mathrm{Li}^{+}$ions in mixed aqueous media. The binding behaviour of compound $\mathbf{1 5}$ was studied by UV-vis and fluorescence spectroscopy which suggests the $\mathrm{Cu}^{2+}$ ions interact with the amino nitrogen centres and $\mathrm{Li}^{+}$ions co-ordinate to the crown ether ring of receptor $\mathbf{1 5}$. The excimer emission band of receptor $\mathbf{1 5}$ $\left(1.0 \mu \mathrm{M} ; \mathrm{EtOH}-\mathrm{H}_{2} \mathrm{O} ; 8: 2, \mathrm{v} / \mathrm{v}\right)$ for the pyrene moieties was clearly observed at $466 \mathrm{~nm}$ due to the fully overlapped position of the two pyrene units resulting in the folded conformation of $\mathbf{1 5}$. Notably, after gradual addition of only $\mathrm{Cu}^{2+}$ ions, the monomer fluorescence emission at $378 \mathrm{~nm}$ shows a major enhancement with a remarkable decrease in the excimer emission intensity and the variation of these emissions led to the formation of an isoemissive point at $430 \mathrm{~nm}$. This ratiometric behaviour of receptor $\mathbf{1 5}$ in the presence of $\mathrm{Cu}^{2+}$ ions was due to the decreased electron density at nitrogen leading to the conformational changes that moved the overlapped pyrene units away from each other.

A novel pyrene containing chemosensor $\mathbf{1 6}$ which possesses a self-assembled $3 \mathrm{D}$ crystal structure via $\mathrm{C}-\mathrm{H} . . . \pi, \pi \ldots \pi$ and different types of $\mathrm{H}$-bonding interactions, has been designed for the efficient and selective detection of $\mathrm{Cu}^{2+}$ and $\mathrm{F}^{-}$ions in a dual sensing mode which do not interfere to each other. ${ }^{82}$ The sensor 16 can recognize $\mathrm{Cu}^{2+}$ by fluorimetric experiments and by visual colour changes under UV-light. The emission spectra of sensor $16\left(1 \times 10^{-7} \mathrm{M}\right)$ in a methanol-water mixture (methanol:water 7:3 v/v) shows, on changing the concentration, a local emission band at $466 \mathrm{~nm}$ which remains almost unchanged, whilst the band at $530 \mathrm{~nm}$ was continuously altered indicating the formation of excimers. After addition of $\mathrm{Cu}^{2+}$ to the sensor 16 , a decrease of the excimer bands at $520 \mathrm{~nm}$ and $560 \mathrm{~nm}$ was initially observed as a result of interaction of the copper with the sensor and then the $16+\mathrm{Cu}^{2+}$ complex causes an increment of the band at $466 \mathrm{~nm}$. The above phenomenon can be explained by an excimer switch-off mechanism for promoting complexation with $\mathrm{Cu}^{2+}$. A Benesi-Hildebrand plot and Job's plot from UV-vis titrations demonstrated that the stoichiometry of the complex formed by $\mathbf{1 6}$ and $\mathrm{Cu}^{2+}$ is $1: 1$ with a binding constant of 4.8 $\mathrm{x} 10^{6} \mathrm{M}^{-1}$. In order to confirm the binding phenomena, the structure and electronic properties of $\mathbf{1 6}$ and its copper complex $\mathbf{1 6}+\mathrm{Cu}^{2+}$ have been investigated by Density Functional Theory (DFT). Moreover, the sensor $\mathbf{1 6}$ has potential for biological applications when detecting $\mathrm{Cu}^{2+}$ as it overcomes the membrane barrier of living cells (HEK 293 cells).

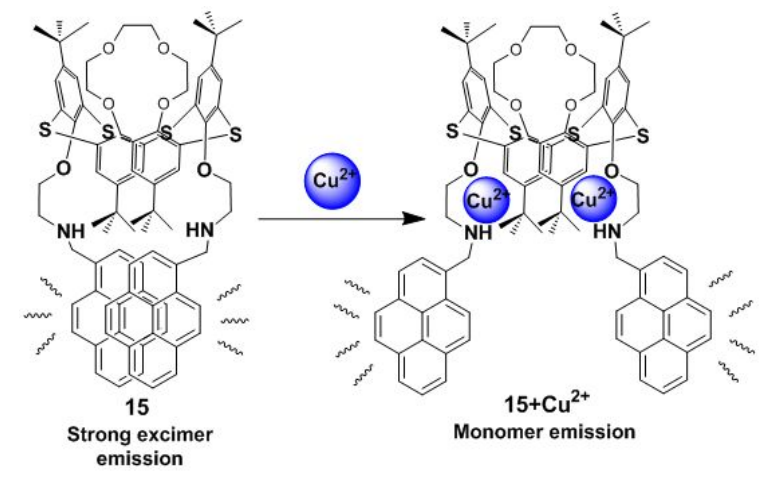

Fig. 16. Schematic representation of possible sensing mechanism for $\mathbf{1 5}$ on interaction with $\mathrm{Cu}^{2+}$. Reproduced from ref. 81 with permission from the Royal Society of Chemistry.

Mallik et al. have reported the development of four new saturated, pyrene-containing, metal-chelating lipids as fluorescent sensors (17-20). ${ }^{83}$ These lipids can interact with transition metal ions via a variety of metal-chelating head groups such as iminodiacetate (IDA), EDTA, DTPA. However, all the lipids (17-20) in DMSO solution failed to show the presence of any excimers in the emission spectra. 
They can form liposomes $(2.0 \mathrm{mg} / \mathrm{mL})$ under standard liposome formation conditions. The emission spectrum of $\mathbf{1 7}$ showed that both pyrene monomers $(395 \mathrm{~nm})$ and excimers $(470 \mathrm{~nm})$ were present in the liposomes in which the excimer to monomer intensity ratio (0.69) clearly indicated that lipid $\mathbf{1 7}$ was aggregated in the liposomes. Upon treatment with $\mathrm{Cu}^{2+}$, the overall fluorescence intensity of the liposomes decreased due to quenching of the excited states of the pyrene monomer by $\mathrm{Cu}^{2+}$ compared to the pyrene excimer, leading to an increase in excimer-to-monomer ratio. Similar behaviour was also observed for liposomes from 17-19 except 20 which showed very little change. Other transition metal ions $\left(\mathrm{Ni}^{2+}, \mathrm{Hg}^{2+}\right.$ and $\left.\mathrm{Zn}^{2+}\right)$ did not show any response in the excimer to monomer intensity ratio.

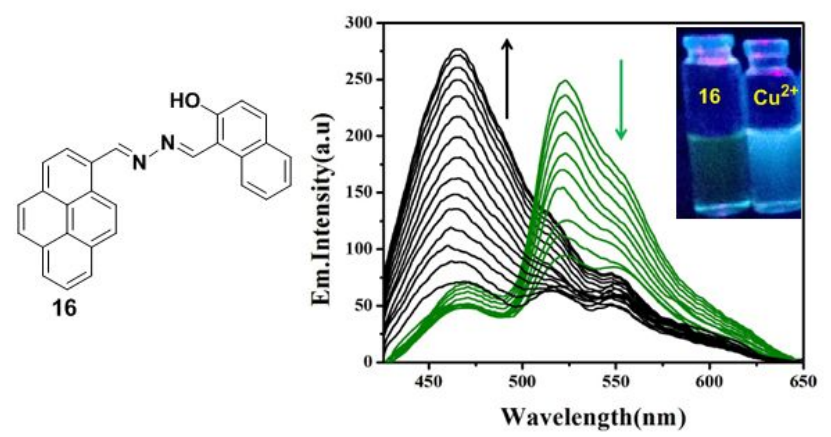

Fig. 17. Structure of compound $\mathbf{1 6}$ showing fluorescence emission spectra of 16 with the addition of $\mathrm{Cu}^{2+}$. Inset: Visual fluorescence changes of $\mathbf{1 6}$ and upon addition of $\mathrm{Cu}^{2+}$ using a handheld UV lamp. Reproduced from ref. 82, with permission from the Royal Society of Chemistry.
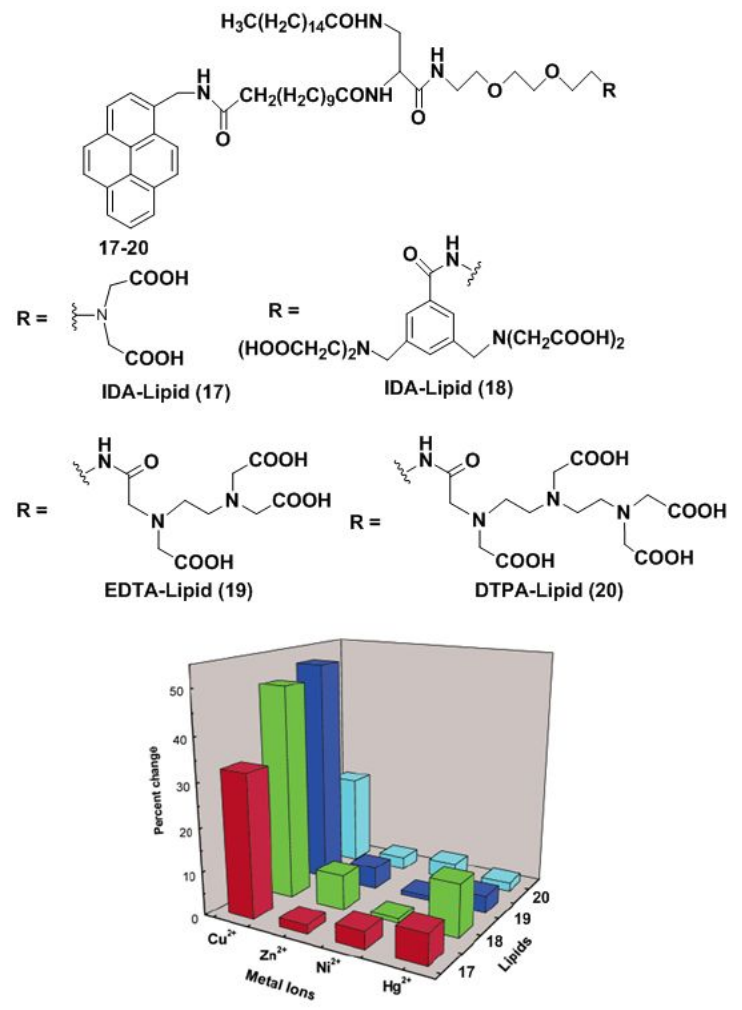

Fig. 18. Structures of molecular receptor 17-20. Relative increase of the $I_{470} / I_{395}$ ratio with transition metal ions for the saturated lipids. Reproduced from ref. 83 with permission from the American Chemical Society, copyright 2003.

Another pyrene-appended ratiometric fluorescent chemosensor 21 has been reported by Yamato and coworkers in 2015. In this case, the homooxacalix[3] arene acts as a molecular spacer incorporating three pyrene fluorophore at the upper rim and three substituted triazole arms as ionophore at the lower rim. ${ }^{84}$ The sensor 21 can serve as a ratiometric chemosensor for heavy and transition metal (HTM) ions $\left(\mathrm{Cu}^{2+}, \mathrm{Hg}^{2+}, \mathrm{Pb}^{2+}\right.$ and $\left.\mathrm{Zn}^{2+}\right)$ resulting in a conformational change for 21. The fluorescence emission spectra of free $\mathbf{2 1}$ show a characteristic pyrene excimer band at $482 \mathrm{~nm}$ in $\mathrm{CH}_{3} \mathrm{CN}$ solution. The interaction of $\mathbf{2 1}$ with $\mathrm{Cu}^{2+}$ and other HTM ions led to the enhancement of monomer emission accompanied by excimer quenching. Herein, the ditopic calixarene as a molecular spacer prevents the heavy atom effect of the HTM ion by insulating the fluorophore from the ionophore through a long distance. The association constant for $1: 1$ complexation of $\mathbf{2 1}+\mathrm{Cu}^{2+}$ was calculated
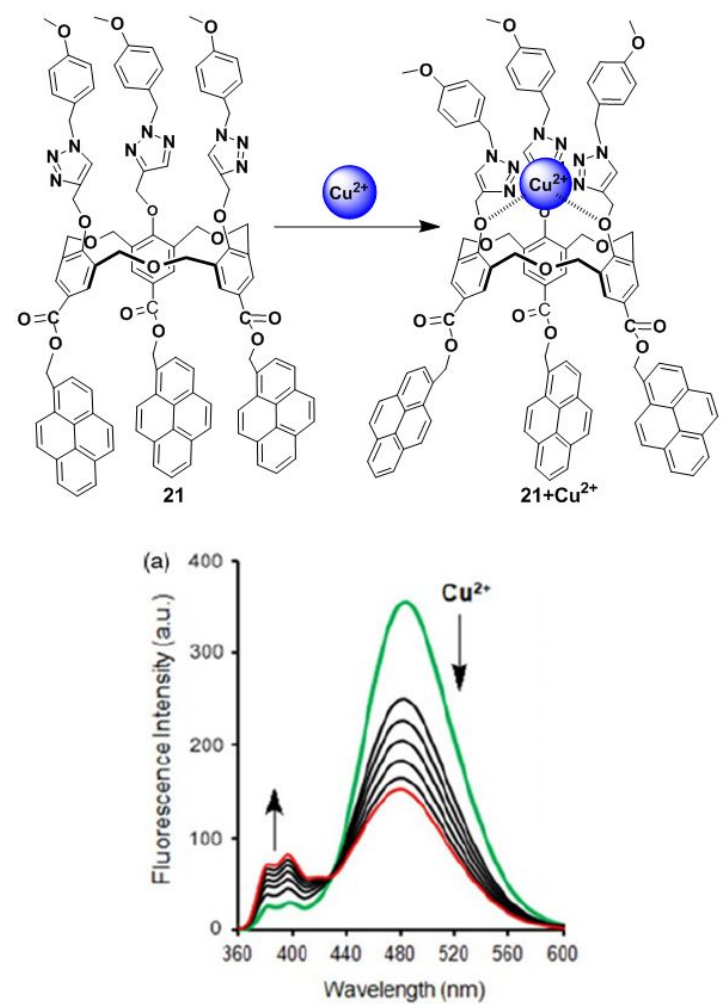

Fig. 19. (a) The structure of ratiometric sensor 21 and it's binding mode with $\mathrm{Cu}^{2+} ;(b)$ showing fluorescence for the $\mathrm{Cu}^{2+}$ ion in $\mathrm{CH}_{3} \mathrm{CN}$. Reproduced from ref. 84 with permission from the Taylor \& Francis, copyright 2015.

to be $1.89 \times 10^{5} \mathrm{M}^{-1}$. FT-IR spectra of the chemosensor 21 have been recorded, and the absorption band of $\mathrm{C}-\mathrm{O}$ present on the lower rim is shifted at $1184 \mathrm{~cm}^{-1}$ whereas no absorption band change is observed for $\mathrm{C}=\mathrm{O}$ at the upper rim of $\mathbf{2 1}$ upon complexation with $\mathrm{Cu}^{2+}$. The authors stated that three substituted triazole moieties at the lower rim 
bind with $\mathrm{Cu}^{2+}$ and cause conformational changes that make the pyrene units move far away from one another.

\subsection{Chemosensors based on PET mechanism}

Receptor molecules have been designed for the enhancement of fluorescence intensity upon binding with a metal ion through the photoinduced electron transfer mechanism. ${ }^{85}$ In 2015, based on the photoinduced electron transfer mechanism, our group developed 7-tert-butylpyrene-appended fluorescent sensors containing dipicolylamine (Dpa) linkages. ${ }^{86}$ Both the mono-chelate and bis-chelate ligand showed selectivity for $\mathrm{Zn}^{2+}$ and $\mathrm{Cd}^{2+}$ ions. Herein, we explain that the binding phenomenon of both ligands towards $\mathrm{Zn}^{2+}$ and $\mathrm{Cd}^{2+}$ varied on changing the solvent system. However, the addition of $\mathrm{Cu}^{2+}$ showed almost no fluorescence enhancement yet the $\mathrm{Cu}^{2+}$ quenched the fluorescence of the bis-chelate ligand and $\mathrm{Zn}^{2+}$ complex, which can be explained by the paramagnetic nature of $\mathrm{Cu}^{2+}$. For the selective and sensitive detection of $\mathrm{Cu}^{2+}$, our group designed and synthesized three new fluorescence 'off-on' chemosensors 22-24 based on pyrene containing Schiff base derivatives with different chain lengths. ${ }^{87}$ Compound 22 was synthesized from the condensation reaction of 1-pyrene carbaldehyde

with 4-(hydrazidocarbonyl)( $N, N$-diethylaminocarbonylmethoxy)benzene. The other compounds $\mathbf{2 2}$ and $\mathbf{2 3}$ were easily synthesized via condensation reactions, and were compared against $\mathbf{2 2}$ towards $\mathrm{Cu}^{2+}$ in terms of binding ability. The probe $22(1.0 \mu \mathrm{M})$ was highly sensitive for the $\mathrm{Cu}^{2+}$ detection due to strong inhibition of PET. After addition of $\mathrm{Cu}^{2+}$, the emission intensity was enhanced approximately 65 times more $(\Phi=0.31)$ than that of the free ligand $22(\Phi=0.01)$, and was 57 times and 40 times greater than free $\mathbf{2 3}$ and $\mathbf{2 4}$, respectively. A Job's plot analysis was carried out at $405 \mathrm{~nm}$ in which the fluorescence intensity showed a maximum at the mole fraction 0.5 which corresponds to a $1: 1$ ratio of ligand and $\mathrm{Cu}^{2+}$ complex. The resulting association constant for $\mathbf{2 2}$ was found to be $1.29 \times 10^{5} \pm 0.32 \mathrm{M}^{-1}$. A DFT computational study together with ${ }^{1} \mathrm{H}$ NMR and ${ }^{13} \mathrm{C}$ NMR spectroscopic titration experiments revealed that $\mathrm{Cu}^{2+}$ was bound at the imine nitrogen atom and the amide carbonyl oxygen of ligands $\mathbf{2 2}$ and $\mathbf{2 3}$. The diethylaminocarbonylmethoxy group of $\mathbf{2 2}$ provides a contribution for $\mathbf{2 2}$ and $\mathrm{Cu}^{2+}$ complexation through an inductive effect.

A pyrene derivative containing a benzothiazolenhydrazone receptor as a fluorescent sensor 25 was reported by Wang and Wu. ${ }^{88}$ Upon addition of $\mathrm{Cu}^{2+}(25 \mu \mathrm{M})$, probe $25(50 \mu \mathrm{M})$ exhibited a significant fluorescence enhancement at $468 \mathrm{~nm}$ in acetonitrile-water $(\mathrm{v} / \mathrm{v}=$ 3/1, $5 \mathrm{mM}$ HEPES, $\mathrm{pH}$ 7.0) from which the limit of detection of chemosensor 25 was estimated to be $2.73 \mu \mathrm{M}$. The coordination of $\mathrm{Cu}^{2+}$ ions inhibited the PET process resulting in a significant enhancement of fluorescence intensity. The Job's plot experiments revealed a 2:1 stoichiometry for ligand 25 to metal complex. Density functional theory (DFT) calculations determined that two chemosensors 25 bind $\mathrm{Cu}^{2+}$ using four nitrogen atoms. Moreover, the fluorescence and bright-field images indicated that the probe $\mathbf{2 5}$ is useful for the detection of $\mathrm{Cu}^{2+}$ ions in live cells.

Molina et al. designed the chemosensor 26 in which a 2-aza-1,3-diene moiety was used as the ionophore for the recognition of $\mathrm{Cu}^{2+}{ }^{29}$ The absorption spectrum of chemosensor $\mathbf{2 6}$ exhibited two well-defined isosbestic points at 275 and $440 \mathrm{~nm}$ with a gradual increase of a new red shifted band at $496 \mathrm{~nm}$ in the presence of $\mathrm{Cu}^{2+}$ ion. This was responsible for the change of colour from yellowish to deep orange. The fluorescence intensity of $26\left(2.5 \times 10^{-5} \mathrm{M}\right)$ in $\mathrm{CH}_{3} \mathrm{CN}$ increased upon addition of $\mathrm{Cu}^{2+}\left(I_{\text {complex }} / I_{\text {free ligand }}=22\right.$-fold $)$, where the excimer emission shifted from 450 to $429 \mathrm{~nm}$. From the emission intensity data, the association constant of the chemosensor $\mathbf{2 6}+\mathrm{Cu}^{2+}$ system was found to be $5.71 \times 10^{5} \mathrm{M}^{-1}$. The stoichiometry of the ligand $\mathbf{2 6}$ to metal complex system was estimated to be 1:1. The response of the fluorescence of $\mathbf{2 6}$ was also studied in $\mathrm{CH}_{3} \mathrm{CN} / \mathrm{H}_{2} \mathrm{O}$ (70/30). Under these conditions, titration experiments demonstrated that the $\mathrm{Cu}^{2+}$ ions yielded a 10 -fold enhancement of quantum yield along with a slight red shift $(10 \mathrm{~nm})$ of the excimer emission band. The titration data indicated the calculated detection limit of 26 was $3.91 \times 10^{-6} \mathrm{M}$ for $\mathrm{Cu}^{2+}$.
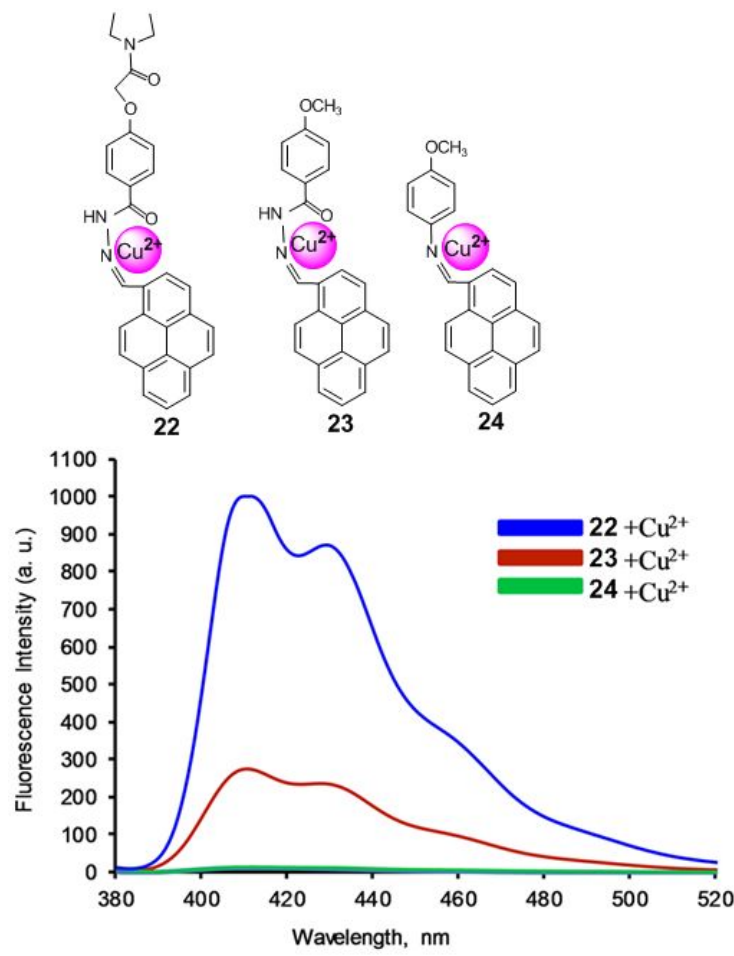

Fig. 20. Structure of chemosensors 22, 23 and 24. Fluorescence response of ligands upon addition of $\mathrm{Cu}^{2+}$ ions in $\mathrm{CH}_{3} \mathrm{CN} / \mathrm{CH}_{2} \mathrm{Cl}_{2}$. Reproduced from ref. 87 with permission from the Elsevier, copyright 2016.

A pyrene based fluorescent chemosensor 27 containing a picolinohydrazide receptor was developed by $\mathrm{Wu}$ and co-workers. ${ }^{90}$ Binding with $\mathrm{Cu}^{2+}$ ions in mixed aqueous media $\left(\mathrm{CH}_{3} \mathrm{OH}: \mathrm{H}_{2} \mathrm{O}=7: 3\right)$ to the chemosensor $\mathbf{2 7}$ blocks PET and greatly enhanced the fluorescence of pyrene. After gradual addition of $\mathrm{Cu}^{2+}$ to the chemosensor $27(25 \mu \mathrm{M})$, a new emission band appeared at $455 \mathrm{~nm}$ and the quantum yield of that emission band was 0.267 , which is 20 -fold that of chemosensor 27, 0.013. The Job's plot experiment indicated that the binding ratio for the chemosensor $27+\mathrm{Cu}^{2+}$ complex was $1: 1$. It was also confirmed from ${ }^{1} \mathrm{H}$ NMR and IR spectroscopy that the $\mathrm{Cu}^{2+}$ was bound to one nitrogen atom from a 
pyridine and one nitrogen atom from an amide. Moreover, fluorescence signals determined by a fluorescence microscope indicated that chemosensor 27 possessed good cell-membrane permeability and could detect $\mathrm{Cu}^{2+}$ present in living cells.

A pyrene-based chemosensor $\mathbf{2 8}$ in which diaminomaleonitrile acted as a chelator, was synthesized and designed for $\mathrm{Cu}^{2+}$ ion detection. ${ }^{91}$ It was observed from UV-visible spectroscopy that the absorbance at $420 \mathrm{~nm}$ was reduced and a new band appeared at 355 $\mathrm{nm}$ after gradual addition of $\mathrm{Cu}^{2+}$ to chemosensor 28. The colour of $\mathbf{2 8}$ also changed from yellow to colourless. Moreover, free ligand $\mathbf{2 8}$ exhibited very weak fluorescence $(\Phi=0.0045)$ due to a photoinduced electron transfer mechanism from the lone pair electrons of the two-nitrile groups to pyrene. However, the $\mathrm{Cu}^{2+}$-bound probe $\mathbf{2 8}$ inhibited the electron withdrawing ability of the two-nitrile groups and showed a sharp emission peak at $417 \mathrm{~nm}(\Phi=0.59)$ under excitation of $350 \mathrm{~nm}$ in acetonitrile-water.
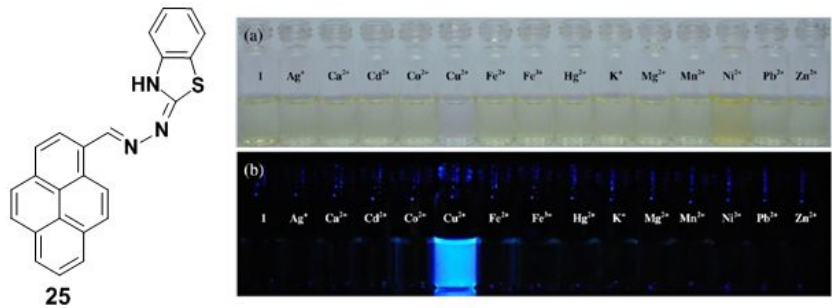

Fig. 21. Structures of probe 25 and Colour (a) and fluorescence (b) changes of chemosensor $25(500 \mu \mathrm{M})$ after addition of various metal ions $(500 \mu \mathrm{M})$. Reproduced from ref. 88 with permission from the Elsevier, copyright 2013.
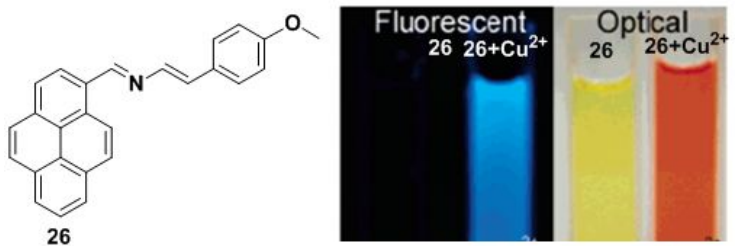

Fig. 22. Structure of chemosensor $\mathbf{2 6}$ and colour and fluorescence changes of 26 with $\mathrm{Cu}^{2+}$ in $\mathrm{CH}_{3} \mathrm{CN}$. Reproduced from ref. 89 with permission from the American Chemical Society, copyright 2006.

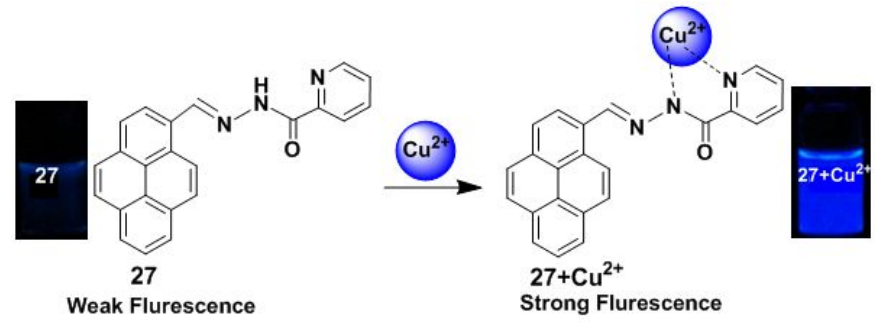

Fig. 23. Schematic representation of the sensing mechanism of probe 27 with $\mathrm{Cu}^{2+}$. Reproduced from ref. 90 with permission from the Springer Nature, copyright 2012.

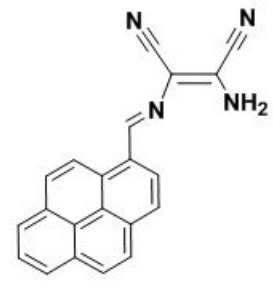

28

Weak fluorescence
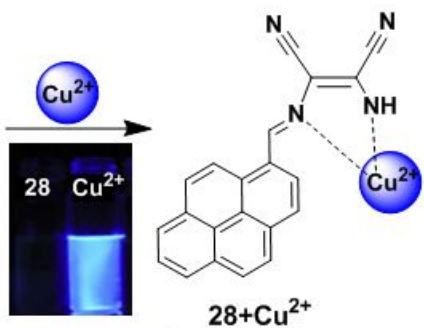

Strong fluorescence

Fig. 24. Structure of chemosensor 28 and possible binding modes for $\mathrm{Cu}^{2+}$. Reproduced from ref. 91 with permission from the Elsevier, copyright 2010.

A newly designed fluorescence chemosensor 29 that contains a pyrene motif with a hydrazinylpyridine moiety has been reported. ${ }^{92}$ The sensor 29 revealed high sensitivity towards $\mathrm{Cu}^{2+}$ ions in a $\mathrm{CH}_{3} \mathrm{CN} / \mathrm{H}_{2} \mathrm{O}$ solvent system over the $\mathrm{pH}$ range 5.0-10. The interaction of $\mathrm{Cu}^{2+}$ inhibited the PET mechanism from the nitrogen lone pairs to the pyrene, resulting in significant enhancement in pyrene fluorescence. The quantum yield of ligand 29 to $\mathrm{Cu}^{2+}$ complex at the emission band $389 \mathrm{~nm}$ was 0.56 , which was 560 times greater than that of the free ligand 29 at 0.001 . The association constant $\left(K_{\mathrm{a}}\right)$ of 29 with $\mathrm{Cu}^{2+}$ was found to be $1.0 \times 10^{4} \mathrm{M}^{-1}$. On binding with $\mathrm{Cu}^{2+}$, the absorption spectra exhibited a $42 \mathrm{~nm}$ blue shift because of hindered conjugation between the double bonds of 29. The colour also changed from light yellow to colourless. Moreover, confocal fluorescence microscopy imaging for detecting $\mathrm{Cu}^{2+}$ in living cells showed that chemosensor 29 can be used as an effective fluorescent probe due to its $(<30 \mu \mathrm{M})$ low cytotoxicity and ability to easily penetrate cell membranes.

A Schiff-base fluorescent compound $\mathbf{3 0}$ was developed by exploiting the photoinduced electron transfer (PET) process for the detection $\mathrm{Cu}^{2+}$ ions. $^{93}$ Ligand $\mathbf{3 0}\left(4 \times 10^{-6} \mathrm{M}\right)$ shows weak fluorescence because of photoinduced electron transfer. The fluorescence intensity was remarkably enhanced after gradual addition of $\mathrm{Cu}^{2+}$ ions (0-65 equiv.) to the chemosensor 30 in DMSO- $\mathrm{H}_{2} \mathrm{O}(1: 1 \mathrm{v} / \mathrm{v}$, HEPES $=50 \mathrm{mM}, \mathrm{pH}=7.4)$. From the emission intensity data, the detection limit of chemosensor $30+\mathrm{Cu}^{2+}$ system was found to be $0.26 \times 10^{-6} \mathrm{M}$ with an association constant $1.16 \times 10^{4} \mathrm{M}^{-1}$. A Job's plot experiment showed that 30 to $\mathrm{Cu}^{2+}$ complex followed a 1:1 binding model. Treatment of chemosensor 30 with various metal ions such as $\mathrm{Pb}^{2+}, \mathrm{Ce}^{3+}, \mathrm{Cd}^{2+}, \mathrm{La}^{3+}, \mathrm{Mg}^{2+}, \mathrm{Zn}^{2+}$, $\mathrm{Ba}^{2+}, \mathrm{Bi}^{2+}, \mathrm{Hg}^{2+}, \mathrm{Fe}^{3+}, \mathrm{Ag}^{+}, \mathrm{Ni}^{2+}, \mathrm{Cr}^{3+}, \mathrm{Ca}^{2+}, \mathrm{Mn}^{2+}, \mathrm{Na}^{+}, \mathrm{K}^{+}, \mathrm{Co}^{2+}, \mathrm{Zr}^{2+}$, $\mathrm{Li}^{+}, \mathrm{Sr}^{2+}, \mathrm{Fe}^{2+}, \mathrm{Al}^{3+}$ and $\mathrm{Th}^{4+}$ (100 equiv.) resulted in insignificant changes in the fluorescence intensity, which indicate high selectivity of $\mathbf{3 0}$ towards the $\mathrm{Cu}^{2+}$ ion. Time-dependence fluorescence intensity indicated that sensor $\mathbf{3 0}$ completely binds with $\mathrm{Cu}^{2+}$ ion within 5 min. Moreover, the bio-imaging and spectroscopic methods confirmed its detection ability for $\mathrm{Cu}^{2+}$ ions in living cells. 


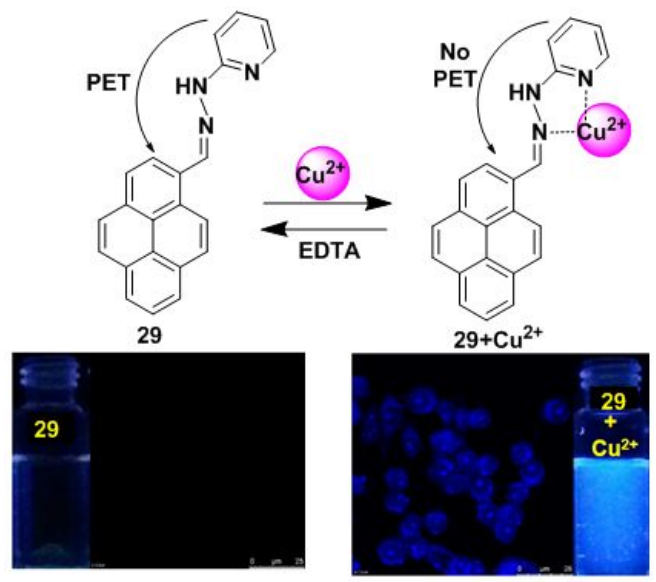

Fig. 25. Possible binding modes and fluorescence images of macrophage (RAW 264.7) cells treated with 29 (left) and then $29+\mathrm{Cu}^{2+}$ (right). Inset. Fluorescence colour changes of solution 29 before and after addition of $\mathrm{Cu}^{2+}$. Reproduced from ref. 92 with permission from the Royal Society of Chemistry.

Patra and co-workers have developed a chemosensor $\mathbf{3 1}$ containing a benzilmonohydrazone moiety for the detection of $\mathrm{Cu}^{2+} .^{94}$ The chemosensor $\mathbf{3 1}$ exhibited a significant colour change from yellow to colourless in the presence of 10 equiv. of $\mathrm{Cu}^{2+}$ ions. The binding properties of $\mathbf{3 1}$ were further investigated by fluorescence titration experiments in acetonitrile-water $(2 / 1, \mathrm{v} / \mathrm{v})$. The fluorescence quantum yield increased from 0.035 to 0.67 after gradual addition of $\mathrm{Cu}^{2+}$. In this case, $\mathrm{Cu}^{2+}$ is coordinated with the outer azino nitrogen atom of the ligand 31, which inhibits the PET mechanism. The detection limit of $\mathbf{3 1}$ based on fluorescent-titration experiments was found to be $7.8 \mathrm{nM}$ for $\mathrm{Cu}^{2+}$. The 1:1 stoichiometric complexation between 31 and $\mathrm{Cu}^{2+}$ was observed by ${ }^{1} \mathrm{H}$ NMR spectroscopic data, the Job's plot and the ESI-MS spectrum. The ligand 31 was efficiently applied in real samples for the recognition of $\mathrm{Cu}^{2+}$ over the wide $\mathrm{pH}$ range of $4-11$.

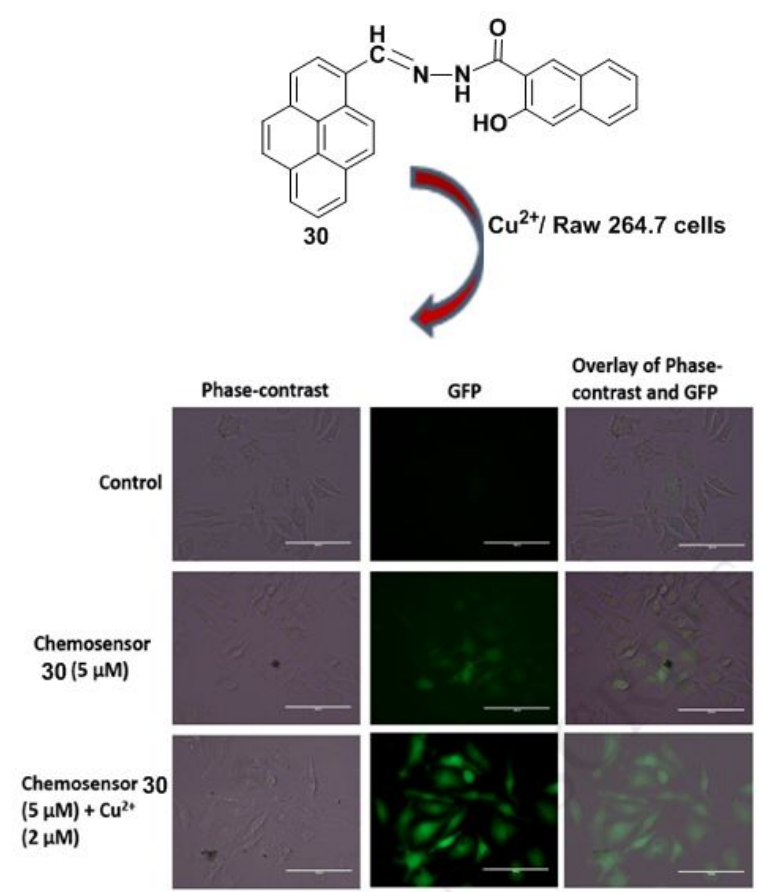

Fig. 26. Structure of ligand 30. Fluorescence images of RAW 264.7 cells treated with chemosensor 30 and $\mathrm{Cu}^{2+}$ ions. Phase-contrast (left); GFP image $\left(\lambda_{\text {ex }}=393 \mathrm{~nm}\right)$ (middle); and overlay of phase contrast and GFP (right). Reproduced from ref. 93 with permission from the Elsevier, copyright 2018.

A new 2-aza-1,3-butadiene ionophore which connects two pyrene groups has been synthesized and studied as a colorimetric and fluorescent chemosensor 32 for $\mathrm{Cu}^{2+}$ ions. ${ }^{95}$ The UV-vis and fluorescence measurements illustrated the binding mechanism of receptor $32\left(\mathrm{c}=2.5 \times 10^{-5} \mathrm{M}\right)$ with several metal cations $\left(\mathrm{Li}^{+}, \mathrm{Na}^{+}\right.$, $\mathrm{K}^{+}, \mathrm{Mg}^{2+}, \mathrm{Ca}^{2+}, \mathrm{Ni}^{2+}, \mathrm{Cu}^{2+}, \mathrm{Zn}^{2+}, \mathrm{Cd}^{2+}, \mathrm{Hg}^{2+}, \mathrm{Pb}^{2+}, \mathrm{Sm}^{3+}, \mathrm{Eu}^{3+}, \mathrm{Yb}^{3+}$ and $\mathrm{Lu}^{3+}$ ) in $\mathrm{CH}_{3} \mathrm{CN}$. The receptor 32 showed selective changes for $\mathrm{Cu}^{2+}$ and $\mathrm{Hg}^{2+}$ ions with a visible colour change by naked eye detection. Compound $\mathbf{3 2}$ exhibits a very weak fluorescence due to photoinduced electron transfer (PET) quenching from the lone pair electrons on the nitrogen atom in the 2-azadiene bridge to the excited state of the pyrene moiety when excited at $350 \mathrm{~nm}(\Phi=0.014)$. Upon addition of $\mathrm{Cu}^{2+}$ to 32, a chelation enhanced fluorescence intensity (CHEF) as well as excimer emission band was observed which was 27 times stronger in acetonitrile and 2.7 times stronger in an acetonitrile/water (7:3) solvent system. Moreover, the detection limit in both solvent systems was $10^{-6} \mathrm{M}$ with a 1:1 stoichiometric of 32 to $\mathrm{Cu}^{2+}$ complex. 


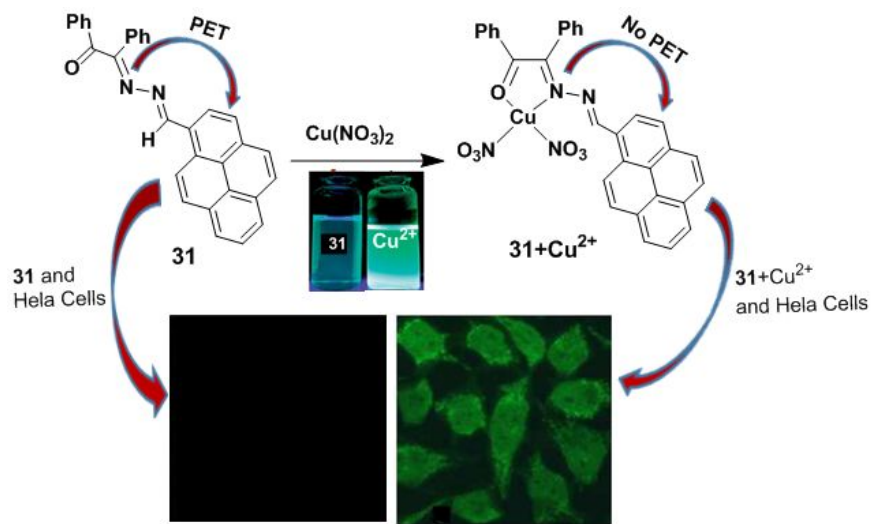

Fig. 27. Representation of possible sensing mechanism of probe $\mathbf{3 1}$. Fluorescence images of Hela cells; cells incubated with probe $\mathbf{3 1}$ only and cells incubated with $\mathbf{3 1}+\mathrm{Cu}^{2+}$. Reproduced from ref. 94 with permission from the Royal Society of Chemistry.

A new fluorescent chemosensor 33 incorporating 1-nitronyl nitroxide pyrene has been developed as an off-on sensor for the selective recognition of $\mathrm{Cu}^{2+} \cdot{ }^{96} \mathrm{As}$ a $\mathrm{Cu}^{2+}$ selective sensor, the fluorogenic behaviour of $\mathbf{3 3}(10 \mathrm{mM})$ was investigated in $\mathrm{CH}_{3} \mathrm{CN}$ in which a weak fluorescence signal at $378 \mathrm{~nm}$ for the free solution of 33 remarkably increased at $444 \mathrm{~nm}$ after addition of 10.0 equiv. of $\mathrm{Cu}^{2+}$. This phenomenon can be explained by the inhibition of PET from nitronyl nitroxide to the pyrene moiety. An ESR experiment confirmed the inhibition caused by the coordination between $\mathrm{Cu}^{2+}$ and nitronyl nitroxide of 33. On the other hand, the fluorescence intensity of $\mathbf{3 3}$ showed no significant changes with various other metal ions $\left(\mathrm{Li}^{+}, \mathrm{Na}^{+}, \mathrm{Ba}^{2+}, \mathrm{Fe}^{3+}, \mathrm{Fe}^{2+}, \mathrm{Mn}^{2+}, \mathrm{Mg}^{2+}, \mathrm{Ag}^{+}, \mathrm{Pb}^{2+}, \mathrm{Cd}^{2+}\right.$, $\left.\mathrm{Co}^{2+}, \mathrm{Ni}^{2+}, \mathrm{Zn}^{2+}, \mathrm{Hg}^{2+}\right)$. Moreover, the absorbances at $345 \mathrm{~nm}$ and $276 \mathrm{~nm}$ reduced sharply and increased at 402 and $295 \mathrm{~nm}$ and were accompanied with four well-defined isosbestic points, which indicated $33+\mathrm{Cu}^{2+}$ complexation; the colour changed from purple to bright yellow. In contrast, a reversible absorption response was observed at $345 \mathrm{~nm}$ by titration of 2,2'-bipyridine with the $33+\mathrm{Cu}^{2+}$ complex, which resulted in the recovery of the colour which is probably due to a stronger coordination between $\mathrm{Cu}^{2+}$ and 2,2'-bipyridine. Furthermore, the Job's plot calculated a 1:1 binding ratio between $\mathrm{Cu}^{2+}$ and 33 with a detection limit of $3.60 \times 10^{-7} \mathrm{M}$ in $\mathrm{CH}_{3} \mathrm{CN}$.

\subsection{Chemosensor based on PCT mechanism}

The calix[4] crown fluorescent chemosensor 34 bearing two facing pyreneamide groups has been designed based on the photoinduced charge transfer (PCT) mechanism. ${ }^{97}$ After addition of $\mathrm{Pb}^{2+}$ or $\mathrm{Cu}^{2+}$, probe 34 showed fluorescence quenching in both the excimer and monomer emissions owing to reverse PET and conformational changes. The $34 / \mathrm{Cu}^{2+}$ complex gave a significant red-shifted excitation spectrum in an acetonitrile solvent system at the excimer wavelength $470 \mathrm{~nm}$ in comparison with monomer wavelength 380 $\mathrm{nm}$, which suggests that the two-pyrene groups form the static excimer. Moreover, in both the fluorescence and absorption spectra, wavelength shifts of $\mathbf{3 4}$ are noted on binding of $\mathrm{Cu}^{2+}$ with the nitrogen atoms of the amide groups, resulting in a PCT mechanism.

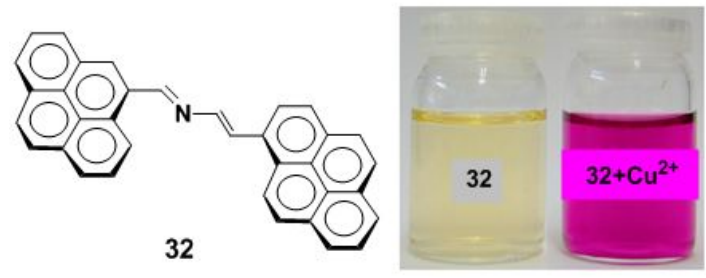

Fig. 28. Molecular structure of receptor 32. Visual changes in the colour of 32 (left) and after addition of $\mathrm{Cu}^{2+}$ ion (right). Reproduced from ref. 95 with permission from the Elsevier, copyright 2010.

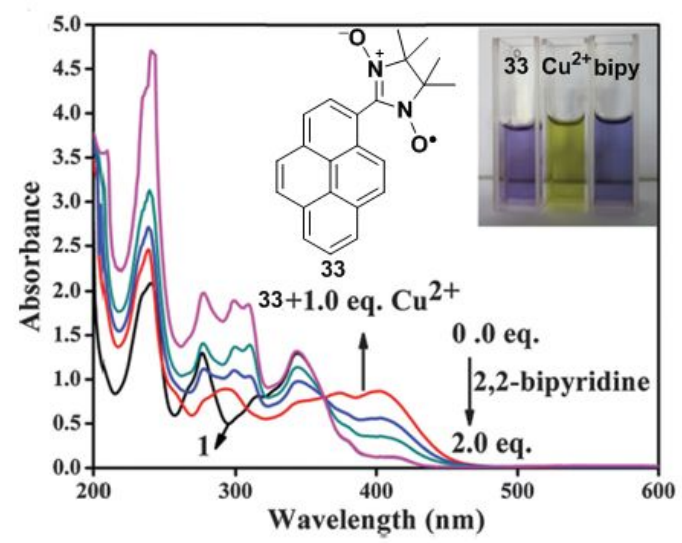

Fig. 29. The UV-vis absorption spectra of $33+\mathrm{Cu}^{2+}$ and upon addition of 2 , 2'-bipyridine in $\mathrm{CH}_{3} \mathrm{CN}$. Inset: visual changes of the colour of compound 33; compound $33+\mathrm{Cu}^{2+}$; compound $\mathbf{3 3}+\mathrm{Cu}^{2+}+2,2^{2}$-bipyridine (from left to right). Reproduced from ref. 96 with permission from the Centre National de la Recherche Scientifique (CNRS) and the Royal Society of Chemistry.

\subsection{Chemosensor based on ligand to metal charge transfer process (LMCT)}

The LMCT process occurs in a complex when electrons are transferred from a molecular orbital $\left(\sigma, \sigma^{*}, \pi, \pi^{*}\right.$ and non-bonding) of the ligand to the empty or partially filled metal d-orbitals. Therefore, a reduction of the metal occurs in LMCT transitions. In this case, this type of transfer predominantly occurs in case of ligands having relatively high energy lone pairs atoms (example $\mathrm{O}, \mathrm{S}$ or Se) or when the metal has low lying empty orbitals. The LMCT based fluorescent sensors depend on the selection of chromophore such as a pyrene unit, along with the nature and location of the receptor. The metal ion binding with a receptor will generally lead to a change in the absorption spectra or quenching of the fluorescence of the pyrene fluorophore. ${ }^{98}$

In 2017, $\mathrm{Lu}$ and co-workers developed chemosensor 35 by combining pyrene with a pyridine unit based on LMCT which exhibited high selectivity for $\mathrm{Cu}^{2+}$ and $\mathrm{Fe}^{3+}$ over other ions. ${ }^{99}$ Sensor 35 exhibited stable absorption or fluorescence intensity over a wide range of $\mathrm{pH}$ from 3 to 12 . Addition of $\mathrm{Cu}^{2+}$ to ligand 35 partially quenched the emission of the fluorophore through electron and/or energy transfer processes due to its paramagnetic nature with an unfilled $\mathrm{d}$ shell. DFT calculations of $35+\mathrm{Cu}^{2+}$ also fully confirmed 
the LUMO was distributed more over the $\mathrm{C}=\mathrm{N}$ bond and receptor rather than the pyrene unit after binding with $\mathrm{Cu}^{2+}$, than that of the free compound 35. The UV-vis absorption spectra of 35 in DMF-HEPES buffer $(2: 8, \mathrm{v} / \mathrm{v}, \mathrm{pH}=7.4)$ showed a red shift $(21 \mathrm{~nm})$ from $352 \mathrm{~nm}$ to $373 \mathrm{~nm}$ after addition of 40 equiv. of $\mathrm{Cu}^{2+}$ with an optical colour change from colourless to pink. The limit of detection toward $\mathrm{Cu}^{2+}$ was $8.5 \mu \mathrm{M}$. The Job's plot experiment revealed a 1:1 binding stoichiometry for $\mathbf{3 5}$ and $\mathrm{Cu}^{2+}$.
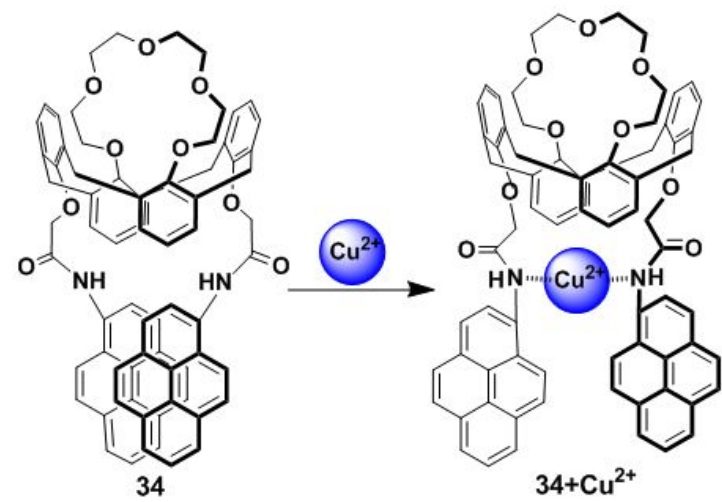

Fig. 30. Schematic representation of proposed sensing mechanism for probe 34 in presence of $\mathrm{Cu}^{2+}$. Reproduced from ref. 97 with permission from the American Chemical Society, copyright 2006.

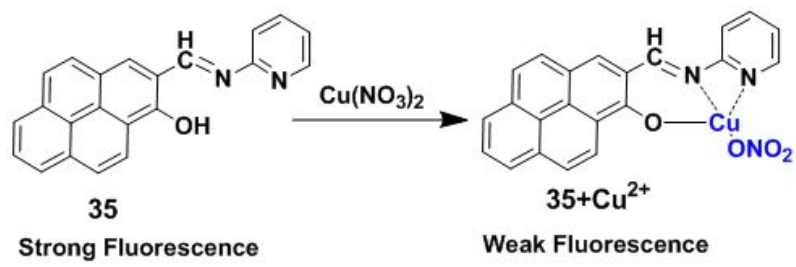

Fig. 31. The possible binding modes of $\mathbf{3 5}$ with $\mathrm{Cu}^{2+}$. Reproduced from ref. 99 with permission from the Elsevier, copyright 2017.

Another example of the LMCT mechanism was shown in the pyrene-based turn-off chemosensor 36 that was synthesized from the condensation reaction of 1-aminopyrene and 2,4-dihydroxy benzaldehyde. ${ }^{100}$ Sensor 36 exhibited high selectivity for recognizing $\mathrm{Cu}^{2+}$ ion in the presence of other metal ions. The UV-Vis absorption spectroscopy of $\mathbf{3 6}$ with $\mathrm{Cu}^{2+}$ exhibited a hypsochromic shift for the absorption peaks at $368 \mathrm{~nm}$ and $340 \mathrm{~nm}$ with the formation of two isosbestic points in $\mathrm{MeCN} / \mathrm{H}_{2} \mathrm{O}(9: 1, \mathrm{v} / \mathrm{v})$. Meanwhile, in aqueous medium, the solution colour of $\mathbf{3 6}$ changed from yellow to brown even at lower concentrations of $\mathrm{Cu}^{2+}$, and this was also directly observed by the naked eye. Moreover, the emission peak at $429 \mathrm{~nm}$ of $36(20 \mu \mathrm{M})$ was gradually quenched after treatment with $\mathrm{Cu}^{2+}$ in which the quenching efficiency was $93 \%$. This phenomenon is due to the ligand to metal charge transfer (LMCT) characteristics resulting in the quenching of the fluorescence chemosensor 36 with $\mathrm{Cu}^{2+}$. The time-resolved fluorescence spectroscopy also confirmed the static quenching mechanism for $\mathbf{3 6}+\mathrm{Cu}^{2+}$. A Job's plot experiment and ESI-mass spectroscopic analysis revealed a 2:2 stoichiometry for binding of $\mathbf{3 6}$ with $\mathrm{Cu}^{2+}$. The lower limit of detection of $\mathrm{Cu}^{2+}$ by $\mathbf{3 6}$ is $0.503 \mu \mathrm{M}$. The sensor $36+\mathrm{Cu}^{2+}$ underwent a reversibility test in the presence of histidine and regained its original colour. Therefore, the sensor 36 can be utilized in real samples to investigate trace amounts of copper.

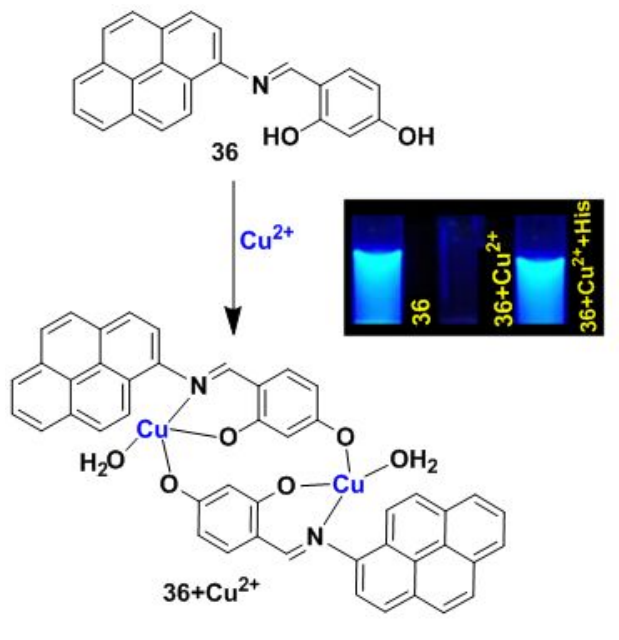

Fig. 32. Schematic representation of possible sensing mechanism of probe $\mathbf{3 6}$ with $\mathrm{Cu}^{2+}$. Reproduced from ref. 100 with permission from the John Wiley and Sons, copyright 2018.

\subsection{Chemosensor based on Intra ligand charge transfer transition (ILCT)}

A ligand sometimes has a donor and an acceptor site simultaneously. The intra ligand charge transfer transition ILCT takes place within the ligands mediated by a metal. In most instances, these complexes exhibit long-lived excited states with low-energy absorptions. Generally, this kind of chemosensor is fluorescent in the presence of a metal ion. ${ }^{101}$

Using the above technique, Mukherjee et al. reported a new simple, reversible, turn-on luminescent chemosensor, namely the hydrazone based pyrene derivative 37 for the detection of $\mathrm{Cu}^{2+} .^{102}$ The binding of the receptor 37 with $\mathrm{Cu}^{2+}$ was studied in $\mathrm{DMSO} / \mathrm{H}_{2} \mathrm{O}$ (2:1) medium, and the generation of new peaks at $512 \mathrm{~nm}$ (broad) and $345 \mathrm{~nm}$ through isosbestic points was evident with a colour change from yellow to reddish brown. The emission intensity of $\mathbf{3 7}$ was enhanced at $495 \mathrm{~nm}$ up to 44-fold upon addition of $\mathrm{Cu}^{2+}$ in DMSO solvent due to intra ligand charge transfer transition (ILCT). The other metal ions $\left(\mathrm{Hg}^{2+}, \mathrm{Pb}^{2+}, \mathrm{Cd}^{2+}, \mathrm{Ni}^{2+}, \mathrm{Co}^{2+}, \mathrm{Fe}^{2+}, \mathrm{Fe}^{3+}, \mathrm{Mn}^{2+}\right.$, $\mathrm{Zn}^{2+}, \mathrm{Al}^{3+}$ and $\mathrm{Cr}^{3+}$ ) causes no significant change in the emission intensity of 37. The limit of detection (LOD) was found to be of the order of $10^{-8} \mathrm{M}$. DFT experiments revealed that the electron spin density was focused only in the pyrene moiety for all the frontier molecular orbitals which also supports the ILCT process. The compound 37 can extract $\mathrm{Cu}^{2+}$ with $94 \%$ extraction efficiency over the $\mathrm{pH}$ range 6.5-11 from an aqueous mixture of metal ions or from real samples by a selective two-phase liquid-liquid extraction using a water-dichloromethane mixture (1:1). During extraction, the $37+\mathrm{Cu}^{2+}$ complex was found to have a 2:1 ratio of ligand and $\mathrm{Cu}^{2+}$. Good recyclability and reusability were observed for chemosensor $\mathbf{3 7}$ as the fluorescence emission reversed to its original condition in the presence of $\mathrm{C}_{2} \mathrm{O}_{4}{ }^{2-}$ and the $37+\mathrm{Cu}^{2+}$ complex, and this characteristic 
was used to "INHIBIT" the logic gate application. As an analysis tool, a smartphone can also be used for detecting colour change of $\mathbf{3 7}$ during $\mathrm{Cu}^{2+}$ extraction.

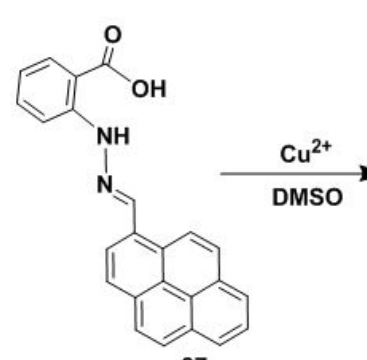

37 Weak fluorescence

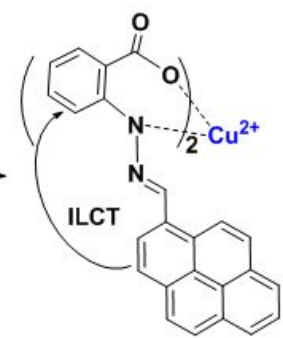

Strong fluorescence
Fig. 33. The sensing mechanism of $\mathbf{3 7}$ with $\mathrm{Cu}^{2+}$. Reproduced from ref. 102 with permission from the Elsevier, copyright 2018.

\subsection{Chemosensor based on aggregation induced emission (AIE)}

In an AIE luminogen, the intramolecular rotations of aromatic compounds are active in dilute solutions, which serve as a relaxation channel for its excitons resulting in non-radiative decay. However, in the aggregate state, the intramolecular rotations are suppressed because of the physical constraints, which opens the radiative pathway to emit efficiently. In the crystalline state, multiple $\mathrm{C}-\mathrm{H}-\pi$ hydrogen bonds are formed between the hydrogen atoms of the aromatic rings of one ligand and the $\pi$ electrons of the aromatic rings of another ligand. These hydrogen bonds stiffen the conformations of the ligand and enhance their light emission. ${ }^{103}$

For these special characteristics of light emission, Wang and co-workers have used AIE or an AEE luminogen to develop chemosensors of type $\mathbf{3 8}$ for $\mathrm{Cu}^{2+}$ ion detection. ${ }^{104}$ In this case, pyrene acted as the strong fluorophore and was combined with Schiff bases which were responsible for the AIE properties in semi-aqueous solution toward $\mathrm{Cu}^{2+}$. The AEE behaviour of 38 (10 $\mu \mathrm{M})$ was explained by measurement of the fluorescence spectra in different volumes of water in mixed $\mathrm{H}_{2} \mathrm{O} / \mathrm{DMF}$ (from $0 \%$ to $100 \%$,) solution. The experiment suggests that with increasing percentage of water the peak continually showed a red shift because of amide-amidic acid tautomerization with water in the aggregation state of 38. Time-resolved fluorescence measurements supported the above observations. Sensor $\mathbf{3 8}$ became strongly emissive at $455 \mathrm{~nm}$ in the presence of $\mathrm{Cu}^{2+}$ (5 eq.) with a quantum yield $\Phi$ from 0.09 to 0.58 in $\mathrm{H}_{2} \mathrm{O} / \mathrm{DMF}(1: 1, \mathrm{v} / \mathrm{v})$. The $\mathrm{UV}-\mathrm{vis}$ absorption spectroscopy also established that self-assembly of $38(10 \mu \mathrm{M})$ prompted by $\mathrm{Cu}^{2+}$ involves a coordination interaction and changes in the aggregation form. A Job's plot experiment evaluated from the fluorescence spectra confirmed that the binding of $\mathbf{3 8}$ to $\mathrm{Cu}^{2+}$ followed a 2:1 stoichiometry.

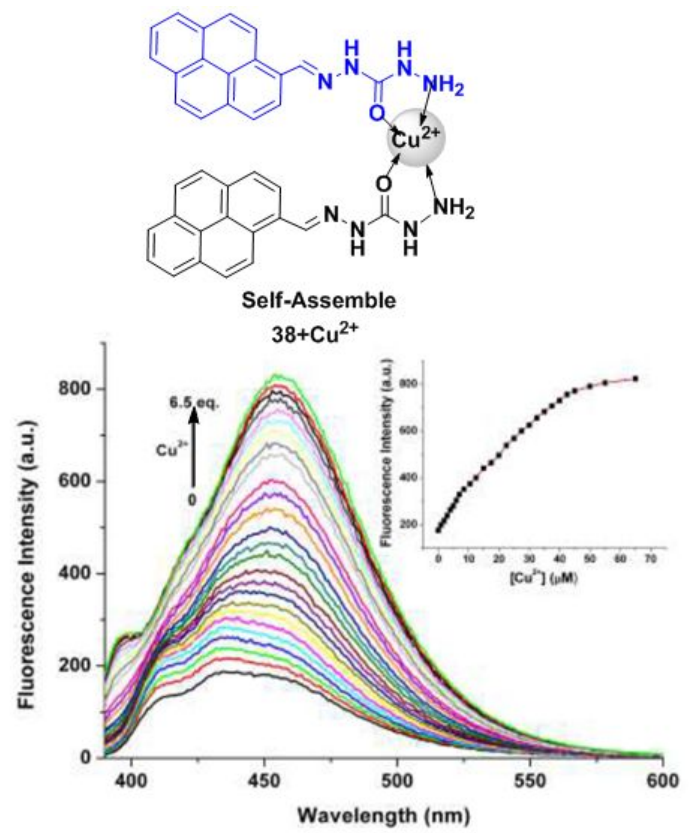

Another example of aggregate formation was observed in a pyrene-based hydrophobic hydrocarbon framework in a binary water-solvent system. ${ }^{105}$ Das et al. have reported a chemosensor 39 in which the pyrene part acts as a fluorescence reporter and the antipyrene part containing the pyrazolone unit plays the role of a chelating moiety. Sensor 39 exhibited very weak fluorescence due to a photoinduced electron transfer mechanism (PET) between $\mathrm{N}$ donors in the imine bond and the pyrene ring. Upon interaction with $\mathrm{Cu}^{2+}$, a fluorescence enhancement of $\mathbf{3 9}$ was observed at $454.5 \mathrm{~nm}$ along with $440 \mathrm{~nm}$ and $509 \mathrm{~nm}$, which indicated complex formation due to prevention of the PET process by an $\mathrm{N}$ donor site in acetonitrile solvent. Time fluorescence titration revealed the maximum fluorescence enhancement of $\mathbf{3 9}$ was observed at $432 \mathrm{~nm}$ (blue shift) up to the addition of $150 \mu \mathrm{M}$ of $\mathrm{Cu}^{2+}$ ion. However, with an increasing percentage of water in the acetonitrile solvent system, the fluorescence emission intensity of $\mathbf{3 9}$ gradually increased at $454.5 \mathrm{~nm}$ with a red shift with poor intensity in pure acetonitrile. At $80 \%$ of water fraction, there was 230 times increase in the emission intensity with a red shift of $16 \mathrm{~nm}$. This was because of the aggregation induced emission (AIE) characteristics of probe 39. The critical aggregate concentration of ligand 39 in this solvent system 
was calculated to be $23.4 \mu \mathrm{M}$. Moreover, the antioxidant nature of the compound 39 was confirmed from UV studies.

Fig. 34. The AIE luminescence mechanism of $\mathbf{3 8}$ and $\mathrm{Cu}^{2+}$. The fluorescence spectra with $\mathrm{Cu}^{2+}$ ions. Inset: Emission intensity at $455 \mathrm{~nm}$ with $\mathrm{Cu}^{2+}$ concentration. Reproduced from ref. 104 with permission from the Elsevier, copyright 2018 .

\section{$5.7 \mathrm{Cu}^{2+}$-promoted reaction based chemosensors}

The development of chemodosimeters that operate on the basis of analyte selective chemical reactions has attracted great attention in the last few years. Among them, $\mathrm{Cu}^{2+}$-selective reaction-based probes show significant fluorescence emission enhancement with high selectivity. In this case, $\mathrm{Cu}^{2+}$-assisted hydrolysis, oxidation, reduction and spirolactam ring-opening methods have been used for building $\mathrm{Cu}^{2+}$-selective reaction-based probes. Generally, fluorescent sensors of this type lead to non-emissive precursors to fluorescent products through irreversible chemical reactions. It is noticeable that $\mathrm{Cu}^{2+}$ induced-catalytic reactions to develop fluorescent sensors are the easiest way to avoid the consideration of the paramagnetic nature of $\mathrm{Cu}^{2+}$ as fluorescent products have a slight attraction to $\mathrm{Cu}^{2+} \cdot{ }^{106}$

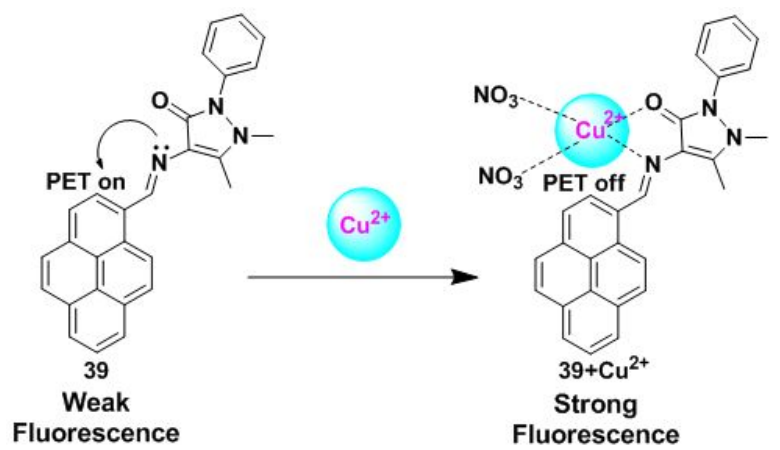

Fig. 35. Schematic representation of $\mathrm{Cu}^{2+}$ sensing by ligand 39. Reproduced from ref. 105 with permission from the Elsevier, copyright 2018.

Using this concept, Chang et al. have reported a chemosensor $\mathbf{4 0}$ in which the pyrene moiety acts as a fluorophore and a fluorescence-quenching hydrazide moiety plays the role of a signaling handle. ${ }^{107}$ The pyrenecarbohydrazide probe $\mathbf{4 0}$ displayed high selectivity towards $\mathrm{Cu}^{2+}$ ions via $\mathrm{Cu}^{2+}$-induced catalytic hydrolysis to pyrenecarboxylic acid and hydrazine. ${ }^{1} \mathrm{H}$ NMR spectroscopy and mass spectrometry also confirmed the hydrolysis of probe 40. It exhibited very weak fluorescence due to PET which was remarkably enhanced (130-fold) at $392 \mathrm{~nm}$ upon addition of $\mathrm{Cu}^{2+}$ in $10 \%$ aqueous DMSO solution (tris-buffered at $\mathrm{pH} 7.0$ ). Moreover, the $\mathrm{Cu}^{2+}$ selective fluorescence signaling behaviour of $\mathbf{4 0}$ was less prominent as the space between the hydrazide functionality and the pyrene fluorophore increased. Probe $\mathbf{4 0}$ has wide application in environmentally related samples, especially for semiconductor waste water sample over a wide $\mathrm{pH}$ range. The detection limit of $\mathbf{4 0}$ for $\mathrm{Cu}^{2+}$ was $5.93 \times 10^{-8} \mathrm{M}$ and $6.93 \times 10^{-8} \mathrm{M}(0.005 \mathrm{ppm})$ in the waste water sample.

Rhodamine derivatives as chemosensors for $\mathrm{Cu}^{2+}$ detection were first utilized by Czarnik in 1997. Even now, they are used for the detection of cations and anions given their excellent photophysical properties and the ring opening process. In general, the carbonyl group in the rhodamine spirolactam form gets activated by complexation with specific metal ions using certain solvent systems and $\mathrm{pH}^{108} \mathrm{Kim}$ et al. introduced a novel fluorescent sensor, a rhodamine based derivative bearing a 1,8-naphthalimide group which performed as a dual-mode sensor for $\mathrm{Cu}^{2+}$ by using two mechanisms, one is the rhodamine ring-opening mechanism and the other, a ratiometric displacement from $\mathrm{Zn}^{2+}$ complexation with the ligand in $\mathrm{CH}_{3} \mathrm{CN}$-HEPES buffer solution. ${ }^{109}$

In 2009, Yoon et al. reported a rhodamine fluorophore combined with the pyrene moiety, which was utilized as a ratiometric and "off-on" fluorescent sensor $\mathbf{4 1}$ for the selective recognition of $\mathrm{Cu}^{2+} \cdot{ }^{110}$ Herein, the spirolactam structure (non-fluorescent) of the rhodamine derivative sensor $\mathbf{4 1}$ was converted into a ring-opened amide form by complexation with $\mathrm{Cu}^{2+}$ and this gave rise to strong fluorescence emission and colour changes from primrose yellow to pink. From the fluorescence spectra, clear ratiometric changes of ligand $41(20 \mu \mathrm{M})$ were obtained upon treatment with $\mathrm{Cu}^{2+}$ in $\mathrm{CH}_{3} \mathrm{CN}$-HEPES buffer solution. A significant decrease of the fluorescence intensity of $424 \mathrm{~nm}$ and a new emission band at 575 $\mathrm{nm}$, with a clear isoemission point was attributed to the $\mathrm{Cu}^{2+}$ induced ring opening process of $\mathbf{4 1}$. The absorption spectra of $\mathbf{4 1}$ showed prominent changes which were reversible by reversible titration using EDTA $/ \mathrm{Cu}^{2+}$. The $\mathbf{4 1}+\mathrm{Cu}^{2+}$ complex followed a 1:1 stoichiometric ratio which was calculated from the absorption spectra data of Job's plots and the nonlinear fitting of the titration curve.

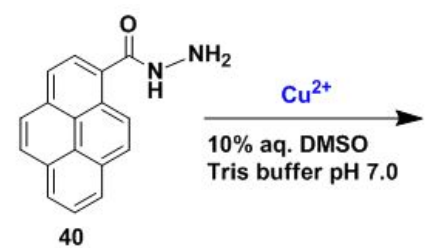

Fluorescence off

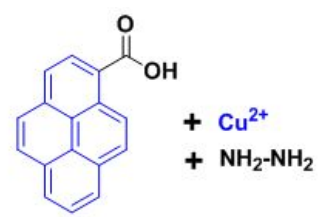

Fluorescence on
Fig. 36. The sensing mechanism of compound $\mathbf{4 0}$ with $\mathrm{Cu}^{2+}$ by catalytic hydrolysis process. Reproduced from ref. 107 with permission from the Elsevier, copyright 2017.
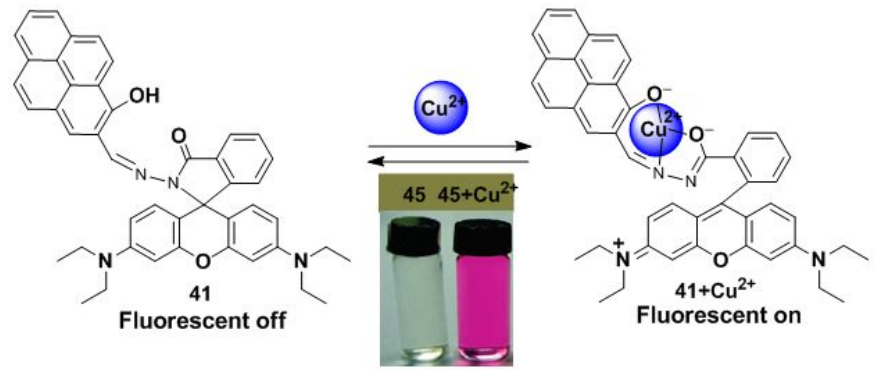

Fig. 37. Proposed binding mechanism for 41 with $\mathrm{Cu}^{2+}$ and a photo of 41 (20 $\mu \mathrm{M})$ as a selective naked-eye chemosensor for $\mathrm{Cu}^{2+}$. Reproduced from ref. 110 with permission from the American Chemical Society, copyright 2009.

\subsection{Chemosensor based on paramagnetic nature and heavy atom effect of $\mathrm{Cu}^{2+}$}

The intrinsic properties of heavy and transition metal cations usually quench the emission of organic lumniophores. The emission 
behaviour of the metal-complexes is directly related to the periodic table and the electronic configuration of the metal ions. For example, the paramagnetic $\mathrm{Cu}^{2+}$ ions have one electron in its $\mathrm{dx}^{2}-\mathrm{dy}^{2}$ orbital which is responsible for fluorescence quenching through an electron or energy transfer process. As the energy of this orbital places between the HOMO and LUMO of the excited fluorophore, so a non-radiative decay of the excited fluorophore can easily occur. ${ }^{19}$, 106b, 111 The free electron of $\mathrm{Cu}^{2+}$ also has the tendency to quench the fluorescence via spin- orbit coupling that can be explained by heavy atom effect. The 'heavier' ions binding with the receptor increases the spin-orbit coupling, and hence leads to reduced fluorescence quantum yields and lifetimes. ${ }^{19,37 b}$

Periasamy et al. have described the fluorescent chemosensor $\mathbf{4 2}$ bearing a pyrene and benzothiozole hydrazide, which shows considerably high fluorescence in the unbound state. ${ }^{12}$ Upon complexation with the paramagnetic $\mathrm{Cu}^{2+}$ ions, quenching interactions probably dominate the emission characteristics of these complexes. The probe $\mathbf{4 2}$ displays high sensitivity and selectivity in DMSO- $\mathrm{H}_{2} \mathrm{O}(8: 2 \mathrm{v} / \mathrm{v})$ for $\mathrm{Cu}^{2+}$ due to chelation with 42 . The ligand $42+\mathrm{Cu}^{2+}$ ensemble shows high sensitivity towards $\mathrm{S}^{2-}$ ions. The UV-vis titration of $\mathbf{4 2}$ showed that the absorption bands at 395 and $410 \mathrm{~nm}$ gradually reduced and the band at $455 \mathrm{~nm}$ increased upon addition of $\mathrm{Cu}^{2+}(0-100 \mu \mathrm{M})$. The association constant $\left(K_{\mathrm{a}}\right)$ of $\mathbf{4 2}$ with $\mathrm{Cu}^{2+}$ ions was found to be $2.3 \times 10^{5} \mathrm{M}^{-1}$. The change in the appearance of solution $\mathbf{4 2}$ from the yellow to brown colour was observed after the addition of $\mathrm{Cu}^{2+}$ ions $(100 \mu \mathrm{M})$ which can be seen by the naked eye. Moreover, the addition of $\mathrm{Cu}^{2+}$ to the solution of 42 gradually quenched the fluorescence emission intensity at $510 \mathrm{~nm}$ which was explained by the paramagnetic nature and the chelation-enhanced fluorescence quenching (CHEQ) effect of the $\mathrm{Cu}^{2+}$ ions. The ligand $\mathbf{4 2}$ was cell-permeable, and was efficiently utilized for the recognition of copper ions in live cells and in real water samples.

Similarly, quenching is promoted by paramagnetic $\mathrm{Cu}^{2+}$ ions for its heavy atom effect in a pyrene-based dipicolylamine derivative sensor 43. ${ }^{113}$ The compound $\mathbf{4 3}$ selectively recognized $\mathrm{Cu}^{2+}$ and $\mathrm{Fe}^{3+}$ over the other metal cations $\mathrm{Ni}^{2+}, \mathrm{Mg}^{2+}, \mathrm{Cd}^{2+}, \mathrm{Hg}^{2+}, \mathrm{Na}^{+}, \mathrm{K}^{+}, \mathrm{Ca}^{2+}$, $\mathrm{Co}^{2+}, \mathrm{Cr}^{3+}, \mathrm{Pb}^{2+}$ and $\mathrm{Zn}^{2+}$. Upon treatment of $\mathrm{Cu}^{2+}$ ions, sensor $\mathbf{4 3}$ exhibited well-defined absorption bands in $\mathrm{MeOH}$ solution in which a newly appeared band at $660 \mathrm{~nm}$ with red shifted peaks at 290, 333 and $358 \mathrm{~nm}$ were observed owing to the $\mathrm{d}-\mathrm{d}$ transition of $\mathrm{Cu}(\mathrm{II})$. This phenomenon was distinguished by naked eye detection. From the results of UV-vis experiments, the stoichiometry of the Job's plot was found to be $1: 1$ with the binding constant $1.48 \times 10^{5} \mathrm{M}^{-1}$ for the $43+\mathrm{Cu}^{2+}$ system. Moreover, ${ }^{1} \mathrm{H}$ NMR spectroscopic titration experiments in $\mathrm{CD}_{3} \mathrm{OD}$ revealed that the seventeen aromatic protons of free receptor $\mathbf{4 3}$ in the $7.00-8.85 \mathrm{ppm}$ region disappeared in the presence of $\mathrm{Cu}^{2+}$ ions due to the paramagnetic effect of the $\mathrm{Cu}^{2+}\left(\mathrm{d}^{9}\right.$ system). The fluorescence spectrum of chemosensor $\mathbf{4 3}$ in methanol solution showed an emission band at $392 \mathrm{~nm}(\Phi \sim 0.31)$ which was quenched significantly $(\Phi \sim 0.05)$. This behaviour was observed because of the efficient non-radiative deactivation by $\mathrm{Cu}^{2+}$, which resulted in the enhanced spin-orbit coupling associated with the heavy atom effect of the complexed $\mathrm{Cu}^{2+}$.

Pandey et al. investigated the difference in the photophysical properties of probes $\mathbf{4 4}$, where coumarin-pyrene conjugates form with the non-conjugated form of probe $\mathbf{4 5}$ for the selective detection of $\mathrm{Cu}^{2+}{ }^{214}$ Herein, it was observed that the paramagnetic nature of the $\mathrm{Cu}^{2+}$ ions have a great influence on the conjugated system of $\mathbf{4 4}$ rather than $\mathbf{4 5}$. The probe $\mathbf{4 4}$ has a conjugated system exhibiting $\mathrm{C}-\mathrm{H}-\pi, \pi-\pi$ interactions, and H-bonding interactions. Successive addition of $\mathrm{Cu}^{2+}$ ions $(1 \mu \mathrm{M}-10 \mu \mathrm{M})$ results in the gradual quenching of fluorescence at $430 \mathrm{~nm}$ indicating the high sensitivity of probe $\mathbf{4 4}$ towards $\mathrm{Cu}^{2+}$ ions. The phenomenon behind the quenching of fluorescence can be attributed to the combined effect of donation of $\pi$-electron from the fluorophore fragment to the adjacent metal ion and is due to the paramagnetic nature of the $\mathrm{Cu}^{2+}$ ions. The binding constant of $\mathbf{4 4}$ with $\mathrm{Cu}^{2+}$ was calculated to be $2.4 \times 10^{4} \mathrm{M}^{-1}$. Besides, sensor $\mathbf{4 5}$ showed no prominent change due to its non-conjugated form. Moreover, sensor $\mathbf{4 4}$ can be effectively applied in medical sciences for the detection of $\mathrm{Cu}^{2+}$ levels in kidney cell lines by using its ability for quenching fluorescence.

Yamato and co-workers have ascribed the reverse PET mechanism for the detection of paramagnetic $\mathrm{Cu}^{2+}$ ions by the heteroditopic receptor 46. ${ }^{115} \mathrm{As}^{\mathrm{Cu}^{2+}}$ has an unfilled d shell, it probably quenches the emission of the fluorophore via electron transfer. ${ }^{116}$ The receptor $\mathbf{4 6}$ has a thiacalix[4]arene moiety with two different side arms in which two pyrene-appended triazole rings are incorporated at one side of the thiacalix[4] arene cavity and the other side contains two urea moieties with various phenyl groups. Herein, an effective positive allosteric effect of $\mathbf{4 6}$ was also observed for $\mathrm{Ag}^{+}$ with $\mathrm{Cl}^{-}$. Besides, the UV-vis absorption, fluorescence spectra and ${ }^{1} \mathrm{H}$ NMR spectroscopic titration experiments of $\mathbf{4 6}$ showed changes in the presence of transition metal cations $\left(\mathrm{Ag}+, \mathrm{Cu}^{2+}\right.$ and $\left.\mathrm{Hg}^{2+}\right)$ and anions in the $\mathrm{CH}_{2} \mathrm{Cl}_{2}$-DMSO solvent system. The interaction of ligand 46 with $\mathrm{Ag}^{+}$ion increased the monomer emission at $393 \mathrm{~nm}$ and decreased the excimer emission at $486 \mathrm{~nm}$ with a 1:1 binding stoichiometry. Furthermore, upon addition of $\mathrm{Cu}^{2+}$, monomer and excimer emissions of free $\mathbf{4 6}$ were significantly quenched. This was because the binding with the pyrene-appended triazole groups caused a reverse PET from the pyrene moieties to the triazole groups. The association constant for the complexation of $46+\mathrm{Cu}^{2+}$ was found to be $330,000 \pm 23,100 \mathrm{M}^{-1}$.
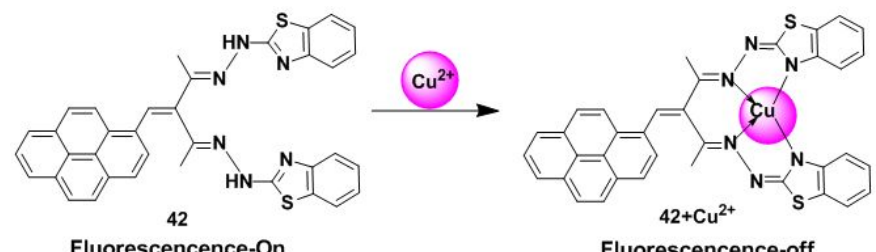

Fig. 38. Proposed sensing mechanism of probe $\mathbf{4 2}$ for $\mathrm{Cu}^{2+}$. Reproduced from ref. 112 with permission from the John Wiley and Sons, copyright 2020. 


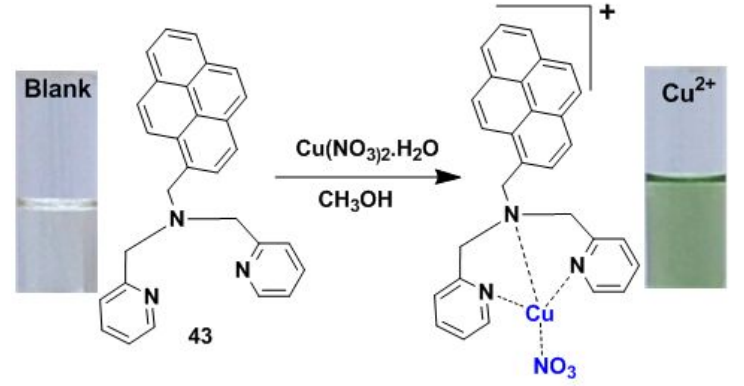

Fig. 39. Possible binding interaction and colorimetric change of ligand $\mathbf{4 3}$ with $\mathrm{Cu}^{2+}$. Reproduced from ref. 113 with permission from the Elsevier, copyright 2017.

\subsection{Miscellaneous}

As discussed in the preceding part of this review, chemosensors operating using different well-known mechanisms have been reported. However, there are still other types of chemosensors which do not belong to the above classified mechanisms or they fall into the category of following several mechanisms for $\mathrm{Cu}^{2+}$ detection. Herein, we will try to briefly discuss these sensors.

Two new fluorescent sensors $\mathbf{4 7 , 4 8}$ based on thiacalix[4]arenes bearing two pyrene groups were developed by Kumar and co-workers for the recognition of $\mathrm{Cu}^{2+}$ and $\mathrm{CN}^{-}$ions. ${ }^{117}$ The authors reported that the former receptor $\mathbf{4 7}$ undergoes a reverse PET process, whereas the later $\mathbf{4 8}$ follows the monomer and excimer emission mechanism with a ratiometric response for $\mathrm{Cu}^{2+}$ detection in $\mathrm{CH}_{2} \mathrm{Cl}_{2} / \mathrm{CH}_{3} \mathrm{CN}(1: 1, \mathrm{v} / \mathrm{v})$. Moreover, the UV-vis absorption spectra of both receptors upon interaction with $\mathrm{Cu}^{2+}$ showed a decrease of the blue shift band and the formation of a new red shift band. This is because of the collaboration between the $\mathrm{Cu}^{2+}$ ion with the nitrogen atoms of the amide groups which reduces the electron donating ability of the $\mathrm{N}$ atom and induces the red shift absorption spectra due to photoinduced charge transfer mechanism. The strong blue fluorescence of compound $\mathbf{4 7}$ indicates the typical monomer emission of pyrene at $377 \mathrm{~nm}$ which confirms there is no $\pi-\pi$ interaction between two pyrene units. Upon addition of $\mathrm{Cu}^{2+}$ ions $(6.0-600 \mu \mathrm{M})$ to the solution of $47(6.0 \mu \mathrm{M})$, the fluorescence emission intensity was significantly decreased due to reverse PET from the pyrene units to the nitrogen atom. The association constant $K_{\text {a }}$ of 47 with $\mathrm{Cu}^{2+}$ was calculated to be $8.55 \times 10^{5} \mathrm{M}^{-1}$. On the other hand, the fluorescence properties of compound 48 were completely different compared with compound $\mathbf{4 7}$. The compound 48 showed weak monomer emission at $375 \mathrm{~nm}$ and strong intramolecular excimer emission at $467 \mathrm{~nm}$. Upon treatment with $60 \mathrm{mM}$ (10 equiv.) of $\mathrm{Cu}^{2+}$ ions, the titration profile of $\mathbf{4 8}$ exhibited a ratiometric response with monomer enhancement and excimer emission quenching. The relative intensity ratio of monomer to excimer emission $\left(\mathrm{I}_{\mathrm{M}} / \mathrm{I}_{\mathrm{E}}\right)$ of free ligand 48 was 0.47 and it increased by 11.7-fold to 5.52 on addition of $\mathrm{Cu}^{2+}$ ion. A selectivity test of 47 and 48 was carried out in the presence of various metal ions with $\mathrm{Cu}^{2+}$ which revealed $47+\mathrm{Cu}^{2+}$ and $48+\mathrm{Cu}^{2+}$ complexes to be selective chemosensors. This observation was in agreement with the 1:1 and 1:2 (H/G) binding model for $47+\mathrm{Cu}^{2+}$ and $48+\mathrm{Cu}^{2+}$ complexes respectively, which was also confirmed by the method of continuous variation (Job's plot).
A pyrene containing Schiff base colorimetric sensor 49 was synthesized via a simple one-pot reaction. ${ }^{118}$ The probe $\mathbf{4 9}$ displayed high sensitivity and selectivity towards $\mathrm{Cu}^{2+}$ and the sensitivity was not interfered with by the presence of other relevant metal ions. In the solvent mixture DMSO $/ \mathrm{H}_{2} \mathrm{O}(\mathrm{v} / \mathrm{v}=8 / 2$, buffered with HEPES, $\mathrm{pH}=7.4$ ), the absorption peaks of probe 49 at 355 and $452 \mathrm{~nm}$ were slowly decreased on gradual addition of $\mathrm{Cu}^{2+}$ and the peaks were blue-shifted to 326 and $410 \mathrm{~nm}$ with two isosbestic points at 349 and $414 \mathrm{~nm}$, respectively with changes of colour from yellow to pale lemon. This phenomenon is due to the formation of the $\mathrm{Cu}^{2+-}$ assisted 49- $\mathrm{Cu}^{2+}$-DMSO complex. The absorption spectrum on changing the $\mathrm{Cu}^{2+}$ concentration indicated a 1:1 stoichiometry between the host 49 and the $\mathrm{Cu}^{2+}$ ions. ${ }^{1} \mathrm{H}$ NMR spectroscopic titration experiments of 49 also found that the proton signal of the $\mathrm{OH}$ became broad and slightly shifted downfield with increasing $\mathrm{Cu}^{2+}$ concentration. The detection limit of $\mathbf{4 9}$ for $\mathrm{Cu}^{2+}$ ions was calculated to be $(2.17 \pm 0.02)$ $\times 10^{-6} \mathrm{M}$.

In 2010, Yen and coworkers synthesized a novel colorimetric and fluorometric receptor $\mathbf{5 0}$ containing a pyrene unit and a 4-methylphenylthiourea moiety for selectively sensing $\mathrm{Cu}^{2+}$ and $\mathrm{Hg}^{2+}$ (Fig. 44). ${ }^{119}$ The coordination with $\mathrm{Cu}^{2+}$ and $\mathrm{Hg}^{2+}$ ions show colour and fluorescence changes of $\mathbf{5 0}$ in aqueous solution $\left(\mathrm{DMSO} / \mathrm{H}_{2} \mathrm{O}=\right.$ 4/1, buffered with HEPES, $\mathrm{pH}$ 7.8) which allowed them to be distinguished from other metal ions. Moreover, the designed sensor 50 can recognize $\mathrm{Cu}^{2+}$ through binding with the thiourea group. For this reason, the typical pyrene absorption bands of $\mathbf{5 0}$ in the region of 235-350 nm gradually increased at 278, $334 \mathrm{~nm}$ with a shoulder peak
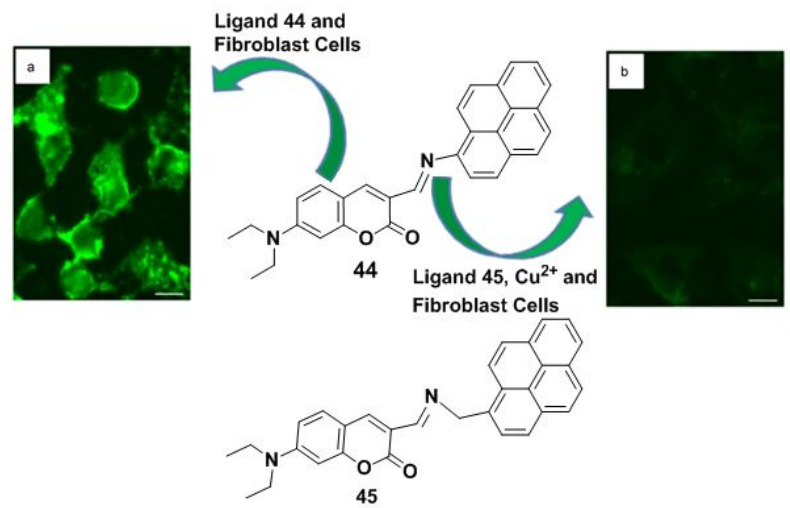

Fig. 40. Structure of chemosensors 44 and 45 . (a) Fluorescence images of 44 in a kidney cell line: cos-7 cells treated with $44(5 \mathrm{mM}, 20 \mathrm{~min})$; (b) Loss of fluorescence after addition of $\mathrm{CuCl}_{2}(10 \mathrm{mM}, 30 \mathrm{~min})$. Reproduced from ref. 114 with permission from the Elsevier, copyright 2016. 

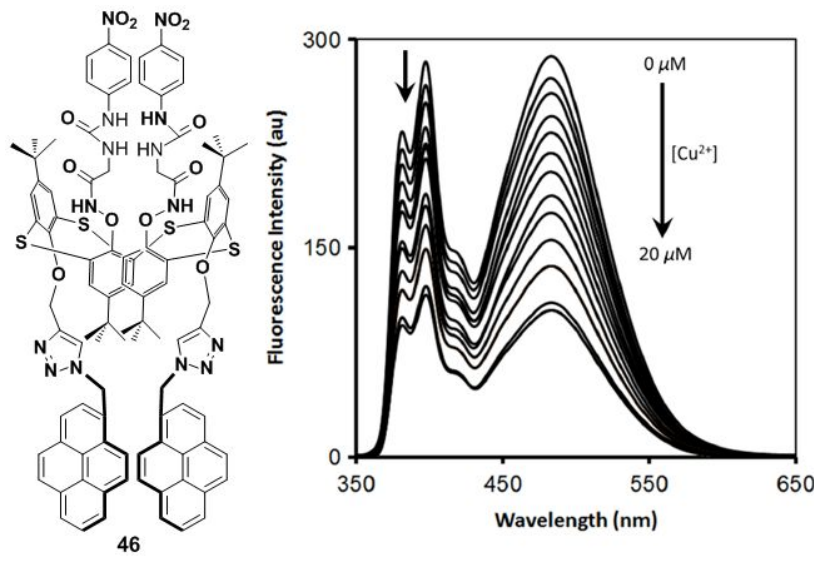

Fig. 41. The molecular structure of fluorescence chemosensor 46, showing fluorescence quenching in the presence of $\mathrm{Cu}^{2+}$ ions. Reproduced from ref. 115 with permission from the Elsevier, copyright 2014.
7). ${ }^{120}$ The absorption spectra of $\mathbf{5 1}$ exhibits a strong red-shifted band at approximately $421 \mathrm{~nm}$ from that of pure pyrene at around $355 \mathrm{~nm}$. On the other hand, compound $\mathbf{5 2}$ showed the characteristic absorption band of pyrene at $342 \mathrm{~nm}$ and another strong band at 380 $\mathrm{nm}$, owing to intramolecular charge transfer. Upon gradual addition of $\mathrm{Cu}^{2+}$ to $\mathbf{5 2}(10 \mu \mathrm{M})$, the absorbance at $380 \mathrm{~nm}$ gradually decreased and the band centered at $280 \mathrm{~nm}$ increased, because of $\mathrm{Cu}^{2+}$ interaction with diaminomaleonitrile moiety which prevents the charge-transfer of pyrene to the electron withdrawing diaminomaleonitrile moiety. This result has resemblance with the spectral changes of receptor $\mathbf{5 1} .^{91}$ The receptors $\mathbf{5 1}$ and $\mathbf{5 2}$ exhibited weak fluorescence (quantum yields in acetonitrile are 0.005 and 0.02 , respectively) because of having the Schiff base moiety and due to the overlap of the emission and absorption spectra. However, only ligand 52 gave a red-shifted band at around $590 \mathrm{~nm}$ except for the other band close to the characteristic emission band of pyrene. A significant fluorescence enhancement of $\mathbf{5 2}$ was observed at the emission band of pyrene on titration of $\mathrm{Cu}^{2+}$. The quantum yield of the fluorescence emission band of $\mathbf{5 2}+\mathrm{Cu}^{2+}$ complex was 0.42 , approximately 20-times more than that of free 52. The apparent association constant $\left(K_{\mathrm{a}}\right)$ of $\mathrm{Cu}^{2+}$ binding to $\mathbf{5 2}$ was estimated to be $5.2 \times 10^{3} \mathrm{M}^{-1}$. However, the authors observed that on changing the solvent system from $\mathrm{CH}_{3} \mathrm{CN} / \mathrm{H}_{2} \mathrm{O}$ to $\mathrm{PBS} / \mathrm{DMF}$, the receptor cannot bind with $\mathrm{Cu}^{2+}$ as DMF trapped the $\mathrm{Cu}^{2+}$ and hindered the interaction between the ligand $\mathbf{5 2}$ and $\mathrm{Cu}^{2+}$.
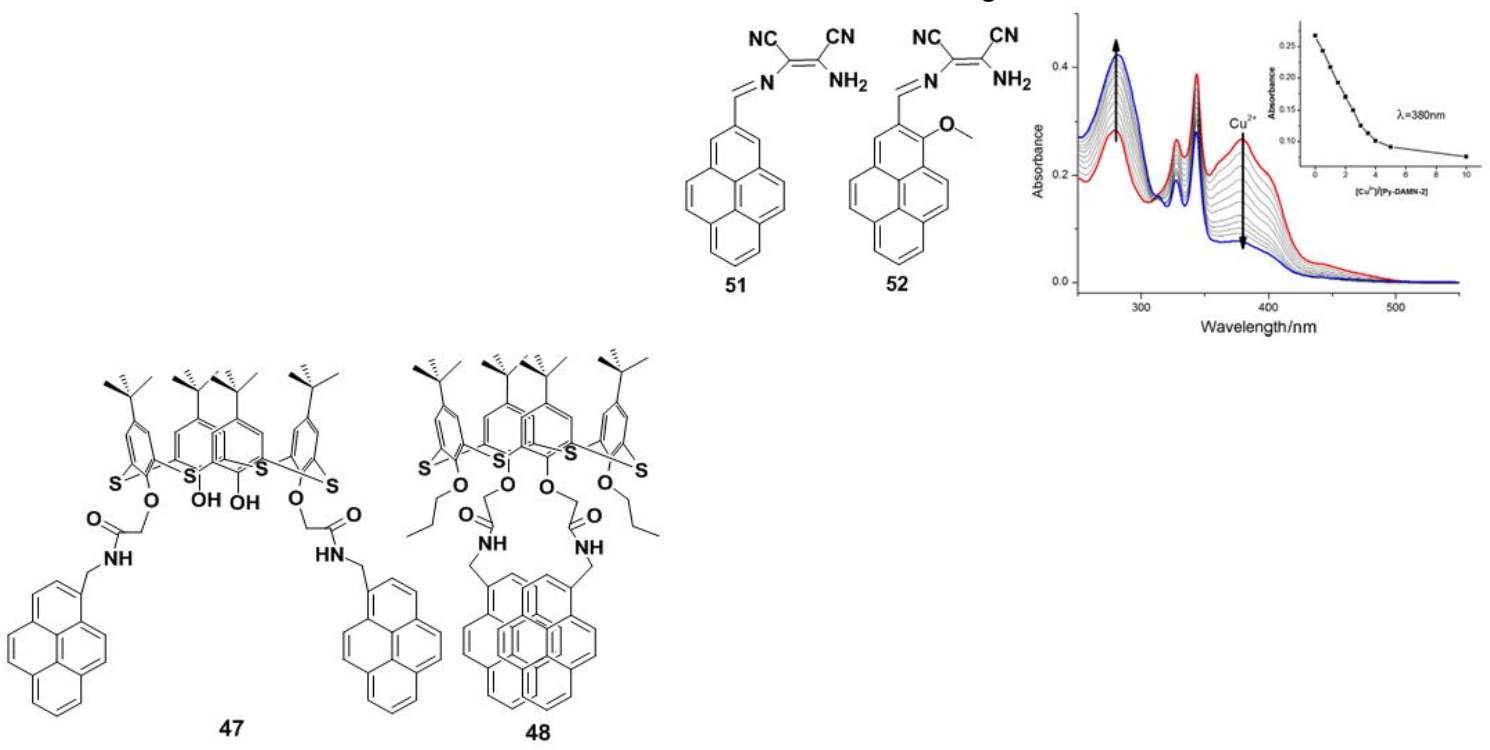

Fig. 42. Molecular structure of receptors 47 and 48.

at $388 \mathrm{~nm}$ and decreased at $348 \mathrm{~nm}$ after addition of $\mathrm{Cu}^{2+}$. The colour of the $\mathbf{5 0}+\mathrm{Cu}^{2+}$ solution changed from pale yellow to green-yellow. Moreover, the enhancement of emission intensity (45 times more) at 396 and $439 \mathrm{~nm}$ was observed for $\mathbf{5 0}$ upon treatment with $\mathrm{Cu}^{2+}$ ions, with a colour change from pale to strong blue. $\mathrm{The}^{2{ }^{2+}}$ ion-induced complexation was also confirmed by NMR and ESI-MS spectra. The Job's plot determined the 1:1 stoichiometry with $1.09 \times 10^{4} \mathrm{M}^{-1}$ binding constant for the $\mathbf{5 0}+\mathrm{Cu}^{2+}$ complex.

Liu et al. have developed the pyrene based diaminomaleonitrile chemosensors 51 and $52\left(1 \times 10^{-5} \mathrm{M}\right)$ which can effectively sense $\mathrm{Cu}^{2+}$ in acetonitrile-water solution $(\mathrm{v} / \mathrm{v}=1: 1,10 \mathrm{mM}$ HEPES, $\mathrm{pH}=$
Fig. 43. Schematic representation of possible sensing mechanism of probe 49 for $\mathrm{Cu}^{2+}$. Reproduced from ref. 118 with permission from the Elsevier, copyright 2014. 
Fig. 44. The colour and fluorescence changes of chemosensor 50 upon addition of $\mathrm{Cu}^{2+}$ ions. Reproduced from ref. 119 with permission from the Elsevier, copyright 2010.

In 2014, Goswami and co-workers designed and synthesized a new pyrene-based fluorescence probe $\mathbf{5 3}$ which was capable of working in both prokaryotic and eukaryotic living cells for the fluorogenic detection of $\mathrm{Cu}^{2+}$. The complexation of receptor $\mathbf{5 3}$ with $\mathrm{Cu}^{2+}$ occurs through a chelation-enhanced fluorescence (CHEF) mechanism and several other reasons. ${ }^{121}$ In a $\mathrm{CH}_{3} \mathrm{CN}-\mathrm{HEPES}$ buffer $(7: 3, \mathrm{v} / \mathrm{v}$, at $\mathrm{pH}$ 7.5) protic solvent system, the free receptor $\mathbf{5 3}$ shows stronger fluorescence compared with aprotic $\mathrm{CH}_{3} \mathrm{CN}$ solvent. This happens because of the hydrogen bonding interaction of the solvent with the $\mathrm{N}$ and $\mathrm{O}$ lone electron pairs of $\mathbf{5 3}$ which weakens the intramolecular radiationless transition and makes the red shifted emission maxima $\left(\lambda_{\mathrm{em}}\right)$ on increasing protonation by the solvent. Moreover, the fluorescence behaviour of $\mathbf{5 3}$ upon addition of $\mathrm{Cu}^{2+}$ was enriched owing to the reduced energy gap between the ground state and the excited state of the metal bound species by possible metal-ligand charge transfer (ICT) and chelation. In addition, ESI LC-MS spectral analysis and the Job's plot confirmed the formation of a mononuclear complex of $\mathbf{5 3}$ with $\mathrm{Cu}^{2+}$. The fluorescence titration experiments confirmed the minimum detection limit of copper was $1.21 \mu \mathrm{M}$ by using $10 \mu \mathrm{M}$ of the ligand $\mathbf{5 3}$. The selectivity of the fluorescence enhancement of $\mathbf{5 3}$ with $\mathrm{Cu}^{2+}$ (2.0 equivalents) was

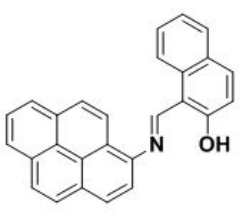

49

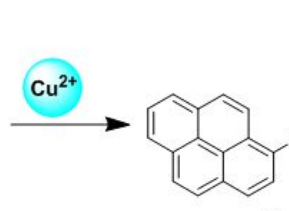

$49+\mathrm{Cu}^{2+}$

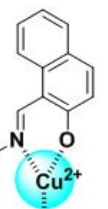

II investigated in the presence of other metal ions $(8.0$ equivalents).

With the exception of $\mathrm{Cd}^{2+}$ and $\mathrm{Co}^{2+}$, no other competing metal data in DMSO- $\mathrm{d}_{6}$ also demonstrated that the adduct formation between $\mathrm{Cu}^{2+}$ and $\mathbf{5 3}$ results in the disappearance of the phenolic protons and downfield shift of the protons of aromatic ring. The receptor $\mathbf{5 3}$ is cell membrane permeable and would provide detection of intracellular copper present in a biological system incubated with copper perchlorate salt $\left(1 \mathrm{mg} \mathrm{mL}^{-1}\right)$ for 45 minutes.

Fig. 45. The structure of probes $\mathbf{5 1}$ and 52. Absorption spectra of $\mathbf{5 2}$ in presence of various amounts of $\mathrm{Cu}^{2+}$ in acetonitrile-water solution. Reproduced from ref. 120 with permission from the Elsevier, copyright 2015.

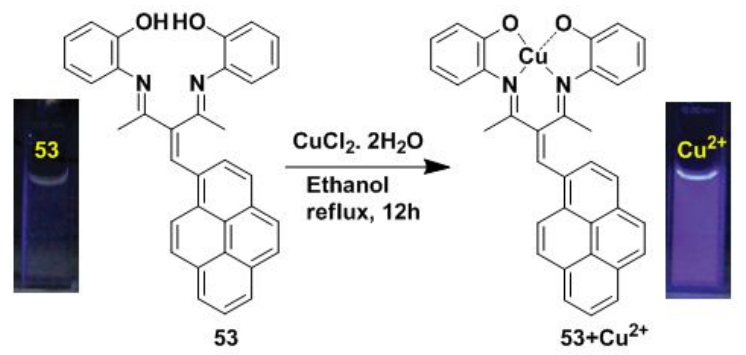

Fig. 46. The binding modes of $\mathbf{5 3}+\mathrm{Cu}^{2+}$ and visual colour change of $\mathbf{5 3}$ with the addition of 2 equiv. of $\mathrm{CuCl}_{2} \cdot 2 \mathrm{H}_{2} \mathrm{O}$ under $\mathrm{UV}$ light. Reproduced from ref. 121 with permission from the Royal Society of Chemistry.

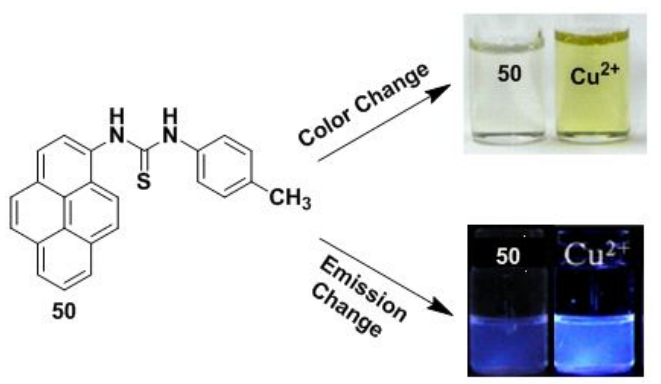

Table 1

Comparison of important features of reported $\mathrm{Cu}^{2+}$ sensors discussed above

\begin{tabular}{|c|c|c|c|c|c|c|c|c|}
\hline $\begin{array}{c}\text { Probe } \\
\text { No. }\end{array}$ & Solvent Medium & Mechanism & $\begin{array}{c}\text { Association } \\
\text { Constant }\end{array}$ & $\begin{array}{c}\text { Limit of } \\
\text { Detection }\end{array}$ & $\begin{array}{c}\lambda_{\mathrm{ex}} / \lambda_{\mathrm{em}} \\
(\mathrm{nm})\end{array}$ & $\begin{array}{l}\text { Stoichiometry } \\
\left(\text { Sensor/ } \mathbf{C u}^{2+}\right)\end{array}$ & Application & Refs. \\
\hline 1 & $\mathrm{EtOH}$ & $\begin{array}{l}\text { Monomer and } \\
\text { excimer } \\
\text { emission }\end{array}$ & $3.5 \times 10^{5}$ & $1.44 \times 10^{-7}$ & $\begin{array}{l}344 / 379, \\
397,484\end{array}$ & $1: 1$ & NA & [57] \\
\hline
\end{tabular}




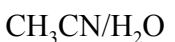
Monomer and
emission

NA

$1.87 \times 10^{-8}$

$343 / 396$,

$1: 1$

NA

[58]

485

3

$\mathrm{CH}_{3} \mathrm{CN} / \mathrm{CH}_{2} \mathrm{Cl}_{2} \quad \begin{gathered}\text { Monomer and } \\ \text { excimer } \\ \text { emission }\end{gathered}$

NA

$367 / 415$,

518

$1: 1$

NA

4

Tris- $\mathrm{HNO}_{3}$ buffer

Monomer and

$2.18 \times 10^{4}$

$2 \times 10^{-8}$

$342 / 375$,

460

emission

NA

NA

$360 / 420$

$1: 1$

$2: 1$

Environmental

Samples, live cells (Hela cells)

5 dioxane

Monomer and

excimer

emission

6 dioxane

Monomer and

$3.10 \times 10^{-2}$

NA

$360 / 420$,

500

emission

7

$\mathrm{CH}_{2} \mathrm{Cl}_{2}$

Dynamic

4.4

NA

$335 / 440$

$1: 1$

NA

[62]

static excimer

8

$$
\mathrm{CH}_{3} \mathrm{CN} / \mathrm{H}_{2} \mathrm{O}
$$

Static excimer

$2.8 \times 10^{4}$ emission

NA

$342 / 375$,

455

9

$\mathrm{CH}_{3} \mathrm{CN}$

Static excimer

$5.42 \times 10^{5}$ emission

NA

$360 / 388$,

460

10

$\mathrm{CH}_{3} \mathrm{CN}$

NA

NA

NA

NA

NA

NA

[64]

11

$\mathrm{CH}_{3} \mathrm{CN}$

NA

NA

NA

NA

NA

NA

12 Tris-HCl buffer containing $\mathrm{CH}_{3} \mathrm{CN} / \mathrm{H}_{2} \mathrm{O}$

Static excimer

$4.583 \times 10^{3}$

$4 \times 10^{-8}$

$350 / 452$

$2: 1$

Drinking

[65] emission

Water

[60] 


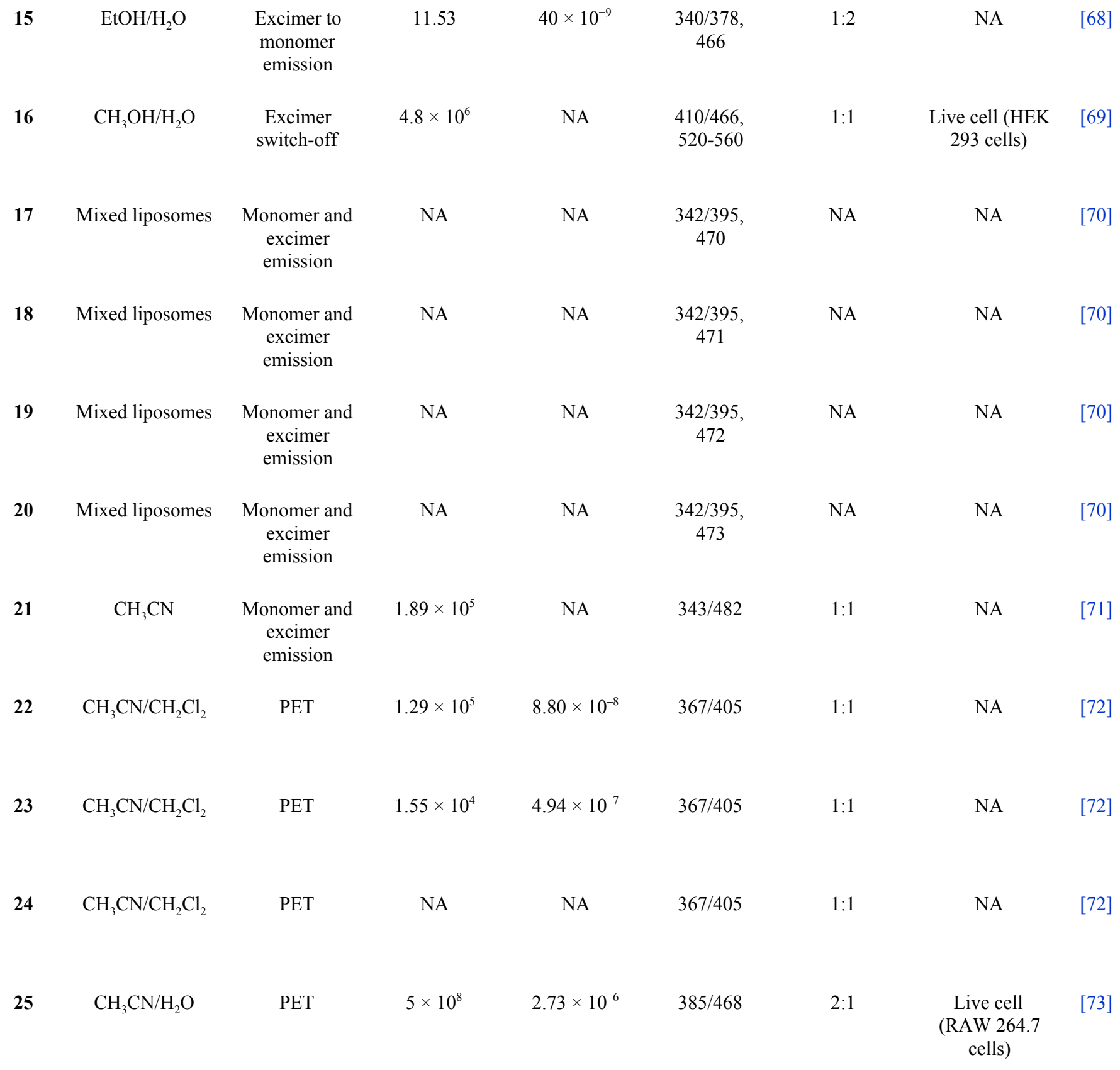

\begin{tabular}{|c|c|c|c|c|c|c|c|c|}
\hline $\begin{array}{c}\text { Probe } \\
\text { No. }\end{array}$ & Solvent Medium & Mechanism & $\begin{array}{c}\text { Association } \\
\text { Constant }\end{array}$ & $\begin{array}{c}\text { Limit of } \\
\text { Detection }\end{array}$ & $\begin{array}{c}\lambda_{\mathrm{ex}} / \lambda_{\mathrm{em}} \\
\quad(\mathbf{n m})\end{array}$ & $\begin{array}{l}\text { Stoichiometry } \\
\left(\text { Sensor/ } \mathbf{C u}^{2+}\right)\end{array}$ & Application & Refs. \\
\hline 26 & $\mathrm{CH}_{3} \mathrm{CN}$ & PET & $5.71 \times 10^{5}$ & $3.91 \times 10^{-6}$ & $350 / 429$ & $1: 1$ & NA & [74] \\
\hline 27 & $\mathrm{CH}_{3} \mathrm{OH} / \mathrm{H}_{2} \mathrm{O}$ & PET & $2.75 \times 10^{3}$ & NA & $360 / 455$ & $1: 1$ & Live cell & [75] \\
\hline
\end{tabular}




$$
\mathrm{CH}_{3} \mathrm{CN} / \mathrm{H}_{2} \mathrm{O}
$$

PET

$$
1.0 \times 10^{4}
$$

$0.04 \times 10^{-6}$

$346 / 389$

1:1

Live cell (RAW 264.7 cells)

30 DMSO- $\mathrm{H}_{2} \mathrm{O}$

PET

$1.16 \times 10^{4}$

$0.26 \times 10^{-6}$

$393 / 463$

$1: 1$

Live cell

(RAW 264.7 cells)

$31 \quad \mathrm{CH}_{3} \mathrm{CN} / \mathrm{H}_{2} \mathrm{O}$

PET

NA

$7.8 \times 10^{-9} \quad 305 / 444$

$1: 1$

Live cell (Hela cells), Real samples

$$
\text { NA }
$$
409,473

33 $\mathrm{CH}_{3} \mathrm{CN}$

PET

NA

$3.60 \times 10^{-7}$

$340 / 444$

$1: 1$

NA

34

$\mathrm{CH}_{3} \mathrm{CN}$

PCT

NA

NA

$343 / 470$

1:1

NA

35

DMF/HEPES

LMCT

NA

$8.5 \times 10^{-6}$

$305 / 370$

$1: 1$

NA

buffer

$36 \quad \mathrm{CH}_{3} \mathrm{CN} / \mathrm{H}_{2} \mathrm{O}$

LMCT

$5.65 \times 10^{5}$

$0.503 \times 10^{-6}$

$384 / 429$

$2: 2$

Real samples

$37 \quad \mathrm{DMSO} / \mathrm{H}_{2} \mathrm{O}$

ILCT

$6.5789 \times 10^{4}$

$6.865 \times 10^{-8}$

$370 / 390$,

$38 \quad \mathrm{H}_{2} \mathrm{O} / \mathrm{DMF}$

AEE

$1.89 \times 10^{9}$

$35 \times 10^{-9}$

$370 / 455$

$2: 1$

Live cell (Hela

\begin{tabular}{|c|c|c|c|c|c|c|c|c|}
\hline $\begin{array}{c}\text { Probe } \\
\text { No. }\end{array}$ & Solvent Medium & Mechanism & $\begin{array}{c}\text { Association } \\
\text { Constant }\end{array}$ & $\begin{array}{c}\text { Limit of } \\
\text { Detection }\end{array}$ & $\begin{array}{l}\lambda_{\text {ex }} / \lambda_{\text {em }}, \\
(\mathrm{nm})\end{array}$ & $\begin{array}{l}\text { Stoichiometry } \\
\left(\text { Sensor/ } \mathbf{C u}^{2+}\right)\end{array}$ & Application & Refs. \\
\hline 39 & $\begin{array}{c}\mathrm{CH}_{3} \mathrm{CN} \\
\mathrm{CH}_{3} \mathrm{CN} / \mathrm{H}_{2} \mathrm{O}\end{array}$ & PET, AIE & NA & $2.5 \times 10^{-6}$ & $\begin{array}{c}393 / 440 \\
454.5,509\end{array}$ & $1: 1$ & $\begin{array}{l}\text { Anioxidant } \\
\text { property }\end{array}$ & [90] \\
\hline 40 & $\begin{array}{c}10 \% \text { aqueous } \\
\text { Tris-buffered } \\
\text { DMSO solution }\end{array}$ & $\begin{array}{c}\mathrm{Cu}^{2+} \text { induced } \\
\text { catalytic } \\
\text { hydrolysis }\end{array}$ & NA & $5.93 \times 10^{-8}$ & $340 / 392$ & NA & $\begin{array}{c}\text { Simulated } \\
\text { semiconductor } \\
\text { waste water }\end{array}$ & [92] \\
\hline
\end{tabular}

[89] cells) 


\begin{tabular}{|c|c|c|c|c|c|c|c|c|}
\hline 41 & $\begin{array}{l}\mathrm{CH}_{3} \mathrm{CN} / \mathrm{HEPES} \\
\text { buffer solution }\end{array}$ & $\begin{array}{l}\mathrm{Cu}^{2+} \text { induced } \\
\text { ring opening } \\
\text { process }\end{array}$ & $2.5 \times 10^{4}$ & NA & $520 / 575$ & $1: 1$ & NA & {$[94]$} \\
\hline 42 & $\mathrm{DMSO} / \mathrm{H}_{2} \mathrm{O}$ & $\begin{array}{l}\text { Paramagnetic } \\
\text { nature, CHEQ } \\
\text { process }\end{array}$ & $2.3 \times 10^{5}$ & $0.73 \times 10^{-9}$ & $440 / 510$ & $1: 1$ & $\begin{array}{l}\text { Live cell } \\
\text { (A549 cells) } \\
\text { and real water } \\
\text { samples }\end{array}$ & {$[96]$} \\
\hline 43 & $\mathrm{CH}_{3} \mathrm{OH}$ solution & $\begin{array}{c}\text { Heavy atom } \\
\text { effect }\end{array}$ & $1.48 \times 10^{5}$ & $10^{-6} \mathrm{M}$ & $340 / 392$ & $1: 1$ & NA & [97] \\
\hline 44 & $\begin{array}{c}\text { Aqueous HEPES } \\
\text { buffer } \\
\left(\mathrm{H}_{2} \mathrm{O} / \mathrm{CH}_{3} \mathrm{CN}\right)\end{array}$ & $\begin{array}{c}\text { Paramagnetic } \\
\text { nature }\end{array}$ & $2.4 \times 10^{4}$ & NA & $353 / 435$ & NA & $\begin{array}{c}\text { Live Cell } \\
\text { (COS-7 kidney } \\
\text { cells), } \\
\text { Biological } \\
\text { samples }\end{array}$ & {$[98]$} \\
\hline 45 & $\begin{array}{c}\text { Aqueous HEPES } \\
\text { buffer } \\
\left(\mathrm{H}_{2} \mathrm{O} / \mathrm{CH}_{3} \mathrm{CN}\right)\end{array}$ & NA & NA & NA & NA & NA & NA & {$[98]$} \\
\hline 46 & $\mathrm{CH}_{2} \mathrm{Cl}_{2 /}$ DMSO & $\begin{array}{l}\text { Paramagnetic } \\
\text { nature, reverse } \\
\text { PET }\end{array}$ & $3.3 \times 10^{5}$ & NA & $\begin{array}{c}343 / 393 \\
486\end{array}$ & $1: 1$ & NA & [99] \\
\hline 47 & $\mathrm{CH}_{2} \mathrm{Cl}_{2} / \mathrm{CH}_{3} \mathrm{CN}$ & Reverse PET & 4.939 & NA & $342 / 377$ & $1: 1$ & NA & [101] \\
\hline 48 & $\mathrm{CH}_{2} \mathrm{Cl}_{2} / \mathrm{CH}_{3} \mathrm{CN}$ & $\begin{array}{l}\text { Monomer and } \\
\text { excimer } \\
\text { emission }\end{array}$ & 10.3086 & NA & $\begin{array}{c}342 / 375 \\
467\end{array}$ & $1: 2$ & NA & [101] \\
\hline 49 & $\mathrm{DMSO} / \mathrm{H}_{2} \mathrm{O}$ & $\begin{array}{l}\mathrm{Cu}^{2+-} \text { assisted-c } \\
\text { omplexation }\end{array}$ & NA & $2.17 \times 10^{-6}$ & NA & $1: 1$ & $\begin{array}{c}\text { Environmental } \\
\text { systems }\end{array}$ & [102] \\
\hline
\end{tabular}


52

$$
\mathrm{CH}_{3} \mathrm{CN} / \mathrm{H}_{2} \mathrm{O}
$$

Inhibition of ICT process

53
$\mathrm{CH}_{3} \mathrm{CN} / \mathrm{HEPES}$
buffer
CHEF and
ICT process

NA
NA

$5.2 \times 10^{3}$
$340 / 420$,

590

$1.21 \times 10^{-6} \quad 330 / 414$

$1: 1$

Live Cell

[105]

\section{Conclusion and future perspectives}

This review article focuses on a particular type of fluorescent probe that contains a pyrene functional group and that have become interesting tools in modern biology and in environmental work. We have focused on the design of fluorescent sensors based on different mechanisms including monomer and excimer emission, PET, PCT, AIE, LMCT, CHEQ, $\mathrm{Cu}^{2+}$-assisted reaction and others for the detection of $\mathrm{Cu}^{2+}$. Interestingly, there have been a large number of fluorescent sensors which show fluorescence enhancement following monomer and excimer emission and inhibition of photoinduced electron transfer mechanism for sensing $\mathrm{Cu}^{2+}$. In the monomer and excimer emission mechanism, the fluorescence response can experience three main spectroscopic signals as monomer, static or dynamic excimer emission processes depending on the binding nature of the ligand to $\mathrm{Cu}^{2+}$. Based on the monomer and excimer emission mechanism, Yamato and co-workers as well as Kumar et al. have developed several ratiometric chemosensors which can easily diagnose $\mathrm{Cu}^{2+}$ ions. Moreover, a $\mathrm{Cu}^{2+}$-promoted reaction based chemosensor in protic solvent systems was reported by Chang et al. and Yoon et al. and such systems may exhibit unique advantages and find special applications in environmental systems. Some probes based on the pyrene moiety show fluorescence quenching due to the paramagnetic nature of $\mathrm{Cu}^{2+}$ ions and ligand to metal charge transfer processes or reverse PET mechanisms with prominent selective and sensitive responses for $\mathrm{Cu}^{2+}$ ions. It is noteworthy to mention that $\mathrm{N}$ and/or O- and/or S-containing ligands find more promise for the detection of $\mathrm{Cu}^{2+}$ ions. However, there are very few chemosensors described with reversible properties, which is a weakness in this type of host-guest chemistry. Therefore, it is necessary to consider the need to recycle these resources to avoid waste generation. Besides, the design and synthesis of fully water soluble efficient pyrene chemosensor remains a challenging task for the detection of $\mathrm{Cu}^{2+}$. Most of the pyrene sensors in this article are found to be only partially soluble in water, on mixing with organic solvents like $\mathrm{CH}_{3} \mathrm{CN}, \mathrm{CH}_{3} \mathrm{OH}, \mathrm{CH}_{2} \mathrm{Cl}_{2}$. The addition of polar functional groups or polar moieties into the chemosensor may increase the water solubility and make it more efficient for sensing $\mathrm{Cu}^{2+}$ in biological and environmental arenas. This review article helps to explore new concepts for designing and synthesizing chemosensors based on pyrene-derivatives and more significant achievements are anticipated in the near future.

\section{Acknowledgements}

CR thanks the EPSRC for an overseas travel grant.

\section{Notes and references}

a Department of Applied Chemistry, Faculty of Science and Engineering, Saga University, Honjo-machi 1, Saga 840-8502 Japan

${ }^{b}$ Department of Chemistry, Faculty of Science, Jashore University of Science and Technology, Jashore - 7408, Bangladesh

${ }^{c}$ Department of Chemistry, Dhaka University of Engineering \& Technology, Gazipur-1700, Bangladesh

${ }^{d}$ Department of Chemistry, The University of Hull, HU6 7RX, UK

1. (a) B. Valeur, Molecular Fluorescence: Principles and Applications, Wiley-VCH: Weinheim, Germany, 2002; (b) A. P. de Silva, H. Q. N. Gunaratne, T. Gunnlaugsson, A. J. M. Huxley, C. P. McCoy, J. T. Rademacher, T. E. Rice, Chem. Rev., 1997, 97, 1515.

2. A. P. S. Gonzales, M. A. Firmino, C.S. Nomura, F.R.P. Rocha, P.V. Oliveira and I. Gaubeur, Anal. Chim. Acta., 2009, 636, 198-204.

3. J. S. Becker, A. Matusch, C. Depboylu, J. Dobrowolska and M. V. Zoriy, Anal. Chem., 2007, 79, 6074-6080.

4. Y. Liu, P. Liang and L. Guo, Talanta. 2005, 68, 25-30.

5. A. A. Ensafi, T. Khayamian, A. Benvidi and E. Mirmomtaz, Anal. Chim. Acta., 2006, 561, 225-232.

6. J. S. Becker, M. V. Zoriy, C. Pickhardt, N. Palomero-Gallagher and K. Zilles, Anal. Chem., 2005, 77, 3208-3216.

7. N. Mekjinda, S. Phunnarungsi, V. Ruangpornvisuti, R. J. Ritchie, I. Hamachi, A. Ojida and J. Wongkongkatep, Sci. Rep., 2020, 10, 2656

8. (a) I. Takashima, M. Kinoshita, R. Kawagoe, S. Nakagawa, M. Sugimoto, I. Hamachi, and A. Ojida, Chem. Eur. J., 2014, 20, 2184 - 2192; (b) J. Guan, P. Zhang, T.-b. Wei, Q. Lin, H. Yao and Y.-m. Zhang, RSC Adv., 2014, 4, 35797; (c) S. Uchinomiya, N. Matsunaga, K. Kamoda, R. Kawagoe, A. Tsuruta, S. Ohdo and A. Ojida, Chem. Commun., 2020, 56, 3023-3026; (d) S. I. Reja, N. Sharma, M. Gupta, P. Bajaj, V. Bhalla, R. D. Parihar, P. Ohri, G. Kaur, M. Kumar, Chem. Eur. J., 2017, 23, 9872-9878; (e) A. Kathiravan, A. Gowri, T. Khamrang, M. D. Kumar, N. Dhenadhayalan, K.-C. Lin, M. Velusamy and M. Jaccob, Anal. Chem. 2019, 91, 13244-13250.

9. (a) S. Lee, K. K. Y. Yuen, K. A. Jolliffe and J. Yoon, Chem. Soc. Rev., 2015, 44, 1749-1762; (b) H. N. Lee, Z. Xu, S. K. Kim, K. M. K. Swamy, Y. Kim, S.-J. Kim and J. Yoon, J. Am. Chem. Soc., 2007, 129, 3828-3829.

10. (a) N. Mekjinda, S. Phunnarungsi, V. Ruangpornvisuti, R. J. Ritchie, I. Hamachi, A. Ojida and J. Wongkongkatep, Sci. Rep., 2020, 10, 2656; (b) W. Shi and H. Ma, Chem. Commun., 2012, 48, 8732-8744; (b) A. X. Trautwein Ed., Bioinorganic Chemistry, Wiley- VCH, Weinheim, 1997; (c) E. Merian Ed., Metals and Their Compounds in the Environment, $\mathrm{VCH}$, Weinheim, 1991; (d) Z. Yang, J. Cao, Y. He, J. H. Yang, T. Kim, X. Peng and J. S. Kim, Chem. Soc. Rev., 2014, 43, 4563. 
11. (a) N. Kaur and S. Kumar, Tetrahedron, 2011, 67, 9233-9264; (b) E. V. Anslyn, J. Org. Chem., 2007, 72, 687-699; (c) P. D. Beer, Acc. Chem. Res., 1998, 31, 71-80; (c) C. Bargossi, M. C. Fiorini, M. Montalti, L. Prodi and N. Zaccheroni, Coord. Chem. Rev., 2000, 208, 17-32.

12. (a) A. B. Ellis and D. R. Walt, Guest editorial, Chem. Rev. 2000, 100, 2477-2478; (b) A. P. de Silva, H. Q. N. Gunaratne, T.Gunnlaugsson, A. J. M. Huxley, C. P. McCoy J. T. Rademacher and T. E. Rice, Chem. Rev., 1997, 97, 1515-1566.

13. L. Prodi, F. Bolletta, M. Montalti and N. Zaccheroni, Coord. Chem. Rev., 2000, 205, 59-83.

14. K. Rurack, Spectrochim. Acta Part A, 2001, 57, 2161-2195.

15. (a) A. T. Afaneh and G. Schreckenbach, J. Phys. Chem. A., 2015, 119, 8106-8116; (b) J.-P. Desvergne, F. Fages, H. Bouas-Laurent and P. Marsau, Pure Appl. Chem. 1992, 64, 1231.

16. Z. Xu, J. Yoon and D. R. Spring, Chem. Soc. Rev., 2010, 39, 1996-2006.

17. D. G. Barceloux and D. D. Barceloux, Clin. Toxicol., 1999, 37, 217-230.

18. (a) Z. L. Harris and J. D. Gitlin, Am. J. Clin. Nutr., 1996, 63, 836S-841S; (b) I. H. Scheinberg and I. Sternlieb, Am. J. Clin. Nutr., 1996, 63, 842S-845S.

19. (a) Y. Xiang, A. Tong, P. Jin and Y. Ju, Org. Lett., 2006, 8, 2863-2866; (b) X. Zhang, Y. Shiraishi, and T. Hirai, Org. Lett., 2007, 9, 5039-5042.

20. G. Li, Z. Xu, C. Chen and Z. Huang, Chem. Commun., 2008, 177, 4-177.

21. H. S. Jung, P. S. Kwon, J. W. Lee, J. I. Kim, C. S. Hong, J. W. Kim, S. Yan, J. Y. Lee, J. H. Lee, T. Joo and J. S. Kim, J. Am. Chem. Soc., 2009, 131, 2008-2012.

22. (a) H. S. Jung, M. Park, D. Y. Han, E. Kim, C. Lee, S. Ham and J. S. Kim, Org. Lett., 2009, 11, 3378-3381; (b) S.-P. Wu, S. R. Liu, Sens. and Actuators B, 2009, 141, 187-191.

23. H. Irving and R. J. P. Williams, Nature, 1948, 162, 746-747.

24. T. L. Banfield and D. Husain, Trans. Faraday Soc., 1969, 65, 1985-1991.

25. A. W. Varnes, R. B. Dodson and E. L. Wehry, J. Am. Chem. Soc., 1972, 94, 946-950.

26. P. C. Bull, G. R. Thomas, J. M. Rommens, J. R. Forbes and D. W. Cox, Nat Genet., 1993, 5, 327-337.

27. (a) D. Udhayakumari, S. Naha and S. Velmathi, Anal. Methods, 2017, 9, 552-578; (b) M. Ware, Medical News Today, October 23, 2017; (c) B. Sarkar, Chem. Rev., 1999, 99, 2535-2544; (d) J. A. Cowan, Inorganic Biochemistry: An Introduction, $2^{\text {nd }}$ ed.; Wiley-VCH: New York, NY, USA, 1997, 133-134; (e) M. DiDonato and B. Sarkar, Biochim. Biophys. Acta, 1997, 1360, 3-16; (f) B. Sarkar, Copper, in seiber, H. G. et al, Handbook on Metals in Clinical and Analytical Chemistry, Marcel Dekker, New York, 1995, 339-347.

28. (a) J. Chelly, Z. Tümer; T. Tønnesen, A. Petterson, Y. Ishikawa-Brush, N. Tommerup, N. Horn and A. P. Monaco, Nat. Genet., 1993, 3, 14-19; (b) J. F. B. Mercer, J. Livingston, B. Hall, J. A. Paynter, C. Begy, S. Chandrasekharappa, P. Lockhart, A. Grimes, M. Bhave, D. Siemieniak and T. W. Glover, Nat. Genet., 1993, 3, 20-25; (c) K. J. Barnham, C. L.
Masters and A. I. Bush, Nature Reviews Drug Discovery, 2004, 3, 205-214; (d) S. H. Hahn, M. S. Tanner, D. M. Danke and W. A. Gahl, Biochemical and Molecular Medicine, 1995, 54, 142-145; (e) D. R. Brown, Brain Research Bulletin, 2001, 55, 165-173; (f) D. Beyersmann, The significance of interactions in metal essentiality and toxicity, E. Merian, Ed., Metals and Their Compounds in the Environment, $\mathrm{VCH}$, Weinheim, 1991, 491.

29. (a) M. Kaur, P. Kaur, V. Dhuna, S. Singh and K. Singh, Dalton Trans., 2014, 43, 5707-5712; (b) I. Berlman, Handbook of Fluorescence Spectra of Aromatic Molecules, $2^{\text {nd }}$ ed., Academic Press, New York, 1971.

30. M. Wang, J. Xu, X. Liu and H. Wang, New J. Chem., 2013, 37, 3869-3872.

31. (a) D. Udhayakumari, Sens. Actuators B, 2018, 259, 1022-1057; (b) M.-H. Yang, P. Thirupathi and K.-H. Lee, Org. Lett., 2011, 13, 5028-5031.

32. (a) X.- L. Ni, S. Wang, X. Zeng, Z. Tao and T. Yamato, Org. Lett., 2011, 13, 552-555; (b) Q. Dai, W. Liu, X. Zhuang, J. Wu, H. Zhang and P. Wang, Anal. Chem., 2011, 83, 6559-6564; (c) G. Sivaraman, T. Anand and D. Chellappa, RSC Adv., 2012, 2, 10605-10609.

33. (a) F. Wang, R. Nandhakumar, J. H. Moon, K. M. Kim, J. Y. Lee and J. Yoon, Inorg. Chem., 2011, 50, 2240-2245.

34. (a) L.Wang, M. Yu, Z. Liu, W. Zhao, Z. Li, Z. Ni, C. Li and L. Wei, New J. Chem., 2012, 36, 2176-2179; (b) F. Wang, R. Nandhakumar, J. H. Moon, K. M. Kim, J. Y. Lee and J. Yoon, J. Inorg. Chem., 2011, 50, 2240-2245; (c) H. S. Jung, M. Park, D. Y. Han, E. Kim, C. Lee, S. Ham and J. S. Kim, Org. Lett., 2009, 11, 3378-3381.

35. E. Manandhar, J. H. Broome, J. Myrick, W. Lagrone, P. J. Cragg and K. J. Wallace, Chem. Commun., 2011, 47, 8796-8798.

36. Irving, H. and R. J. P. Williams, J. Chem. Soc., 1953, 3192-3210.

37. (a) A. W. Varnes, R. B. Dodson and E. L. Whery, J. Am. Chem. Soc., 1972, 94, 946-950; (b) G. Sivaraman, M. Iniya, T. Anand, N. G. Kotla, O. Sunnapu, S. Singaravadivel, A. Gulyani and D. Chellappa, Coord. Chem. Rev., 2018, 357, 50-104; (c) J. A. Kemlo and T. M Shepherd, Chem. Phys. Lett., 1977, 47, 158-162; (d) K. Rurack, U. Resch, M. Sensoer and S. Daehne, J Fluoresc., 1993, 3, 141-143; (e) K. Li, N. Li, X. Chen and A. Tong, Anal. Chim. Acta., 2012, 712, 115-119; (f) X. Lou, D. Ou, Q. Li and Z. Li, Chem. Commun., 2012, 48, 8462-8477.

38. (a) T. Jin, K. Ichikawa and T. Koyama, J. Chem. Soc., Chem. Commun., 1992, 499; (b) I. Aoki, H. Kawabata, K. Nakashima, and S. Shinkai, J. Chem. Soc., Chem. Commun., 1991, 1771-1773; (c) I. Aoki, T. Sakaki and S. Shinkai, J. Chem. Soc. Chem. Commun., 1992, 730-732.

39. (a) H.-F. Ji, R. Dabestani, G. M. Brown and R. A. Sachleben, Chem. Commun., 2000, 833-834; (b) H.-F. Ji, R. Dabestani, G. M. Brown and R. L. Hettich, J. Chem. Soc., Perkin Trans. 2, 2001, 585-591; (c) H.-F. Ji, G. M. Brown and R. Dabestani, Chem. Commun., 1999, 609-610; (d) I. Leray, F. O'Reilly, J.-L.Habib-Jiwan, J.-Ph. Soumillion and B. Valeur, Chem. Commun., 1999, 795-796. 
40. (a) C. D. Gutsche, "Calixarene," in Monographs in Supramolecular Chemistry, J. F. Stoddart, Ed., Royal Society of Chemistry, Cambridge, U. K., 1989, Vol. 1; (b) C. D. Gutsche, In Inclusion Compounds, J. L Atwood, J. E. D Davies, D. D. MacNicol, Eds., Oxford University Press, New York, 1991, 4, 27; (c) J. D. V. Loon, W. Verboom and D. N. Reinhoudt, Org. Prep. Proced. Int., 1992, 24, 437-462.

41. (a) R. Ungaro, A. Pochini, Frontiers in Supramolecular Organic Chemistry and Photochemistry, H.-J. Schneider, Ed. VCH: Weinheim, Germany, 1991, 57-81; (b) M.-Z. Asfari, V. Böhmer, J. Harrowfield and J. Vicens, Eds. Calixarenes 2001; (c) T. Jin, K. Ichikawa and T. Koyama, Chem. Commun., 1992, 499-501.

42. S. Nishizawa, H. Kaneda, T. Uchida and N. Teramae, J. Chem. Soc., Perkin Trans. 2, 1998, 2325-2328.

43. (a) S. K. Kim, S. H. Lee, J. Y. Lee, J. Y. Lee, R. A. Bartsch and J. S. Kim, J. Am. Chem. Soc., 2004, 126, 16499-16506; (b) F. M. Winnik, Chem. Rev., 1993, 93, 587-614; (c) S. H. Lee, S. H. Kim, S. K. Kim, J. H. Jung and J. S. Kim, J. Org. Chem., 2005, 70, 9288-9295; (d) J. Y. Lee, S. K. Kim, J. H. Jung and J. S. Kim, J. Org. Chem., 2005, 70, 1463-1466.

44. J. B. Briks, Rep. Prog. Phys., 1975, 38, 903-974.

45. (a) J. K. Choi, S. H. Kim, J. Yoon, K.-H. Lee, R. A. Bartsch and J. S. Kim, J. Org. Chem., 2006, 71, 8011-8015; (b) J.-S. Yang, C.-S. Lin and C.-Y. Hwang, Org. Lett., 2001, 3, 889-892; (c) H. J. Kim, S. K. Kim, J. Y. Lee and J. S. Kim, J. Org. Chem., 2006, 71, 6611-6614.

46. (a) W. Klöpffer, Organic Molecular Photophysics, J. B. Birks, Ed.; Wiley, New York, 1973, 1, Chapter 7; (b) J. B. Birks, Photophysics of Aromatic Molecules, Wiley-Interscience, London, 1970.

47. S. Sarkar, S. Roy, A. Sikdar, R. N. Saha and S. S. Panja, Analyst, 2013, 138, 7119-7126.

48. (a) A. P. de Silva, H. Q. N. Gunaratne, T. Gunnlaugsson, A. J. M Huxley, C. P. McCoy, J. T. Rademacher and T. E. Rice, Chem. Rev.,1997, 97, 1515-1566; (b) B. Valeur, I. Leray, Inorg. Chim. Acta, 2007, 360, 765-774; (c) S. H. Kim, H. J. Kim, J. Yoon and J. S. Kim, Calixarenes in the Nanoworld, J. Vicens and J. Harrowfield, Springer, Dordrecht, The Netherlands, 2007, Chapter 15.

49. (a) F. M. Winnik, Chem. Rev., 1993, 93, 587-614; (b) A. Okamoto, T. Ichiba and I. Saito, J. Am. Chem. Soc., 2004, 126, 8364-8365; (c) H. Nohta, H. Satozono, K. Koiso, H. Yoshida, J. Ishida and M. Yamaguchi, Anal. Chem., 2000, 72, 4199-4204.

50. (a) J. R. Lakowicz, Principles of Fluorescence Spectroscopy, $2^{\text {nd }}$ ed., New York, Plenum Publishers, 1999; $(b)$ A. P. de Silva, T. S. Moody and G. D. Wright, Analyst, 2009, 134, 2385-2395.

51. T. Jin, K. Ichikawa and T. Koyama, J. Chem. Soc., Chem. Commun., 1992, 499-501.

52. I. Aoki, H. Kawabata, K. Nakashima and S. Shinkai, J. Chem. Soc. Chem. Commun., 1991, 1771-1773.

53. I. Aoki, T. Sakaki and S. Shinkai, J. Chem. Soc. Chem. Commun., 1992, 730-732.
54. H.-F. Ji, R. Dabestani, G. M. Brown and R. A. Sachleben, Chem. Commun., 2000, 833-834.

55. H.-F. Ji, R. Dabestani, G. M. Brown and R. L. Hettich, J. Chem. Soc., Perkin Trans. 2, 2001, 585-591.

56. H.-F. Ji, G. M. Brown and R. Dabestani, Chem. Commun., 1999, 609-610.

57. I. Leray, F. O'Reilly, J.-L. Habib Jiwan, J.-Ph. Soumillion and B. Valeur, Chem. Commun., 1999, 795-796.

58. (a) J. S. Kim, K. H. Noh, S. H. Lee, S. K. Kim, S. K. Kim and J. Yoon, J. Org. Chem., 2003, 68, 597-600; (b) J. S. Kim, O. J. Shon, J. A. Rim, S. K. Kim and J. Yoon, J. Org. Chem., 2002, 67, 2348-2351.

59. (a) Z. R. Grabowski and J. Dobkowski, Pure \& Appl. Chem., 1983, 55, 245-252. (b) M. Liu, X. Yu, M. Li, N. Liao, A. Bi, Y. Jiang, S. Liu, Z. Gong and W. Zeng, RSC Adv., 2018, 8, 12573-12587.

60. W. Rettig, R. Lapouyade, Probe design and chemical sensing, J. R. Lakowicz, Ed. Topics in Fluorescence Spectroscopy, Plenum press, New York, 1994, 4, 109-149.

61. H.-G. Löhr and F. Vögtle, Acc. Chem. Res., 1985, 18, 65-72.

62 (a) P. Neri, J. L. Sessler, M.-X.Wang, Calixarenes and Beyond, Eds.; Springer, 2016; (b) R. Kumar, A. Sharma, H. Singh, P. Suating, H. S. Kim, K. Sunwoo, I. Shim, B. C. Gibb, and J. S. Kim, Chem. Rev. 2019, 16, 9657-9721; (c) J. S. Kim, and D. T. Quang Chem. Rev. 2007, 107, 3780-3799; (d) K. Sharma and P. Cragg, Chem. Senses., 2011, 1, 1-18; (e) R. Kumar, Y. O. Lee, V. Bhalla, M. Kumar and J. S. Kim, Chem. Soc. Rev., 2014, 43, 4824-4870; (e) J-Y. Fu, L. Mu, X. Zeng, J-L. Zhao, C. Redshaw, X-L. Ni and T. Yamato, Dalton Transactions, 2013, 42, 3552-3560

63. (a) J.-L. Zhao, H. Tomiyasu, X.-L. Ni, X. Zeng, M. R. J. Elsegood, C. Redshaw, S. Rahman, P. E. Georghiou and T. Yamato, New J. Chem., 2014, 38, 6041-6049; (b) J.-L. Zhao, C. Wu, X. Zeng, S. Rahman, P. E. Georghiou, M. R. J. Elsegood, T. G. Warwick, C. Redshaw, S. J. Teat and T. Yamato, ChemistrySelect, 2016, 1, 1541-1547; (c) J.-L. Zhao, C. Wu, H. Tomiyasu, X. Zeng, M. R. J. Elsegood, C. Redshaw and T. Yamato, Chemistry Asian J., 2016, 11, 1606-1612; (d) S. Rahman, H. Tomiyasu, H. Kawazoe, J.-L. Zhao, H. Cong, X.-L. Ni, X. Zeng, M. R. J. Elsegood, T. G. Warwick, S. J. Teat, C. Redshaw, P. E. Georghiou and T. Yamato, New J. Chem., 2016, 40, 9245-9251; (e) M. Kumar, A. Dhir and V. Bhalla, Eur. J. Org. Chem., 2009, 26, 4534-4540.

64. M. Kumar, R. Kumar and V. Bhalla, Tetrahedron Lett., 2013, 54, 1524-1527.

65. H. Tomiyasu, X.-L. Ni, X. Zeng, C. Redshaw and T. Yamato, Org. Biomol. Chem., 2014, 12, 4917-4923.

66. J.-L. Zhao, H. Tomiyasu, C. Wu, H. Cong, X. Zeng, S. Rahman, P. E. Georghiou, D. L. Hughes, C. Redshaw and T. Yamato, Tetrahedron, 2015, 71, 8521-8527.

67. (a) X.-L. Ni, X. Zeng and T. Yamato, J. Org. Chem., 2011, 76, 5696-5702; (b) X.-L. Ni, S. Rahman, S. Wang, C.-C. Jin, X. Zeng, D. Hughes, C. Redshaw and T. Yamato, Org. Biomol. Chem., 2012, 10, 4618-4626.

68. X.-L. Ni, S. Wang, X. Zeng and T. Yamato, Org. Lett., 2011, 13, 552-555. 
69. X.-L. Ni, Y. Wu, C. Redshaw and T. Yamato, Dalton Trans., 2014, 43, 12633-12638.

70. (a) X.-L. Ni, C.-C. Jin, X.-K. Jiang, M. Takimoto, S. Rahman, X. Zeng, D.L. Hughes, C. Redshaw and T. Yamato, Org. Biomol. Chem., 2013, 11, 5435-5442; (b) C-C. Jin, T. Kinoshita, H. Cong, X-L. Ni, X. Zeng, D. L. Hughes, C. Redshaw and T. Yamato, New J. Chem., 2012, 36, 2580-2586; (c) X.-L. Ni, X. Zeng, D. L. Hughes, C. Redshaw and T. Yamato, Org. Biomol. Chem., 2011, 9, 6535-6541.

71. C.-C. Jin, H. Cong, X.-L. Ni, X. Zeng, C. Redshaw and T. Yamato, RSC Adv., 2014, 4, 31469-31475.

72. C.-C. Jin, M. Fukuda, C. Wu, X. Jiang, X.-L. Ni, X. Zeng, C. Redshaw and T. Yamato, Tetrahedron, 2015, 71, 9593-9597.

73. Y.-S. Wu, C.-Y. Li, Y.-F. Li, D. Li and Z. Li, Sens. Actuators B., 2016, 222, 1226-1232.

74. J. Fernández-Lodeiro, C. Núñez, J. S. S. de Melo, J. S. Capelo and L. Carlos, Inorg. Chem., 2013, 52, 121-129.

75. J.-S. Yang, C.-S. Lin and C.-Y. Hwang, Org. Lett., 2001, 3, 889-892.

76. H. J. Kim, J. Hong, A. Hong, S. Ham, J. H. Lee and J. S. Kim, Org. Lett., 2008, 10, 1963-1966.

77. H. S. Jung, M. Park, D. Y. Han, E. Kim, C. Lee, S. Ham and J. S. Kim, Org. Lett., 2009, 11, 3378-3381.

78. S. Sarkar, S. Roy, A. Sikdar, R. N. Saha and S. S. Panja, Analyst, 2013, 138, 7119-7126.

79. M. Shellaiah, Y.-H. Wu, A. Singh, M. V. R. Raju and H.-C. Lin, J. Mater. Chem. A, 2013, 1, 1310-1318.

80. E. J. Jun, H. N. Won, J. S. Kim, K.-H. Lee and J. Yoon, Tetrahedron Lett., 2006, 47, 4577-4580.

81. M. Kumar, N. Kumar and V. Bhalla, Dalton Trans., 2012, 41, 10189-10193.

82. S. Ghosh, A. Ganguly, M. R. Uddin, S. Mandal, M. A. Alam and N. Guchhait, Dalton Trans., 2016, 45, 11042-11051.

83. B. C. Roy, B. Chandra, D. Hromas and S. Mallik, Org. Lett., 2003, 5, 11-14.

84. Y. Wu, X.-L. Ni, L. Mou, C.-C. Jin, C. Redshaw and T. Yamato, Supramolecular Chemistry, 2015, 27, 501-507.

85. (a) S. Sumiya, Y. Shiraishi, and T. Hirai, J. Phys. Chem. A., 2013, 117, 1474-1482; (b) D. T. Shi, B. Zhang, Y. X. Yang, C. C. Guan, X. P. He, Y. C. Li, G. R. Chen and K. X. Chen, Analyst, 2013, 138, 2808-2811; (c) C. Gao, H. Zhu, M. Zhang, T. Tan, J. Chen and H. Qiu, Anal. Methods, 2015, 7, 8172-8176; (d) X. Sun, Q. Xu, G. Kim, S. E. Flower, J. P. Lowe, J. Yoon, J. S. Fossey, X. Qian, S. D. Bull and T. D. James, Chem. Sci., 2014, 5, 3368-3373.

86. Z. Kowser, H. Tomiyasu, X. Jiang, U. Rayhan, C. Redshaw and T. Yamato, New J. Chem., 2015, 39, 4055-4062.

87. Z. Kowser, C.-C. Jin, X. Jiang, S. Rahman, P. E. Georghiou, X.-L. Ni, X. Zeng, C. Redshaw and T. Yamato, Tetrahedron, 2016, 72, 4575-4581.

88. H.-F. Wang, and S.-P. Wu, Sens. Actuators, B. 2013, 181, 743-748.

89. R. Martínez, F. Zapata, A. Caballero, A. Espinosa, A. Tárraga and P. Molina, Org. Lett., 2006, 8, 3235-3238.

90. S.-P. Wu, Z.-M. Huang, S.-R. Liu and P. K. Chung, J. Fluoresc., 2012, 22, 253-259.
91. S.-P. Wu, T.-H. Wang and S.-R. Liu, Tetrahedron, 2010, 66, 9655-9658.

92. P. Venkatesan and S.-P. Wu, RSC Adv., 2015, 5, 42591-42596.

93. A. Saravanan, G. Subashini, S. Shyamsivappan, T. Suresh, K. Kadirvelu, N. Bhuvanesh, R. Nandhakumar and P. S. Mohan, $J$ Photochem. Photobiol. A: Chem., 2018, 364, 424-432.

94. A. Ghorai, J. Mondal, A. K. Manna, S. Chowdhury and G. K. Patra, Anal. Methods, 2018, 10, 1063-1073.

95. R. Martínez, A. Espinosa, A. Tárraga and P. Molina, Tetrahedron, 2010, 66, 3662-3667.

96. H. Han, M. Wang and H. Wang, New J. Chem., 2014, 38, 914-917.

97. J. K. Choi, S. H. Kim, J. Yoon, K.-H. Lee, R. A. Bartsch and J. S. Kim, J. Org. Chem., 2006, 71, 8011-8015.

98. L. Mohapatra and K. Parida, Catal. Sci. Technol., 2017, 7, 2153-2164.

99. Y. Guo, L. Wang, J. Zhuo, B. Xu, X. Li, J. Zhang, Z. Zhang, H. Chi, Y. Dong and G. Lu, Tetrahedron Lett., 2017, 58, $3951-3956$.

100. S. Dalbera, S. Kulovi and S. Dalai, Chemistry Select, 2018, 3, 6561-6569.

101. A. Vogler and H. Kunkely, Coord. Chem. Rev. 2007, 251, 577-583.

102. S. Mukherjee and S. Betal, J. Lumin., 2018, 204, 145-153.

103. (a) Y. Hong, J. W. Y. Lam and B. Z. Tang, Chem. Soc. Rev., 2011, 40, 5361-5388; (b) T. Han, Y. Hong, N. Xie, S. Chen, N. Zhao, E. Zhao, J. W. Y. Lam, H. H. Y. Sung, Y. Dong, B. Tong and B. Z. Tang, J. Mater. Chem. C, 2013, 1, 7314-7320; (c) T. Han, X. Gu, J. W. Y. Lam, A. C. S. Leung, R. T. K. Kwok, T. Han, B. Tong, J. Shi, Y. Dong and B. Z. Tang, J. Mater. Chem. C, 2016, 4, 10430-10434.

104. W.-N. Wu, P.-D. Mao, Y. Wang, X.-J. Mao, Z.-Q. Xu, Z.-H. Xu, X.-L. Zhao, Y.-C. Fan and X.-F. Hou, Sens. Actuators. B, 2018, 258, 393-401.

105. N. Chakraborty, A. Chakraborty and S. Das, J. Lumin., 2018, 199, 302-309.

106. N. Li, Y. Xiang and A. Tong, Chem. Commun., 2010, 46, 3363-3365; (b) S. Liu, Y.-M. Wang, J. Han, J. Photochem. Photobiol. C. Photochem. Rev. 2017, 32, 78-103.

107. H. Ryu, J. H. Baek, M. G. Choi, J. C. Lee and S.-K. Chang, Tetrahedron Lett., 2017, 58, 2927-2930.

108. (a) V. Dujols, F. Ford and A. W. Czarnik, J. Am. Chem. Soc., 1997, 119, 7386-7387.; (b) A. Mokhir and R. Kramer, Chem. Commun., 2005, 2244-2246; (c) J. Kovacs, T. Rödler and A. Mokhir, Angew. Chem., Int. Ed., 2006, 45, 7815-7817; (d) J. Kovacs and A. Mokhir, Inorg. Chem., 2008, 47, 1880-1882; (e) R. M. Kierat and R. Kraemer, Bioorg. Med. Chem. Lett., 2005, 15, 4824-4827; (f) L. Zeng, E. W. Miller, A. Pralle, E. Y. Isacoff and C. J. Chang, J. Am. Chem. Soc., 2006, 128, 10-11; (g) X. Qi, E. J. Jun, L. Xu, S.-J. Kim, J. S. J. Hong, Y. J. Yoon and J. Yoon, J. Org. Chem., 2006, 71, 2881-2884; (h) M. H. Kim, H. H. Jang, S. Yi, S.-K. Chang and M. S. Han, Chem. Commun., 2009, 4838-4840; (i) E. J. Corey and S. Knapp, Tetrahedron Lett., 1976, 17, 3667-3668; (j) Q. Wu and E. V. Anslyn, J. Am. Chem. Soc., 2004, 126, 14682-14683; $(k)$ Y. Xiang and A. Tong, Luminescence, 2008, 23, 28-31; (l) L. 
Mei, Y. Xiang, N. Li and A. Tong, Talanta, 2007, 72, 1717-1722.

109. J. F. Zhang, Y. Zhou, J. Yoon, Y. Kim, S. J. Kim and J. S. Kim, Org. Lett., 2010, 12, 3852-3855.

110. Y. Zhou, F. Wang, Y. Kim, S.-J. Kim and J. Yoon, Org. Lett., 2009, 11, 4442-4445.

111. (a) T. L. Banfield, D. Husain, Trans. Faraday Soc., 1969, 65, 1985; (b) A. W. Varnes, R. B. Dodson and E. L. Wehry, J. Am. Chem. Soc., 1972, 94, 946.

112. D. Rajasekaran, K. Venkatachalam and V. Periasamy, Appl. Organometal.Chem., 2020, 34, 1-9.

113. D. Phapale, A. Gaikwad and D. Das, Spectrochim Acta Part A Mol. and Biomol. Spectrosc., 2017, 178, 160-165.

114. M. A. Wani, P. K. Singh, R. Pandey and M. D. Pandey, J. Lumin., 2016, 171, 159-165.

115. H. Tomiyasu, N. Shigyo, X.-L. Ni, X. Zeng, C. Redshaw and T. Yamato, Tetrahedron, 2014, 70, 7893-7899.

116. G. Huang, C. Li, X. Han. S. O. Aderinto, K. Shen, S. Mao and $\mathrm{H}$. Wu, Luminescence., 2018, 1-10.

117. R. Kumar, V. Bhalla and M. Kumar, Tetrahedron, 2008, 64, 8095-8101.

118. Y. R. Bhorge, H.-T. Tsai, K.-F. Huang, A. J. Pape, S. N. Janaki and Y.-P. Yen, Spectrochim. Acta Part A Mol. Biomol. Spectrosc., 2014, 130, 7-12.

119. W.-C. Lin, C.-Y. Wu, Z.-H. Liu, C.-Y. Lin and Y.-P. Yen, Talanta, 2010, 81, 1209-1215.

120. Y. Chen, Q. Lv, Z. Liu and Q. Fang, Inorg. Chem. Commun., 2015, 52, 38-40.

121. S. Goswami, S. Chakraborty, S. Paul, S. Halder, S. Panja and S. K. Mukhopadhyay, Org. Biomol. Chem., 2014, 12, 30373044 . 